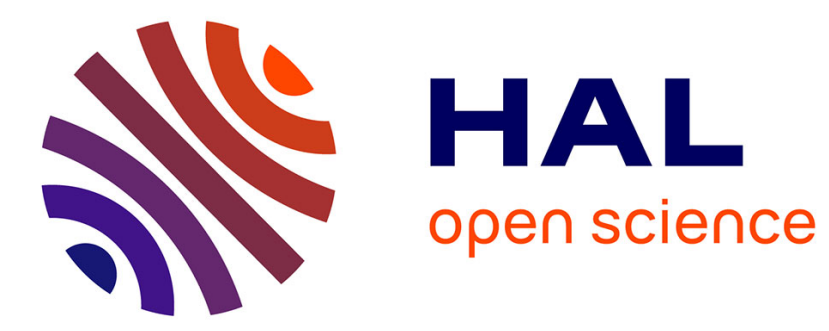

\title{
Ultra-depleted 2.05 Ga komatiites of Finnish Lapland: Products of grainy late accretion or core-mantle interaction?
}

Igor S Puchtel, Andrea Mundl-Petermeier, Mary Horan, Eero J Hanski, Janne Blichert-Toft, Richard J Walker

\section{To cite this version:}

Igor S Puchtel, Andrea Mundl-Petermeier, Mary Horan, Eero J Hanski, Janne Blichert-Toft, et al.. Ultra-depleted 2.05 Ga komatiites of Finnish Lapland: Products of grainy late accretion or coremantle interaction?. Chemical Geology, 2020, 554, pp.119801. 10.1016/j.chemgeo.2020.119801 . hal02991119

\section{HAL Id: hal-02991119 \\ https://hal.science/hal-02991119}

Submitted on 5 Nov 2020

HAL is a multi-disciplinary open access archive for the deposit and dissemination of scientific research documents, whether they are published or not. The documents may come from teaching and research institutions in France or abroad, or from public or private research centers.
L'archive ouverte pluridisciplinaire HAL, est destinée au dépôt et à la diffusion de documents scientifiques de niveau recherche, publiés ou non, émanant des établissements d'enseignement et de recherche français ou étrangers, des laboratoires publics ou privés. 


\section{Ultra-depleted 2.05 Ga komatiites of Finnish Lapland: Products of grainy late accretion or core-mantle interaction?}

3

4

5

6

7

8

9

10

Igor S. Puchtel ${ }^{1 *}$, Andrea Mundl-Petermeier ${ }^{1,2}$, Mary Horan ${ }^{3}$, Eero J. Hanski ${ }^{4}$, Janne Blichert-Toft ${ }^{5}$, and Richard J. Walker ${ }^{1}$,

\footnotetext{
${ }^{1}$ Department of Geology, University of Maryland, 8000 Regents Drive, College Park, MD 20742, USA

${ }^{2}$ Department of Lithospheric Research, University of Vienna, Althanstraße 14, 1090 Vienna, Austria

${ }^{3}$ Department of Terrestrial Magnetism, Carnegie Institution for Science, 5241 Broad Branch Rd. NW, Washington, DC 20015, USA

${ }^{4}$ Oulu Mining School, P.O. Box 3000, FI-90014 University of Oulu, Finland
}

${ }^{5}$ Laboratoire de Géologie de Lyon, Ecole Normale Supérieure de Lyon, CNRS UMR 5276, Université de Lyon, 46 Allée d'Italie, 69007 Lyon, France

*Corresponding author: ipuchtel@umd.edu

Revised for: Chemical Geology

\section{Revised for Chemical Geology}

Version: June 24, 2020

Keywords: Hf-W, Sm-Nd, Lu-Hf, Re-Os and Pt-Os isotope systems; highly siderophile elements; Paleoproterozoic komatiites; grainy late accretion; core-mantle interaction; Finnish Lapland 


\section{Abstract}

Rhenium-Os, Pt-Os, Sm-Nd, Lu-Hf, and Hf-W isotope data, together with lithophile trace element and highly siderophile element (HSE: Re, Os, Ir, Ru, Pt, and Pd) abundances, are reported for $2.05 \mathrm{Ga}$ Jeesiörova and Kevitsa komatiites from the Central Lapland Greenstone Belt, Fennoscandia, Finland. Both komatiites are closely genetically related, with the Kevitsa dikes having served as feeding magma conduits to the Jeesiörova pillowed and massive lavas. The parental komatiite magma is estimated to have contained $\sim 25 \mathrm{wt} . \% \mathrm{MgO}$ and was, thus, derived from a mantle source at least as hot as those of some of its late Archean counterparts. A suite of Jeesiörova and Kevitsa whole-rock komatiite samples and olivine and chromite separates define an internal Re-Os isochron with an age of $2049 \pm 13 \mathrm{Ma}$ and an initial $\gamma^{187}$ Os $=-0.2 \pm 0.2$ (2SE), indicating long-term chondritic Re/Os in the mantle source. By contrast, PtOs data for a set of Jeesiörova chromite separates define an average initial $\mu^{186}$ Os $=+29 \pm 2$ (2SE), indicating a long-term history of suprachondritic Pt/Os in the mantle source. The absolute HSE abundances in the mantle source of the Jeesiörova-Kevitsa komatiite system are estimated to have been $120 \pm 5 \%$ of the present-day Bulk Silicate Earth (BSE). This is the first komatiite system for which excess HSE in the mantle source, relative to modern BSE, has been documented.

The ${ }^{147} \mathrm{Sm}-{ }^{143} \mathrm{Nd}$ and ${ }^{176} \mathrm{Lu}-{ }^{176} \mathrm{Hf}$ data yield isochron ages and initial ratios of, respectively, 2046 $\pm 22 \mathrm{Ma}$ with $\varepsilon^{143} \mathrm{Nd}=+3.7 \pm 0.3$, and $2072 \pm 20$ Ma with $\varepsilon^{176} \mathrm{Hf}=+8.7 \pm 0.4$ (2SE), indicating a long-term history of depletions of $\mathrm{Nd}$ relative to $\mathrm{Sm}$, and $\mathrm{Hf}$ relative to $\mathrm{Lu}$. The measured $\mu^{182} \mathrm{~W}=+1.5 \pm 3.3$ is indistinguishable from the modern mantle value. Despite being strongly depleted in highly incompatible lithophile trace elements, the Th-Nb-La systematics of the komatiites indicate $\sim 1 \%$ crustal contamination of the original komatiite magma, assuming the contaminant was similar in composition to the calculated Fennoscandian Tonalite Average (FTA). This level of contamination would have also significantly modified the $\mathrm{Nd}, \mathrm{Hf}$, and $\mathrm{W}$ isotope compositions of the original komatiitic magma, but not the Os isotope compositions or HSE abundances. The calculated original komatiite magma, corrected for the effects of crustal contamination, would have had initial $\varepsilon^{143} \mathrm{Nd} \sim+4.9, \varepsilon^{176} \mathrm{Hf} \sim+10.2$, and $\mu^{182} \mathrm{~W} \sim-10$.

Our modeling indicates that the initial ${ }^{186,187} \mathrm{Os} /{ }^{188} \mathrm{Os}$ isotopic compositions and suprachondritic HSE abundances, coupled with the projected negative $\mu^{182} \mathrm{~W}$, are best explained by either (1) derivation from a mantle domain characterized by an excess of late accreted, differentiated planetesimal core metal, i.e., "grainy" late accretion, or (2) addition of chemically fractionated terrestrial core metal to the mantle source domain of the komatiites. The presence of these characteristics in the Jeesiörova-Kevitsa komatiite mantle source provides further evidence for the early creation and long-term survival of chemically diverse domains within the mantle. 


\section{Introduction}

The chemically and isotopically heterogeneous nature of the mantle has long been established, largely through the study of modern rocks (e.g., Gast et al., 1964; Hart and Brooks, 1977; Zindler et al., 1982; White and Hofmann, 1982; White and Patchett, 1984; Hofmann, 1984, 1997; Jacobsen, 1988; Galer and Goldstein, 1991). However, the origin of the heterogeneities for different elements and isotopic systems (e.g., ${ }^{146,147} \mathrm{Sm}^{-1}{ }^{142,143} \mathrm{Nd},{ }^{176} \mathrm{Lu}-$ ${ }^{176} \mathrm{Hf},{ }^{182} \mathrm{Hf}_{-}{ }^{182} \mathrm{~W}$ ), as well as their length scales and residence times, remain topics of debate. Some of the heterogeneities have been argued to be primordial, reflecting initial planetary accretion/differentiation, including magma ocean crystallization processes (e.g., Goldstein and Galer, 1992; Albarède et al., 2000; Boyet and Carlson, 2005; Touboul et al., 2012; Jacobsen and Yu, 2015; Puchtel et al., 2013; 2016a; Rizo et al., 2016b; Mundl et al., 2017; Mundl-Petermeier et al., 2019; Tusch et al., 2019), while others may have originated as a result of a protracted accretion history (Willbold et al., 2011; Kruijer et al., 2015; Touboul et al., 2015; Puchtel et al., 2018; Archer et al., 2019).

Osmium isotope and highly siderophile element (HSE, including Re, Os, Ir, Ru, Pt, and Pd) abundance systematics of the mantle through time provide information about certain aspects of early Earth processes. For example, the observation that the HSE occur in approximately chondritic relative proportions in the Bulk Silicate Earth (BSE), and that absolute abundances of at least some of the HSE are higher than would be expected from metal-silicate equilibration during core formation, have led to the concept of late accretion, which purports that $0.5-1 \%$ of Earth's mass was accreted to the mantle subsequent to cessation of core formation (Kimura et al., 1974; Chou et al., 1983; Morgan, 1985, 1986). Issues related to the nature of late accretion include the composition of the late accreted materials and the time frame within which they were delivered to Earth and homogenized within the mantle (e.g., Bennett et al., 2002; Maier et al., 2009; Coggon et al., 2013; Walker et al., 2015; van de Löcht et al., 2018).

The Os isotopic composition and absolute HSE abundances of portions of the Archean mantle have been the subject of considerable prior study (e.g., Brügmann et al., 1987; Walker et al., 1988; Foster et al., 1996; Gangopadhyay and Walker, 2003; Puchtel et al., 2014, 2016a,b; 2018; Maier et al., 2009). These studies have mostly focused on komatiites because komatiites are valuable probes of absolute HSE abundances and Os isotopic compositions in some portions of the mantle. This stems from the fact that most komatiites were formed by sufficiently high degrees of partial melting that the dominant sulfide hosts of HSE in the mantle were dissolved into the melts. Under such conditions, the HSE abundances in 
komatiitic melts are much more similar to the initial mantle source compositions than those in basaltic melts. These high degrees of partial melting also led to comparatively high Os abundances in komatiitic melts, which make their Os isotopic compositions insensitive to crustal contamination. The high Os concentrations in komatiites, coupled with typically low $\mathrm{Re} / \mathrm{Os}$ ratios, mean that they can provide precise initial Os isotopic compositions of mantle sources.

Compared to Archean komatiites, HSE and Os isotopes have been much less extensively studied in their Proterozoic counterparts, primarily due to the paucity of Proterozoic komatiites in the rock record. Here, we report combined ${ }^{147} \mathrm{Sm}-{ }^{143} \mathrm{Nd},{ }^{176} \mathrm{Lu}-{ }^{176} \mathrm{Hf},{ }^{187} \mathrm{Re}-$ ${ }^{187} \mathrm{Os},{ }^{190} \mathrm{Pt}-{ }^{186} \mathrm{Os},{ }^{182} \mathrm{Hf}-{ }^{182} \mathrm{~W}$, and HSE and lithophile trace element abundance data for the Proterozoic Kevitsa komatiitic dikes and associated Jeesiörova komatiites, all part of the Central Lapland Greenstone Belt in Fennoscandia, Finland. The Kevitsa komatiite dikes in particular display strong chemical differentiation trends, excellent preservation of igneous minerals, including olivine, and no signs of interaction with their wall rocks (Mutanen, 1997; Huhma et al., 2018). They hence provide ample opportunity for dating and obtaining information on the composition of the original komatiitic magmas. We use these data to (i) constrain the long-term evolution of the mantle domain from which the Fennoscandian Shield was produced and which also gave rise to the komatiite parental magmas, and (ii) further evaluate the extent of Archean-Paleoproterozoic mantle heterogeneity.

\section{Geological background}

Paleoproterozoic komatiites of Finnish Lapland are part of the Central Lapland Greenstone Belt (Fig. 1), which consists of a thick supracrustal rock series spanning $570 \mathrm{Ma}$ (Hanski and Huhma, 2005). The komatiites are known to occur at two stratigraphic levels and, as such, have been referred to as the lower and upper komatiites (Hanski et al., 2001). The lower komatiites are found near the bottom of the succession and are assigned to the 132 Kuusamo Group. They were emplaced subaerially and, locally, lie directly on Archean granitoid basement. A type occurrence has been described from the Möykkelmä area, where komatiites form part of a 250-m-thick komatiite-tholeiite sequence with a strong upper crustal signature in their chemical composition (Hanski and Huhma, 2005). Stratigraphically, the 136 lower komatiites can be correlated with the komatiitic lavas of the Vetreny Belt in the SW 137 part of the Fennoscandian Shield, which have an internal Re-Os isochron age of $2407 \pm 6 \mathrm{Ma}$ (Puchtel et al., 2016b). 
The upper komatiites are associated with phyllites and black schists of the Savukoski Group whose sedimentary precursors were deposited on cratonic siliciclastic sediments of the Sodankylä Group (Hanski and Huhma, 2005). The upper komatiitic volcanic rocks extend from Finnish Lapland to northern Norway over a distance of $\sim 400 \mathrm{~km}$ and are associated with Ti-rich picrites and basalts (Hanski et al., 2001). Unlike typical Archean komatiites, the upper komatiites are characterized by the abundance of volcaniclastic eruptions (Saverikko, 1985; Barnes and Often, 1990). They also occur as massive lava flows, pillow lavas, tuffs, and rare layered flows. The volcanic structures and types of the associated sedimentary rocks attest to submarine conditions of eruption in a deepened sedimentary basin. Although belonging to the Al-undepleted, or Munro-type of lavas of Nesbitt et al. (1979) typical of late Archean komatiite sequences, the upper komatiites are further distinct from Archean komatiites in having elevated $\mathrm{TiO}_{2}$ contents and, therefore, they were classified as a Ti-enriched komatiite type (Hanski et al., 2001).

The upper komatiites are best preserved in the Jeesiörova area studied by Hanski et al. (2001). Magmatic olivine has not been reported to have been preserved in komatiitic lavas anywhere in Finnish Lapland, but magmatic clinopyroxene is well preserved at Jeesiörova, occurring as poikilitic intergrowths in olivine cumulates, as prismatic grains in gabbroic rocks, and as needle-like crystals in pillowed and massive lavas. The presence of magmatic clinopyroxene in the lavas allowed Hanski et al. (2001) to obtain a weighted average Sm-Nd isochron age of $2056 \pm 25 \mathrm{Ma}$ for clinopyroxene-whole-rock pairs for the Jeesiörova komatiites. The initial $\varepsilon^{143} \mathrm{Nd}$ values range from +2 to +4 for individual samples, with the most LREE-depleted samples having the highest initial $\varepsilon^{143} \mathrm{Nd}$ values. This inverse correlation between the $\mathrm{La} / \mathrm{Sm}$ and $\varepsilon^{143} \mathrm{Nd}$ values was interpreted to be the result of contamination by material of the upper crustal rocks through which the Jeesiörova komatiite magma ascended (Hanski et al., 2001).

Gangopadhyay et al. (2006) analyzed a set of whole-rock Jeesiörova komatiite samples and chromite separates for Re-Os isotope systematics. Although the Re-Os system in the whole-rock samples was found to be disturbed by post-magmatic processes, by analyzing chromite separates, the authors constrained the initial ${ }^{187} \mathrm{Os} /{ }^{188} \mathrm{Os}$ ratio for the komatiite lavas to be chondritic $\left(\gamma^{187} \mathrm{Os}(\mathrm{T})=+0.1 \pm 0.6\right)$.

The Kevitsa komatiitic dikes were discovered by Mutanen (1997) during an exploration drilling campaign of the Kevitsa Ni-Cu sulfide deposit. The dikes were penetrated by at least a dozen drill holes in an area of $\sim 1 \mathrm{~km}^{2}$, covering the ore-bearing part of the Kevitsa mafic- 
172 ultramafic intrusion (Fig. 1c). This intrusion is located approximately $50 \mathrm{~km}$ east of the Jeesiörova area within pelitic metasediments of the Savukoski Group (Fig. 1a) and has a U$\mathrm{Pb}$ zircon age of $2058 \pm 4 \mathrm{Ma}$ (Mutanen and Huhma, 2001), which is identical, within uncertainty, to the Sm-Nd age of the Jeesiörova komatiites. Each of the drill cores contains from one to four dike intersections at depths varying from 12 to $870 \mathrm{~m}$ beneath the surface. Although the true thickness of the dikes is less than $7 \mathrm{~m}$, the lengths of the intersections reach up to $16 \mathrm{~m}$ because the drill holes cut through the dikes at sharp angles $\left(\leq 30^{\circ}\right)$.

The dikes are generally subvertical, with the dip varying between $65^{\circ}$ and $90^{\circ}$, and strike approximately ENE (Mutanen, 2005). They are characterized by strong internal differentiation related to olivine fractionation, having an olivine-enriched central part and finer-grained chilled zones near contacts with the wall rocks, which are composed of olivinepyroxene cumulates of the Kevitsa intrusion. The differentiation is rather symmetrical across the dikes, suggesting that originally they were also steeply dipping. The dikes are chemically similar to the Jeesiörova komatiites and have been interpreted to represent their feeder magma conduits (Huhma et al., 2018); the absolute age of the dikes, however, has so far remained unknown.

\section{Samples}

Sampling of the Kevitsa komatiite dikes was done at the National Drill Core Depot of the Geological Survey of Finland, Loppi, Finland. Samples for chemical and isotopic analyses were selected from drill core DDH 814, which contains two dike intersections at depths of 152.10-159.55 and 175.00-188.50 m, with the corresponding estimated thicknesses of the dikes being $\sim 1.3$ and $\sim 6.8 \mathrm{~m}$.

For this study, we also prepared powders from hand specimens of the best preserved and most primitive komatiite lava samples 12D-PPR, 13-EJH, and 17.1-PPR from the Jeesiörova area (Hanski et al., 2001). In addition, we powdered sample LP-10 that was recently collected from an olivine-phyric massive komatiite lava flow from the same area.

\section{Analytical techniques}

Details of the majority of the analytical techniques used in this study have been reported in a number of previous publications (e.g., Puchtel et al., 2016a,b; 2018); these, therefore, are only briefly summarized here. In contrast, full details are provided for those techniques implemented here for the first time.

\subsection{Analysis of mineral compositions}


Mineral compositions were determined using a JEOL JXA-8530F Plus Hyper Probe instrument at the

Center of Material Analysis, University of Oulu. The analytical conditions were an accelerating voltage of $15 \mathrm{kV}$ and a beam current of $15 \mathrm{nA}$. Peak and background counting times were 10 and $5 \mathrm{~s}$, respectively. The standard built-in ZAF correction routine was used.

\subsection{Re-Os isotopic compositions and HSE abundances}

The measurements of $\mathrm{Ru}, \mathrm{Pd}, \mathrm{Re}$, Ir, and Pt were performed at the Plasma Laboratory (PL) on Faraday cups of a ThermoFisher Neptune Plus ICP-MS in static mode using $10^{13} \mathrm{Ohm}$ amplifiers. Isotopic mass fractionation was monitored and corrected for by interspersing samples and standards. The external precision of the analyses was estimated, on the basis of standard measurements performed during the period of the analytical campaign, to be ${ }^{185} \mathrm{Re} /{ }^{187} \mathrm{Re}=0.25 \%,{ }^{99} \mathrm{Ru} /{ }^{101} \mathrm{Ru}=0.26 \%,{ }^{191} \mathrm{Ir} /{ }^{193} \mathrm{Ir}=0.15 \%,{ }^{194} \mathrm{Pt} /{ }^{196} \mathrm{Pt}=0.10 \%$, and ${ }^{105} \mathrm{Pd} /{ }^{106} \mathrm{Pd}=0.08 \%$ relative (2SD). The accuracy of the data was assessed by comparing the results for the reference materials IAG MUH-1 (Austrian harzburgite), IAG OKUM (ultramafic komatiite), and NRC TDB-1 (Diabase PGE Rock Material) obtained at the Isotope Geochemistry Laboratory $(I G L)$ with the reference values. Concentrations of all HSE and Os isotopic compositions obtained at the $I G L$ are within the uncertainties of the certified reference values (Supplementary Table A1).

The average total analytical blank (TAB) measured during the present analytical campaign was (in $\mathrm{pg}$ ): $\mathrm{Ru}$ 6.0, Pd 17, Re 0.53, Os 0.42, Ir 1.2, and Pt $174(N=9)$. For the whole-rock komatiite samples, the average TAB constituted less than $0.1 \%$ for $\mathrm{Os}, \mathrm{Re}, \mathrm{Ir}, \mathrm{Ru}$, and $\mathrm{Pd}$, and less than $1 \%$ for $\mathrm{Pt}$ of the total amount of element analyzed. For the olivine and chromite separates, the TAB for Os and Ir constituted less than $0.1 \%$, for Ru less than $0.4 \%$, for Re between 0.1 and 3\%, for Pt between 14 and 19\%, and for Pd less than $1 \%$ of the total amount of element analyzed. We, therefore, cite $\pm 0.1 \%$ as the uncertainty on the concentrations of Os, $\pm 0.2 \%$ for Ir, between 0.3 and $0.4 \%$ for Ru, between 0.1 and $1 \%$ for Pd, between 0.1 and 3\% for Re, and between 1.0 and $19 \%$ for Pt, of the total amount of element analyzed. The uncertainty on the Re/Os ratio for each sample was calculated by multiplying the estimated uncertainties on the Re and Os abundances. These uncertainties vary between 0.30 and $3.0 \%$ relative.

\subsection{Pt-Os isotopic data.}

In order to obtain the amount of Os required for high-precision measurements of ${ }^{186} \mathrm{Os} /{ }^{188} \mathrm{Os}$ and ${ }^{187} \mathrm{Os} /{ }^{188} \mathrm{Os}$ $(\sim 100 \mathrm{ng}), \sim 1.0 \mathrm{~g}$ of pure chromite separates from Jeesiörova komatiite samples 12D-PPR and 13-EJH, representing different fractions in terms of magnetic susceptibility and density, were digested in Carius tubes. For the initial unspiked digestions, six $\sim 1 \mathrm{~g}$ fractions of chromite separate 12D-PPR and two fractions of 13-EJH were digested. After the digestion was complete, the tubes were chilled, opened, and $\sim 2 \%$ of the acid sample solution from each CT were transferred into a $25 \mathrm{~mL}$ Pyrex $^{\mathrm{TM}} \mathrm{CT}$ for precise determination of $\mathrm{Pt} / \mathrm{Os}, \mathrm{Re} / \mathrm{Os}$, and Ir/Os. The spiked aliquots were processed using the same procedure utilized for the Re-Os and HSE analyses. From the remaining part of the unspiked acid sample solutions, Os was extracted and purified using the same protocol utilized for the Re-Os work. The Os cuts from the batch of two CT containing sample 13-EJH were combined into one cut and used for the precise measurements of ${ }^{186} \mathrm{Os} /{ }^{188} \mathrm{Os}$ and ${ }^{187} \mathrm{Os} /{ }^{188} \mathrm{Os}$ in this sample. For sample 12D-PPR, every Os cut from six individual CT was used for the precise measurements of Os isotopic compositions. For TAB-corrections of the data from the spiked aliquots, since the ID digestion introduced $~ 98 \%$ of the total blank, the TAB of the initial (IC) digestion was considered negligible. 
The high-precision measurements of the ${ }^{186} \mathrm{Os} /{ }^{188} \mathrm{Os}$ and ${ }^{187} \mathrm{Os} /{ }^{188} \mathrm{Os}$ ratios were performed by N-TIMS in static mode on a ThermoFisher Triton ${ }^{\circledR}$ mass spectrometer at the IGL. During each run, between 1200 and 2400 ratios were collected for each sample load; the in-run uncertainties on the measured ${ }^{186} \mathrm{Os} /{ }^{188} \mathrm{Os}$ and ${ }^{187} \mathrm{Os} /{ }^{188} \mathrm{Os}$ ratios are quoted as 2SE. The possible isobaric interference of ${ }^{186} \mathrm{~W}^{16} \mathrm{O}_{3}{ }^{-}$on ${ }^{186} \mathrm{Os}^{16} \mathrm{O}_{3}-$ was monitored and corrected for by measuring masses ${ }^{184} \mathrm{OsO}_{3}{ }^{-}$and ${ }^{183} \mathrm{~W}^{16} \mathrm{O}_{3}{ }^{-}$using the electron multiplier.

The mean of the Johnson-Matthey Os standard runs during the period of data collection was $0.001302 \pm 2$ for ${ }^{184} \mathrm{Os} /{ }^{188} \mathrm{Os}, 0.1198432 \pm 18( \pm 15 \mathrm{ppm})$ for ${ }^{186} \mathrm{Os} /{ }^{188} \mathrm{Os}$, and $0.1137950 \pm 18(16 \mathrm{ppm})$ for ${ }^{187} \mathrm{Os} /{ }^{188} \mathrm{Os}(2 \mathrm{SD}, N=$ 14); these long-term reproducibilities were used to assess the true uncertainty on the measured ${ }^{186} \mathrm{Os} /{ }^{188} \mathrm{Os}$ and ${ }^{187} \mathrm{Os} /{ }^{188} \mathrm{Os}$ ratios for individual samples.

\subsection{Tungsten isotopic compositions and abundances}

The $\mathrm{W}$ isotope analyses were carried out at the IGL. For each sample, approximately 100 grams of powder were processed to obtain the $\sim 1 \mu \mathrm{g}$ of $\mathrm{W}$ necessary for high-precision $\mathrm{W}$ isotope measurements. The sample powders for each sample were digested in four $300 \mathrm{~mL}$ Savillex Teflon screw-cap vials using a 5:1 mixture of double-distilled concentrated $\mathrm{HF}$ and $\mathrm{HNO}_{3}$ on a hot plate at $150^{\circ} \mathrm{C}$ for one week. Tungsten was separated and purified using the four-stage ion-exchange chromatography protocol described in Peters et al. (2019), with minor modifications. The third stage involving a $1.5 \mathrm{~mL}$ anion-exchange column was repeated to improve the separation of Ti from $\mathrm{W}$, and this step significantly increased $\mathrm{W}$ ionization efficiency. Tungsten recovery using this procedure was better than $90 \%$.

Tungsten isotopic compositions were measured by N-TIMS on a ThermoFisher Triton mass spectrometer at the IGL using a 2-line multi-static acquisition protocol and following a slightly modified technique described by Archer et al. (2017). All data are reported as $\mu^{182} \mathrm{~W}$ and $\mu^{183} \mathrm{~W}$, which are the part per million (ppm) deviations of ${ }^{182} \mathrm{~W} /{ }^{184} \mathrm{~W}$ and ${ }^{183} \mathrm{~W} /{ }^{184} \mathrm{~W}$, respectively, in a given sample from those of the in-house Alfa Aesar laboratory $\mathrm{W}$ standard. Uncertainties on $\mu^{182} \mathrm{~W}$, based on the long-term 2SD of our Alfa Aesar laboratory standard, were \pm 4.5 ppm. The measured ${ }^{183} \mathrm{~W} /{ }^{184} \mathrm{~W}$ ratios were identical within uncertainties ( $\pm 6 \mu^{183} \mathrm{~W}$ units) to those in the average Alfa Aesar standard data.

Tungsten abundances were determined by isotope dilution ICP-MS. Tungsten was purified using a previously established anion-exchange chromatography technique (e.g., Kleine et al., 2004). Concentrations were measured using the Element 2 single-collector ICP-MS at the $P L$. Typical uncertainties were $\sim 5 \%$ relative.

\subsection{Sm-Nd isotopic compositions and abundances}

The Sm-Nd isotopic data were collected at the $I G L$. Approximately $300 \mathrm{mg}$ of whole-rock komatiite sample powder, or between 300 and $400 \mathrm{mg}$ of pure clinopyroxene separates, were digested. Measurements of the $\mathrm{Nd}$ isotopic compositions were performed on Faraday cups of the ThermoFisher Neptune Plus ICP-MS at the PL in static mode followed by off-line correction for spike contributions. For each sample, 200 to 300 ratios were collected with $8 s$ integration times in blocks of 100 ratios each. For every block of data collected, the peaks were centered, and a $30 \mathrm{~s}$ baseline measurement was performed for each Faraday cup/amplifier pair by beam deflection. The effects of instrumental mass fractionation were corrected for relative to ${ }^{146} \mathrm{Nd} /{ }^{144} \mathrm{Nd}=0.7219$ using an exponential law. A total of five to six 60 ppb AMES Nd standard solutions were run at the beginning and end of the analytical session, with 200 to 300 ratios collected during each measurement. The in-run precision 
of the measured ${ }^{143} \mathrm{Nd} /{ }^{144} \mathrm{Nd}$ ratio for both samples and standards was between 5 and $7 \mathrm{ppm}$ (2SE). During the course of the present analytical campaign, the external reproducibility of the $60 \mathrm{ppb}$ AMES Nd standard solution measurements for ${ }^{143} \mathrm{Nd} /{ }^{144} \mathrm{Nd}$ was $\pm 7.0 \mathrm{ppm}$ (2SD). The average ${ }^{143} \mathrm{Nd} /{ }^{144} \mathrm{Nd}$ measured for the AMES $\mathrm{Nd}$ standard during each analytical session was used to calculate the instrumental mass bias coefficient for correction of the measured ${ }^{143} \mathrm{Nd} /{ }^{144} \mathrm{Nd}$ in the samples using the long-term average ${ }^{143} \mathrm{Nd} /{ }^{144} \mathrm{Nd}$ value measured precisely for the AMES Nd standard on the IGL ThermoFisher Triton (0.512152 \pm 2 ; Puchtel et al., 2018).

In order to assess the accuracy of the analyses, several separate powder aliquots of USGS GRM BIR-1 and BCR-1 were processed and analyzed using the same analytical protocol. The measured ${ }^{143} \mathrm{Nd} /{ }^{144} \mathrm{Nd}$ ratios for both GRM are identical, within their respective uncertainties, to the GeoRem preferred values (Supplementary Table A2), as well as to the average high-precision value for BCR-1 obtained on the IGL ThermoFisher Triton (0.512645 \pm 1 ; Puchtel et al., 2018).

Measurements of the Sm isotopic compositions were also performed on Faraday cups of the ThermoFisher Neptune Plus ICP-MS at the PL in static mode. For each sample, 20 ratios were collected with $8 s$ integration times in blocks of 10 ratios each. The effects of instrumental mass fractionation were corrected for relative to ${ }^{147} \mathrm{Sm} /{ }^{152} \mathrm{Sm}=0.56081$ using an exponential law. The uncertainty on the $\mathrm{Sm} / \mathrm{Nd}$ ratio in the samples analyzed was estimated on the basis of replicate analyses of the USGS GRM BCR- $1\left({ }^{147} \mathrm{Sm} /{ }^{144} \mathrm{Nd}=0.13941 \pm 0.00014\right)$ to be $0.10 \%$ relative $(2 \mathrm{SD})$.

\subsection{Lu-Hf isotopic compositions and abundances}

The Hf isotopic compositions and Lu and Hf concentrations in the Jeesiörova komatiites were determined at the IGL and the Department of Terrestrial Magnatism (DTM), Carnegie Institution for Science. At the IGL, approximately $500 \mathrm{mg}$ of the whole-rock sample powder and pure clinopyroxene separate were weighted out in $15 \mathrm{~mL}$ Teflon inserts of Parr bombs with $7 \mathrm{~mL}$ double-distilled concentrated HF, $1.5 \mathrm{~mL} \mathrm{HNO}_{3}$, and an appropriate amount of mixed ${ }^{176} \mathrm{Lu}-{ }^{178} \mathrm{Hf}$ spike, sealed in stainless steel jackets and digested in an oven at $170{ }^{\circ} \mathrm{C}$ for one week. The solutions were dried down, $0.7 \mathrm{~mL}$ of concentrated SeaStar $\mathrm{HClO}_{4}$ added to the residue, the inserts re-sealed and kept on a hotplate at $180^{\circ} \mathrm{C}$ for 24 hours. The solutions were then dried down at $\sim 230^{\circ} \mathrm{C}$, and the residues converted into the chloride form using $6 \mathrm{M} \mathrm{HCl}$. This step was repeated several times until clear solutions were obtained, and then dried down.

At $D T M$, the residue was re-dissolved in $5 \mathrm{ml}$ of a $1 M \mathrm{HCl}-0.1 M \mathrm{HF}$ mixture, and loaded onto a $0.6 \times 20$ cm column filled with AG50W-X8 200-400 mesh cation-exchange resin. High field strength elements, including $\mathrm{Hf}$, were eluted in the loading solution and an additional $5 \mathrm{~mL}$ of $1 M \mathrm{HCl}-0.1 M \mathrm{HF}$. After eluting $44 \mathrm{ml}$ of 2.5M HCl, heavy REE, including $\mathrm{Lu}$, were eluted in $12 \mathrm{~mL}$ of $4 M \mathrm{HCl}$ (Blichert-Toft, 2001). Hafnium was purified on a $0.6 \times 10 \mathrm{~cm}$ column of Eichrom $\mathrm{LN}$ resin (100-150 $\mu \mathrm{m}$ bead size) by loading the sample in $5 \mathrm{~mL}$ of $2.5 N \mathrm{HCl}$, followed by washes of $10 \mathrm{~mL} 2.5 \mathrm{M} \mathrm{HCl}, 10 \mathrm{~mL} 6 \mathrm{M} \mathrm{HCl}, 4 \mathrm{~mL} \mathrm{H}_{2} \mathrm{O}, 40 \mathrm{~mL}$ of a mixture consisting of $0.09 M$ Citric acid $-0.45 M \mathrm{HNO}_{3}-1 \% \mathrm{H}_{2} \mathrm{O}_{2}, 5 \mathrm{~mL}$ of the same solution without $\mathrm{H}_{2} \mathrm{O}_{2}$, and, finally, $20 \mathrm{~mL}$ of $6 \mathrm{M} \mathrm{HCl}-0.06 \mathrm{~N} \mathrm{HF}$. Hafnium was then eluted in $8 \mathrm{~mL}$ of $6 \mathrm{M} \mathrm{HCl}-0.4 M \mathrm{HF}$. Lutetium was purified using Eichrom $\mathrm{LN}$ resin $(50-100 \mu \mathrm{m}$ bead size) on a $0.4 \times 7 \mathrm{~cm}$ column. The HREE fraction from the first column was loaded in $2.5 \mathrm{M} \mathrm{HCl}$, followed by a wash of $30 \mathrm{~mL} 2.5 \mathrm{M} \mathrm{HCl}$ to remove much of the other HREE, then Lu was collected in $10 \mathrm{~mL} 6 \mathrm{M} \mathrm{HCl}$. The resultant $\mathrm{Hf}$ and $\mathrm{Lu}$ cuts were used for the measurements of the $\mathrm{Hf}$ and $\mathrm{Lu}$ isotopic compositions. 
Measurements of the Hf isotopic compositions were performed on the Faraday cups of the ThermoFisher Neptune Plus ICP-MS at the PL in static mode followed by off-line correction for spike contributions. For each sample, 200 to 300 ratios were collected with $8 s$ integration time in blocks of 100 ratios each. Before each sample measurement, a $60 \mathrm{~s}$ baseline measurement was performed for each Faraday cup/amplifier pair without beam deflection, and this baseline was then automatically subtracted from the sample beam. Instrumental mass fractionation was corrected for relative to ${ }^{179} \mathrm{Hf} /{ }^{177} \mathrm{Hf}=0.7325$ using an exponential law. The $\mathrm{Yb}, \mathrm{Lu}, \mathrm{Ta}$, and $\mathrm{W}$ isobaric interferences were corrected for using ${ }^{173} \mathrm{Yb} /{ }^{176} \mathrm{Yb}=1.256,{ }^{175} \mathrm{Lu} /{ }^{176} \mathrm{Lu}=37.70,{ }^{181} \mathrm{Ta} /{ }^{180} \mathrm{Ta}=8129$, and ${ }^{183} \mathrm{~W} /{ }^{180} \mathrm{~W}=109.0$. A total of five $30 \mathrm{ppb}$ JMC-475 Hf standard solutions were run at the beginning and end of the analytical session, with 200 ratios collected during each measurement. During the measurements, the signal intensities for both the standard and the samples were kept at constant levels, between 1.8 and $2.6 \mathrm{~V}$ on the ${ }^{178} \mathrm{Hf}$ mass; the in-run precision of the measured ${ }^{176} \mathrm{Hf} /{ }^{177} \mathrm{Hf}$ ratio for both samples and standards was between 11 and $13 \mathrm{ppm}$ (2SE). During the course of the present analytical campaign, the external reproducibility of the $30 \mathrm{ppb}$ JMC-475 Hf standard solution measurements for ${ }^{176} \mathrm{Hf} /{ }^{177} \mathrm{Hf}$ was $\pm 14 \mathrm{ppm}(2 \mathrm{SD})$; this value was used to estimate the true uncertainty on the Hf isotopic analyses. The average ${ }^{176} \mathrm{Hf} /{ }^{177} \mathrm{Hf}$ ratio measured for the JMC$475 \mathrm{Hf}$ standard solution during the analytical session was used to calculate the instrumental mass bias coefficient for correction of the measured ${ }^{176} \mathrm{Hf} /{ }^{177} \mathrm{Hf}$ ratio in the samples using the true value of ${ }^{176} \mathrm{Hf} /{ }^{177} \mathrm{Hf}=$ $0.282163 \pm 0.000009$ as determined by a multiple dynamic analysis protocol of Blichert-Toft et al. (1997).

In order to assess the accuracy of the analyses, an aliquot of USGS GRM BCR-1 was processed and analyzed using the same protocol as that used for the samples. The measured ${ }^{176} \mathrm{Hf} /{ }^{177} \mathrm{Hf}$ ratio of BCR-1 is identical, within the uncertainty, to the GeoRem preferred value.

Measurements of the $\mathrm{Lu}$ isotopic compositions were also performed on the Faraday cups of the ThermoFisher Neptune Plus ICP-MS at the PL in static mode. For each sample, 40 ratios were collected with $4 \mathrm{~s}$ integration time in blocks of 20 ratios each. Before each sample measurement, a $60 \mathrm{~s}$ baseline measurement was performed for each Faraday cup/amplifier pair without beam deflection, and this baseline was then automatically subtracted from the sample beam. Instrumental mass fractionation was corrected for by analysis of a $10 \mathrm{ppb} \mathrm{Lu}$ standard solution before and after every 4 samples. The $\mathrm{Yb}$ and $\mathrm{Hf}$ isobaric interferences were corrected for online using ${ }^{176} \mathrm{Yb} /{ }^{173} \mathrm{Yb}=0.7962$ and ${ }^{176} \mathrm{Hf} /{ }^{177} \mathrm{Hf}=0.2822$. The Lu concentration obtained for the SRM BCR-1 in this study was identical, within the uncertainty, to the GeoRem recommended value. The propagated uncertainty on the $\mathrm{Lu} / \mathrm{Hf}$ ratio in the samples analyzed is estimated to be $0.5 \%$. The total analytical blanks were $70 \mathrm{pg}$ for $\mathrm{Hf}$ and $2 \mathrm{pg}$ for $\mathrm{Lu}$.

\section{Results}

\subsection{Petrography of the komatiites}

The studied samples of the Jeesiörova komatiites are massive rocks with up to $1 \mathrm{~mm}$-sized euhedral, completely serpentinized olivine phenocrysts in a groundmass of prismatic or needle-like clinopyroxene crystals and devitrified glass (Fig. 2a in Hanski and Kamenetsky, 2003). The rocks also contain euhedral chromite grains up to $0.3 \mathrm{~mm}$ in size, often containing melt inclusions (Figs. 2b and 2d in Hanski and Kamenetsky, 2003). 
Compared to the Jeesiörova rocks, the Kevitsa komatiites analyzed in this study are characterized by a much better preserved magmatic mineralogy. The rocks are olivineporphyritic, with the most coarse-grained varieties found in dike centers, due to the presence of olivine phenocrysts (Fig. 2A, B, E). The size of the phenocrysts is commonly less than 6 $\mathrm{mm}$ in the center of the dikes, decreasing gradually to $0.1-0.2 \mathrm{~mm}$ near the dike margins. Occasionally, large amoeboid and embayed megacrysts are observed, with a maximum grain size of $\sim 2 \mathrm{~cm}$ (Fig. 3). Olivine phenocrysts show various morphologies; they are usually euhedral to subhedral, but sometimes have irregular shapes with ragged outlines (Fig. 2D). The latter are interpreted to be broken pieces of larger phenocrysts. Also observed are elongated olivine bars up to $1 \mathrm{~cm}$ in length, with an aspect ratio of up to 20 (Fig. 2B). Although olivine phenocrysts contain ubiquitous chrome spinel inclusions $0.1-0.3 \mathrm{~mm}$ in size, some of the largest phenocrysts are nearly devoid of them; in these cases, chrome spinel grains are concentrated along the olivine grain boundaries.

The holocrystalline groundmass is composed of clinopyroxene, orthopyroxene, olivine, plagioclase, brown amphibole, and opaque minerals, including two kinds of spinels, chrome spinel, and lamellar ilmenomagnetite (Fig. 2C). These oxides occur as individual or composite grains, in which chrome spinel is partly surrounded by ilmenomagnetite. Plagioclase forms lath-like grains up to $1 \mathrm{~cm}$ in length, but other silicates are anhedral or equant, with their grain size ranging commonly between 0.1 and $0.5 \mathrm{~mm}$.

The chilled margins of the dikes contain olivine microphenocrysts $(<0.5 \mathrm{~mm}$ in size $)$ and some chrome spinel grains in a fine-grained to cryptocrystalline groundmass composed mostly of clinopyroxene and plagioclase. It is noteworthy that no vesicles are found in the contact zones, indicating that either the pressure of emplacement was too high for volatiles to form a gas phase, or the volatile content was very low.

\subsection{Mineral chemistry}

Representative electron probe analyses of igneous minerals from the Kevitsa komatiites are listed in the Supplementary Table A3.

5.2.1. Olivine. Olivine exhibits a continuous compositional range from $\mathrm{Fo}_{94.1}$ to $\mathrm{Fo}_{73.8}$, with the highest forsterite content reported for large phenocrysts and the lowest for small grains in the groundmass. Microphenocrysts in the chilled margin samples vary from Fo ${ }_{83.5}$ to Fo93.2. The $\mathrm{CaO}$ content of all analyzed olivine grains is $0.20-0.32 \mathrm{wt} . \%$, typical of magmatic olivine. This, together with a negative correlation between $\mathrm{MgO}$ and $\mathrm{MnO}$, indicates the 
391 absence of xenocrystic mantle olivine among the grains analyzed. Instead, all olivine grains

5.2.2. Pyroxenes and plagioclase. Groundmass clinopyroxene has an augitic average composition of $\mathrm{En}_{49} \mathrm{Fs}_{10} \mathrm{Wo}_{41}$ with $\mathrm{Al}_{2} \mathrm{O}_{3}$ ranging from 2.4 to 5.8 wt.\% and $\mathrm{TiO}_{2}$ from 0.12 to 0.71 wt.\%. Orthopyroxene grains average $\mathrm{En}_{71} \mathrm{Fs}_{25} \mathrm{Wo}_{4}$ and have 3.4-4.5 wt. $\% \mathrm{Al}_{2} \mathrm{O}_{3}$ and $0.40-0.57 \mathrm{wt} . \% \mathrm{TiO}_{2}$. The anorthite content of the analyzed plagioclase grains in the groundmass ranges from 57.7 to $72.1 \mathrm{~mol} . \%$.

5.2.3. Chrome spinel. The most primitive chrome spinel grains have $\mathrm{MgO}$ contents of around 15-16 wt.\% and corresponding Mg\# of $0.71-0.76$, whereas in the most evolved grains, $\mathrm{MgO}$ and $\mathrm{Mg} \#$ drop to $2.7 \mathrm{wt} . \%$ and 0.14 , respectively. The $\mathrm{MgO}$-rich grains show an average $\mathrm{Al}_{2} \mathrm{O}_{3}$ content of $14.7 \mathrm{wt} . \%$ and an average $\mathrm{TiO}_{2}$ concentration of $0.38 \mathrm{wt} . \%$, yielding $\mathrm{Al}_{2} \mathrm{O}_{3} / \mathrm{TiO}_{2}$ typical of well-preserved chrome spinel grains in komatiitic lavas in Central Lapland, but distinct from the more Ti-rich spinels that occur in the associated picrites (Hanski and Kamenetsky, 2013).

5.2.4. Amphibole. The compositions of the brown groundmass amphibole (Fig. 2B, C) straddle the boundary between Ti-rich pargasite and Ti-rich magnesio-hastingsite. $\mathrm{The}^{\mathrm{TiO}_{2}}$ contents fall between 2.9 and $4.0 \mathrm{wt} . \%$, consistent with the magmatic nature of the mineral. Amphibole shows moderate $\mathrm{Na}_{2} \mathrm{O}$ contents of $2.3-3.0$ wt. \%, whereas $\mathrm{K}_{2} \mathrm{O}$ is low, $0.10-0.26$ wt.\%, consistent with the low level of $\mathrm{K}_{2} \mathrm{O}$ in the parental komatiite magma.

\subsection{Major and lithophile trace element abundances}

The major and trace element concentration data for the Jeesiörova and Kevitsa komatiites are listed in Tables $\mathbf{1}$ and $\mathbf{2}$, and selected elements are plotted against $\mathrm{MgO}$ contents on variation diagrams in Fig. 4 and as BSE-normalized values in Fig. 5.

The $\mathrm{MgO}$ abundances range between 25.3 and $28.6 \mathrm{wt} . \%$ in the Jeesiörova komatiites and between 16.2 and 28.3 wt.\% in the Kevitsa komatiites. In the Kevitsa komatiite dikes, the lowest abundances are observed in the chilled margin samples and the highest abundances in the samples from the central parts. The abundances of $\mathrm{TiO}_{2}, \mathrm{CaO}, \mathrm{Al}_{2} \mathrm{O}_{3}$ and incompatible lithophile trace elements in the dikes plot on well-constrained trends with negative slopes that intersect the $\mathrm{MgO}$ axes at $~ 51 \mathrm{wt} . \%$; these intersections correspond to the composition of liquidus olivine obtained in this study and also reported for the dikes by Nicklas et al. (2019). The abundances of the compatible elements $\mathrm{Ni}$ and $\mathrm{Cr}$ show positive correlations with $\mathrm{MgO}$ 
contents (Fig. 4). These strong correlations reflect olivine and chromite control during magmatic differentiation of the dikes, and also indicate immobile behavior of the elements analyzed during secondary alteration processes.

The four samples of the Jeesiörova komatiites analyzed in this study have slightly higher $\mathrm{Ti}, \mathrm{Cr}, \mathrm{La}, \mathrm{Ce}$, Th, and U concentrations compared to the Kevitsa komatiites (Fig. 4), but for the rest of major and trace elements, plot on the same trends. The Jeesiörova and Kevitsa komatiites have $\mathrm{Al}_{2} \mathrm{O}_{3} / \mathrm{TiO}_{2}(11.7 \pm 0.3$ and $13.9 \pm 0.1$, respectively, 2SE) that are lower, and $(\mathrm{Gd} / \mathrm{Yb})_{\mathrm{N}}(1.53 \pm 0.08$ and $1.49 \pm 0.01$, respectively, $2 \mathrm{SE})$ that are higher, than the BSE values of 22.4 and 1.00, respectively. This is due to enrichment of the parental komatiite magma in $\mathrm{Ti}$ and the middle REE, rather than to depletion in $\mathrm{Al}$ and the heavy REE, as is evident from comparison with the typical Al-undepleted komatiites from Pyke Hill, Ontario, Canada (Fig. 4A). As such, they are classified as the Al-undepleted komatiite type of Nesbitt et al. (1979).

The BSE-normalized lithophile trace element abundances (Fig. 5) are characterized by strong depletions in light REE $\left((\mathrm{La} / \mathrm{Sm})_{\mathrm{N}}=0.347 \pm 0.022\right.$ and $0.264 \pm 0.002$ in the Jeesiörova and Kevitsa komatiites, respectively; 2SE), sloping $\operatorname{HREE~}\left((\mathrm{Gd} / \mathrm{Yb})_{\mathrm{N}}=1.53 \pm 0.08\right.$ and $1.49 \pm 0.01$, respectively; $2 \mathrm{SE}$ ), and enrichments in Th and $U$ relative to the neighboring element with similar incompatibility, i.e., $\mathrm{Nb}\left((\mathrm{Nb} / \mathrm{Th})_{\mathrm{N}}=0.595 \pm 0.019\right.$ and $0.583 \pm 0.011$, respectively).

\subsection{Re-Os isotopic compositions and HSE abundances}

The Re-Os isotopic and HSE abundance data for the Jeesiörova and Kevitsa komatiites and olivine and chromite separates are listed in Table 3 and plotted on the ${ }^{187} \mathrm{Re} /{ }^{188} \mathrm{Os}$ versus ${ }^{187} \mathrm{Os} /{ }^{188}$ Os diagram in Fig. 6, on a CI chondrite-normalized plot in Fig. 7, and on $\mathrm{MgO}$ versus HSE variation diagrams in Fig. 8.

Thirty-three whole-rock samples and olivine and chromite separates define a regression line with a slope corresponding to an ISOPLOT Model 3 age of 2049 \pm 13 Ma and a chondritic initial ${ }^{187} \mathrm{Os} /{ }^{188} \mathrm{Os}=0.11284 \pm 28\left(\gamma^{187} \mathrm{Os}=-0.2 \pm 0.2\right)$. This age is in good agreement with the internal Sm-Nd isochron age of $2056 \pm 25$ Ma obtained by Hanski et al. (2001) for the Jeesiörova komatiites. The initial $\gamma^{187}$ Os $=-0.2 \pm 0.2$ is identical, within uncertainty, to the less precise average initial $\gamma^{187}$ Os $=+0.1 \pm 0.6$ obtained for chromite separates from the Jeesiörova komatiites by Gangopadhyay et al. (2006).

In CI chondrite-normalized HSE diagrams (Fig. 7), the Jeesiörova and Kevitsa komatiite samples display typical komatiitic patterns with moderate enrichments in incompatible Pt, Pd, 
and Re relative to compatible $\mathrm{Os}$, Ir, and $\mathrm{Ru}\left((\mathrm{Pd} / \mathrm{Ir})_{\mathrm{N}}=2.84-10.1\right)$. By contrast, the two olivine separates analyzed show an inverse relationship, being enriched in compatible relative to incompatible HSE, with the exception of the elevated Re abundance in one of the separates. This elevated Re concentration is, however, supported by the correspondingly more radiogenic Os isotopic composition of this separate, indicating that the olivine likely contained inclusions of interstitial melt enriched in incompatible elements.

In the $\mathrm{MgO}$ versus HSE diagrams (Fig. 8), variations in the Os and Ir contents show broad positive correlations with the $\mathrm{MgO}$ abundances, with the large degree of scatter most likely due to the presence of Os-Ir alloy on the liquidus, along with olivine. The $\mathrm{Ru}$ abundances display a more regular behavior and were likely mostly controlled by chromite fractionation during differentiation of the komatiites.

The Pt, Pd, and Re abundances show strong negative correlations with $\mathrm{MgO}$ contents and, with the exception of some scatter in the Re content, especially among the Jeesiörova komatiites, plot on the trends that pass through the olivine compositions; these variations are consistent with olivine control, indicating both incompatible behavior of these HSE during komatiite differentiation and their immobile behavior during post-magmatic processes. Of note, the Jeesiörova and Kevitsa rocks show a subchondritic $(\mathrm{Pt} / \mathrm{Pd})_{\mathrm{N}}=0.78 \pm 0.01$, which is typical of komatiites (e.g., Puchtel et al., 2009b), but is $\sim 20 \%$ lower than the near-chondritic ratios in the Ni-Cu-PGE sulfide deposits of Finnish Lapland (Mutanen 1997; Törmänen et al., 2016).

\subsection{Pt-Os isotope systematics}

The high-precision Os isotopic data for the chromite separates from the Jeesiörova komatiite samples 12D-PPR and 13 EJH are presented in Table 4 and plotted on the ${ }^{190} \mathrm{Pt} /{ }^{188}$ Os versus ${ }^{186} \mathrm{Os} /{ }^{188}$ Os diagram in Fig. 6B. The data for the seven chromite separates define a regression line with a slope corresponding to an age of $\sim 2.0 \mathrm{Ga}$ and an average initial ${ }^{186} \mathrm{Os} /{ }^{188} \mathrm{Os}=0.1198369 \pm 3\left(\mu^{186} \mathrm{Os}=+29 \pm 2,2 \mathrm{SE}\right)$ calculated for the time of the komatiite emplacement derived from the Re-Os isochron (2049 Ma).

\subsection{W isotopic compositions and abundances}

The $\mathrm{W}$ abundances and isotopic compositions of the Jeesiörova and Kevitsa komatiites are listed in Tables 2 and 5 and plotted in Fig. 4B and as BSE-normalized values in Fig. 5. The W abundances vary between 8.8 and 13 ppb in the Kevitsa komatiites; the only analyzed sample of the Jeesiörova komatiite contains $27 \mathrm{ppb} \mathrm{W}$. In the $\mathrm{MgO}$ versus $\mathrm{W}$ variation 
diagram (Fig. 4B), the data for the Kevitsa komatiites plot with some scatter around a nearly horizontal trend line, whereas the only data point for the Jeesiörova komatiite plots above the trend line.

The BSE-normalized trace element abundances (Fig. 5) for the Kevitsa komatiites are characterized by small negative to positive $\mathrm{W}$ abundance offsets relative to neighboring elements (i.e., Th and $U$ ) with similar incompatibility during mantle melting (W/W* = $0.95 \pm 0.13$, where $\mathrm{W} / \mathrm{W}^{*}=\mathrm{W}_{N} /\left(\sqrt{ }\left[\mathrm{Th}_{N} \times \mathrm{U}_{N}\right]\right)$ and $N$ are BSE-normalized values from Arevalo and McDonough (2008) and Hofmann (1988)). The W/W* ratio in the only Jeesiörova komatiite sample analyzed (LP10) is 2.1 .

The two Kevitsa komatiite samples and two replicates analyzed in this study for W isotopic composition, are characterized by ${ }^{182} \mathrm{~W} /{ }^{184} \mathrm{~W}$ ratios that are indistinguishable from ${ }^{182} \mathrm{~W} /{ }^{184} \mathrm{~W}$ measured in the laboratory reference material, with an average $\mu^{182} \mathrm{~W}=+1.5 \pm 3.3$ (2SE, $n=4$ ), where $\mu^{182} \mathrm{~W}$ is the parts per million deviation of ${ }^{182} \mathrm{~W} /{ }^{184} \mathrm{~W}$ of a given sample from that of the reference material, which, by definition, is equal to zero (Table 5).

\subsection{Sm-Nd and Lu-Hf isotopic compositions and abundances}

The ${ }^{147} \mathrm{Sm}^{143} \mathrm{Nd}$ isotopic and concentration data for the whole-rock samples and clinopyroxene separates of the Jeesiörova and Kevitsa komatiites are listed in Table 6 and plotted in Fig. 9. Regression of the combined Sm-Nd isotopic data (Fig. 9a) for 13 samples yields a Model 1 ISOPLOT internal isochron age of 2046 \pm 22 Ma (MSWD $=2.4$ ), which is identical, within the uncertainty, to the Re-Os isochron age of $2049 \pm 13 \mathrm{Ma}$. The initial $\varepsilon^{143} \mathrm{Nd}$ derived from the isochron is $+3.8 \pm 0.9$. The individual samples have very uniform initial $\mathrm{Nd}$ isotopic compositions, with initial $\varepsilon^{143} \mathrm{Nd}$ ranging between +3.5 and +3 .9. A more precise initial $\varepsilon^{143} \mathrm{Nd}=+3.7 \pm 0.3(2 \mathrm{SD}, n=13)$ is obtained by averaging the initial ${ }^{143} \mathrm{Nd} /{ }^{144} \mathrm{Nd}$ ratios calculated for each sample using the measured ${ }^{147} \mathrm{Sm} /{ }^{144} \mathrm{Nd}$ and ${ }^{143} \mathrm{Nd} /{ }^{144} \mathrm{Nd}$ ratios. Our results are consistent with those obtained earlier for the most LREE-depleted Jeesiörova komatiites (Hanski et al., 2001).

The ${ }^{176} \mathrm{Lu}^{176} \mathrm{Hf}$ data (Fig. 9b) for the Jeesiörova whole-rock komatiite sample 13-EJH and clinopyroxene separate define a regression line in ${ }^{176} \mathrm{Lu} /{ }^{177} \mathrm{Hf}-{ }^{176} \mathrm{Hf} /{ }^{177} \mathrm{Hf}$ space with a slope corresponding to an ISOPLOT Model 1 age of 2072 \pm 37 Ma, which also overlaps, within uncertainties, the Re-Os emplacement age of the Jeesiörova and Kevitsa komatiites. The initial $\varepsilon^{176} \mathrm{Hf}$ value derived from the regression is $+8.7 \pm 0.7$. The average initial $\varepsilon^{176} \mathrm{Hf}$ 
value calculated for the two samples analyzed $(+8.7 \pm 0.3,2 \mathrm{SD}, n=2)$ is identical to the one derived from the isochron.

Plotted in Fig. 9c are the Nd and Hf isotopic data for the Jeesiörova komatiites, together with the Nd-Hf terrestrial array from Blichert-Toft and Puchtel (2010). In contrast to other late Archean and post-Archean komatiite systems (e.g., Kostomuksha: Blichert-Toft and Puchtel, 2010; Abitibi: Puchtel et al., 2018; Vetreny: Puchtel et al., 2016a; Gorgona: Thompson et al., 2003), the calculated initial $\varepsilon^{143} \mathrm{Nd}$ and $\varepsilon^{176} \mathrm{Hf}$ values of the Jeesiörova komatiites (Fig. 9c) do not plot on the terrestrial array of Blichert-Toft and Puchtel (2010).

\section{Discussion}

\subsection{Jeesiörova-Kevitsa emplaced komatiite magma composition}

Nicklas et al. (2019) reported major and trace element abundance data for olivine phenocrysts and whole-rock samples of the Kevitsa komatiites. Based on the Mg-Fe olivinekomatiite melt equilibria, these authors estimated that the parental magma to the Kevitsa komatiites contained 27.4 \pm 2.4 wt.\% MgO. By comparison for this study, in order to estimate the parental magma composition, we used an approach different from that of Nicklas et al. (2019). We performed mathematical incremental step-wise addition of olivine to a melt composition represented by sample $\mathrm{KD}-14(\mathrm{MgO}=16.3$ wt.\%) until the melt was in equilibrium with olivine Fo94.1, the most MgO-rich olivine population found in the Kevitsa komatiites (Nicklas et al., 2019, and this study). To select appropriate olivine-melt Fe-Mg distribution coefficients $\left(\mathrm{K}_{\mathrm{D}}\right)$, we utilized the results of the isothermal crystallization experiments of komatiitic liquids carried out by Sossi and O’Neill (2016). Using the empirical $\mathrm{K}_{\mathrm{D}}$ defined as $\left(\mathrm{Fe}^{2+} / \mathrm{Mg}\right)_{\mathrm{ol}} /(\Sigma \mathrm{Fe} / \mathrm{Mg})_{\text {melt }}$ and the $\mathrm{T}-\mathrm{MgO}-\mathrm{K}_{\mathrm{D}}-\log f \mathrm{O}_{2}$ relationships from their study, we adjusted the $K_{D}$ values at each step of olivine addition. Because $K_{D}$ defined in this way using bulk Fe in the melt is dependent on the oxygen fugacity, two different redox conditions were considered, $\triangle \mathrm{FMQ}=+0.9$ and $\triangle \mathrm{FMQ}=0.0$. The former choice is based on the observed V partitioning between olivine and melt in the Kevitsa komatiites (Nicklas et al., $2019)$ and the latter on the composition of chrome spinel $\left(\mathrm{Fe}^{3+} /\left(\mathrm{Fe}^{3+}+\mathrm{Al}+\mathrm{Cr}\right)=0.06\right)$. The $\mathrm{K}_{\mathrm{D}}$ values were varied between $0.28-0.26$ and $0.29-0.27$ in these two cases, respectively, and the required additions of olivine were 34 and $40 \%$.

The two resulting major element compositions of the emplaced komatiite melt are similar, with the most important difference being the $\mathrm{MgO}$ content. The more oxidized conditions yielded an $\mathrm{MgO}$ content of 25.2 wt.\%, while the FMQ buffer conditions gave an $\mathrm{MgO}$ content 
of 26.3 wt.\%. These estimates are identical, within the uncertainties, to those obtained by Nicklas et al. (2019) using an independent technique, and corroborate the komatiitic composition of the emplaced Kevitsa komatiite magma. The results indicate that the parental magmas to the Kevitsa, and, therefore, also Jeesiörova, komatiites approached those of their late Archean counterparts from the Abitibi and Belingwe greenstone belts (Puchtel et al., $2009 \mathrm{~b}$ ) in terms of $\mathrm{MgO}$ content, and, therefore, their liquidus temperatures.

\subsection{Lithophile trace element and isotope systematics of the komatiites}

The Jeesiörova and Kevitsa komatiites have low $(\mathrm{La} / \mathrm{Sm})_{\mathrm{N}}(0.347 \pm 0.022$ and $0.264 \pm 0.002$, respectively), and high positive initial $\varepsilon \mathrm{Nd}$ and $\varepsilon \mathrm{Hf}(+3.7 \pm 0.3$ and $+8.7 \pm 0.3$, respectively), indicating derivation from a mantle source that was strongly depleted in highly incompatible, lithophile trace elements. These komatiites are $\sim 2.5$ times more strongly depleted in the light REE than, e.g., modern N-MORB (average $(\mathrm{La} / \mathrm{Sm})_{\mathrm{N}}=0.654$ : Hofmann, 1988). Yet, the lavas are also characterized by enrichments in $\mathrm{Th}, \mathrm{U}$, and $\mathrm{W}$ relative to $\mathrm{Nb}$, an element with similar incompatibility during melting of spinel peridotite $\left((\mathrm{Nb} / \mathrm{Th})_{\mathrm{N}}=0.583 \pm 0.011\right)$, and a negative $\mathrm{Nb}$ anomaly $\left(\mathrm{Nb} / \mathrm{Nb}^{*}=0.582 \pm 0.010\right.$, where $\left.\mathrm{Nb} / \mathrm{Nb}^{*}=\mathrm{Nb}_{\mathrm{N}} / \sqrt{ }\left(\mathrm{Th}_{\mathrm{N}} * \mathrm{La}_{\mathrm{N}}\right)\right)$. This is most likely indicative of minor, yet significant crustal contamination.

Upper crustal rocks are generally characterized by low $(\mathrm{Nb} / \mathrm{Th})_{\mathrm{N}}$ and $(\mathrm{Nb} / \mathrm{La})_{\mathrm{N}}$ ratios and, as a result, display pronounced negative $\mathrm{Nb}$ anomalies relative to the elements with similar incompatibility during mantle melting (Th and La) on BSE-normalized trace element diagrams, i.e., their Nb/Nb* $<<1.0$ (Rudnick and Fountain, 1995; Rudnick and Gao, 2014). By contrast, primary uncontaminated komatiitic magmas commonly do not show a $\mathrm{Nb}$ anomaly, i.e., their $\mathrm{Nb} / \mathrm{Nb}^{*}=1.00$ (Jochum et al., 1991; Puchtel et al., 1998). Jochum et al. (1991) noted that the elements most sensitive to crustal contamination in komatiite magmas include Th, $\mathrm{U}$, and light REE and, to a lesser extent, $\mathrm{Nb}$. As a result, the $\mathrm{Nb} / \mathrm{Nb}^{*}$ ratio can be utilized as a measure of the degree of crustal contamination and, when applied in combination with the lithophile element isotopic systems, to discriminate between contaminated and uncontaminated lavas. Based on these observations, it is likely that the original JeesiörovaKevitsa komatiite magma was contaminated with upper crustal rocks of the Fennoscandian Shield en route to the surface.

In order to test this hypothesis and calculate the major and trace element and $\mathrm{Nd}, \mathrm{Hf}$, and $\mathrm{W}$ isotopic compositions of the original Jeesiörova-Kevitsa komatiite magma, we performed model mixing calculations, the results of which are presented in Table 8. For the crustal contaminant endmember, we assumed an average composition of the Vodla Block tonalitic 
gneisses that are the dominant upper crustal rock type within the adjacent Karelian granitegreenstone terrane (Puchtel et al., 2016b). These Karelian tonalites are similar in age and major- and trace element composition to their counterparts from Finnish Lapland (e.g., Huhma et al., 2012), but, unlike the latter, have been better characterized in terms of the isotopic systematics of interest (Table 8). This average tonalite composition from Puchtel et al. (2016b) is henceforth referred to as the Fennoscandian Tonalite Average (FTA). In order to calculate the degree of contamination and the trace element abundances and $\mathrm{Nd}$ and $\mathrm{Hf}$ isotopic compositions of the original, uncontaminated Jeesiörova-Kevitsa komatiite magma, we assumed that it had a $\mathrm{Nb} / \mathrm{Nb}^{*}=1.00$. Calculations show that to produce the emplaced Jeesiörova-Kevitsa komatiite magma with $\mathrm{Nb} / \mathrm{Nb}^{*}=0.582$, the original komatiite magma had to be mixed with $\sim 1 \%$ of the average FTA $\left(\mathrm{Nb} / \mathrm{Nb}^{*}=0.118\right)$.

Using $1 \%$ contamination and the $\mathrm{Nd}$ and $\mathrm{Hf}$ abundances and initial $\mathrm{Nd}$ and $\mathrm{Hf}$ isotopic compositions of the FTA calculated at the time of the Kevitsa komatiite magma emplacement, the original Kevitsa komatiite magma and, thus, its source is calculated to have had initial $\varepsilon \mathrm{Nd}$ and $\varepsilon \mathrm{Hf}$ values of +4.9 and +10.2 , respectively.

On the $\varepsilon N d$ versus $\varepsilon H f$ evolution diagram in Fig. 9c, the calculated datum for the Jeesiörova-Kevitsa komatiite source plots within uncertainty of the terrestrial evolution curve of Blichert-Toft and Puchtel (2010). This indicates coupled, or congruent, behavior of the two isotope systems in the source of the original komatiite magma. It appears, therefore, that the $\mathrm{Nd}-\mathrm{Hf}$ isotope decoupling observed in the Jeesiörova-Kevitsa emplaced komatiite magma was caused by contamination with the older tonalitic crust that had isotopically evolved away from the terrestrial evolution curve by the time it was mixed with the original komatiite magma (Table 8). The datum for the Jeesiörova-Kevitsa komatiite source also plots near the Depleted MORB Mantle (DMM) value of Goldstein and Jacobsen (1988) at 2049 Ma (Fig. 9c), indicating derivation from a mantle source that was already as long-term depleted in incompatible lithophile trace elements as DMM at $2.05 \mathrm{Ga}$.

\subsection{Osmium isotope - HSE systematics of the Jeesiörova-Kevitsa komatiite source}

Although the Os isotopic compositions and absolute and relative HSE abundances in the mantle sources of early and late Archean komatiites have been the subject of numerous studies over nearly four decades (e.g., Brügmann et al., 1987; Walker et al., 1988; Foster et al., 1996; Gangopadhyay and Walker, 2003; Puchtel et al., 2009a; 2014, 2016b; Maier et al., 2009), studies of post-Archean komatiites have been rare, in part because the number of Proterozoic and younger komatiites is far more limited. 
In order to characterize the HSE present in the Paleoproterozoic mantle source of the Jeesiörova-Kevitsa komatiites, the effects of crustal contamination must first be evaluated. We again use the average FTA composition from Puchtel et al. (2016b) to assess the effects of $1 \%$ contamination of the original Jeesiörova-Kevitsa komatiite magma on its Os isotopic composition and HSE abundances. Because of the very low concentrations of these elements in the FTA, the effects are negligible. Contamination of this magnitude would have increased $\mu^{186}$ Os and $\gamma^{187}$ Os values by only 0.004 (based on the calculated ${ }^{186} \mathrm{Os} /{ }^{188} \mathrm{Os}=0.1198767$ at 2.05 Ga for the FTA assuming its derivation from a BSE-type mafic source at $3.2 \mathrm{Ga}$, per Puchtel et al., 2016b) and 0.01 (based on the calculated ${ }^{187} \mathrm{Os} /{ }^{188} \mathrm{Os}=1.2091$ at $2.05 \mathrm{Ga}$ for the FTA assuming its derivation from a BSE-type mafic source at $3.2 \mathrm{Ga}$, per Puchtel et al., 2016b) units, respectively, which are well within the uncertainties of the current estimates for these values. Similarly, effects on absolute HSE abundances would have been $<<1 \%$.

Estimation of the HSE abundances in the mantle source of the Jeesiörova-Kevitsa komatiites is achieved by the bootstrap method of Puchtel et al. (2004b) that sequentially combines Os isotopic and HSE concentration data. First, we used the initial ${ }^{187} \mathrm{Os} /{ }^{188}$ Os and ${ }^{186} \mathrm{Os} /{ }^{188}$ Os ratios calculated for the Jeesiörova-Kevitsa komatiites to estimate the timeintegrated evolution of Re/Os and $\mathrm{Pt} / \mathrm{Os}$ in their mantle source. In order to place minimum constraints on these long-term source ratios, we calculated the parent/daughter elemental ratios necessary to arrive at the Os isotopic composition at 2049 Ma by assuming generation of this mantle domain soon after Solar System formation. It is estimated that this source evolved from an early Solar System ${ }^{187} \mathrm{Os} /{ }^{188} \mathrm{Os}=0.09517$ at $4567 \mathrm{Ma}$ (Archer et al., 2014) to the initial ${ }^{187} \mathrm{Os} /{ }^{188} \mathrm{Os}=0.11285 \pm 23$ at $2049 \mathrm{Ma}$ with ${ }^{187} \mathrm{Re} /{ }^{188} \mathrm{Os}=0.397 \pm 5$. This ratio is well within the range of bulk chondritic meteorites. Using the early Solar System ${ }^{186} \mathrm{Os} /{ }^{188} \mathrm{Os}=$ 0.1198269 at $4567 \mathrm{Ma}$ (Brandon et al., 2006) requires a source with a ${ }^{190} \mathrm{Pt} /{ }^{188} \mathrm{Os}=0.00269 \pm 8$ to have evolved to its ${ }^{186} \mathrm{Os} /{ }^{188} \mathrm{Os}=0.1198369 \pm 3$ at $2049 \mathrm{Ma}$. In contrast to Re/Os, the required minimum ${ }^{190} \mathrm{Pt} /{ }^{188} \mathrm{Os}$ ratio is $\sim 50 \%$ higher than the average ${ }^{190} \mathrm{Pt} /{ }^{188} \mathrm{Os}=0.00180 \pm 17$ (2SD) in bulk chondritic meteorites (as compiled from the data of Horan et al. (2003), Brandon et al. (2005, 2006), Fischer-Gödde et al. (2010), and van Acken et al. (2011)).

The calculated initial $\gamma^{187}$ Os of the Jeesiörova-Kevitsa komatiite source is also within the range of those for the majority of Archean and Paleoproterozoic komatiite sources, which were characterized by initial $\gamma^{187}$ Os values between -0.1 and +1.3 , also well within the range of $95 \%$ of chondritic meteorites (Fig. 10a). The ${ }^{186} \mathrm{Os} /{ }^{188} \mathrm{Os}$ isotope data available for Archean and Paleoproterozoic komatiite sources indicate that mantle sources of the $2.7 \mathrm{Ga}$ 
Abitibi (Canada), 2.7 Ga Belingwe (South Africa), and 2.4 Ga Vetreny (Fennoscandia) komatiite systems evolved with time-integrated Pt/Os within the chondritic range (Fig. 10b), whereas the coupled high initial ${ }^{186,187} \mathrm{Os} /{ }^{188}$ Os of the 2.8 Ga Kostomuksha komatiite system (Fennoscandia) require long-term suprachondritic Pt/Os and Re/Os (Puchtel et al., 2005). By contrast, the $3.5 \mathrm{Ga}$ Komati and $3.3 \mathrm{Ga}$ Weltevreden komatiite systems (South Africa) evolved with non-chondritic Pt/Os, but chondritic Re/Os ratios (Puchtel et al., 2014), displaying decoupling of the Re-Os and Pt-Os isotopic systems. The calculated suprachondritic initial $\mu^{186}$ Os $=+29 \pm 2$ in the Jeesiörova-Kevitsa komatiite source obtained in this study is similar to $\mu^{186} \mathrm{Os}=+22 \pm 7$ in the source of the Weltevreden komatiite system (Puchtel et al., 2014).

Because of the availability of high-precision Os isotopic data and immobile behavior of HSE in the Kevitsa komatiites during post-magmatic alteration, absolute abundances of incompatible $\mathrm{Re}, \mathrm{Pt}$, and $\mathrm{Pd}$ and compatible Os in the Jeesiörova-Kevitsa komatiite source can be estimated using the bootstrap protocol of Puchtel et al. (2004b).

As was shown in a number of previous studies (e.g., Alard et al., 2000; Lorand and Alard, 2001; Luguet et al., 2007), $\geq 90 \%$ of the HSE budget of the mantle resides in two major types of sulfides. The high-temperature Os-Ir-Ru-rich Fe-Ni monosulfide solid solution (mss) usually occurs as inclusions in liquidus phases, primarily olivine, whereas lower-temperature $\mathrm{Cu}-\mathrm{Ni}$ sulfides occupy interstitial space between the liquidus phases. During partial melting of mantle peridotite, $\mathrm{Cu}-\mathrm{Ni}$ sulfides enter the melt, whereas mss remains trapped in the melting residue. It takes $\sim 18-25 \%$ partial melting (Barnes et al., 1985; Keays, 1995; Luguet et al., 2007; Mungall and Naldrett, 2008; Naldrett, 2010; Fonseca et al., 2011; 2012; Kiseeva et al., 2017) for all the low-temperature $\mathrm{Cu}-\mathrm{Ni}$ sulfides to get exhausted in the mantle. As the degree of melting continues to increase, the magma becomes sulfide-undersaturated. It has also recently been shown that decrease in $f S_{2}$ with increase in the degree of melting triggers exsolution of Os-Ir alloys from the refractory mss in the residue (Fonseca et al., 2011; 2012). All low-degree (basalts) and the majority of higher-degree (picrites and komatiites) partial melts are characterized by compatible behavior of Os and Ir during magmatic differentiation, indicating that their parental magmas remained saturated in Os-Ir alloys (Puchtel et al., 2004b; Barnes and Fiorentini, 2008). However, some lavas, such as the 2.8 Ga Kostomuksha and the $3.55 \mathrm{Ga}$ Schapenburg komatiites, exhibited an incompatible behavior of Os and Ir during magma differentiation, likely indicating near-complete exhaustion of Os-Ir alloys in the mantle sources of these komatiites (Puchtel and Humayun, 2005; Puchtel et al., 2009a). 
Apparently, the sulfide saturation status of komatiite magmas is a crucial parameter that plays a key role in determining whether their HSE abundances accurately reflect those in their mantle sources. In the following discussion, we evaluate the sulfide saturation status of the Jeesiörova-Kevitsa komatiite magma during both mantle melting and after emplacement.

Sulfide saturation of a mafic magma is determined by several key parameters, the most important of which are pressure $(\mathrm{P})$, temperature $(\mathrm{T})$, and $\mathrm{FeO}$ content. In their recent study, Steenstra et al. (2020) combined the results of their own work with previously published experimental data of Mavrogenes and O’Neill (1999), Li and Agee (2001), Holzheid and Grove (2002), O’Neill and Mavrogenes (2002), Jugo et al. (2005), Liu et al. (2007), Brenan (2008), Kiseeva and Wood (2013, 2015), Ding et al. (2014, 2018), Fortin et al., (2015), Wood and Kiseeva (2015), Smythe et al. (2017), and Steenstra et al. (2018) to produce a refined parameterization model for the sulfur concentration at sulfide saturation (SCSS) as a function of P, T, and major and trace element abundances in silicate liquids (Eq. 4 in Steenstra et al., 2020).

In order to calculate the P-T parameters of the Jeesiörova-Kevitsa komatiite magma generation, we used the mantle melting parameterization model of McKenzie and Bickle (1988). These calculations yield the following parameters: potential mantle temperature of the Jeesiörova-Kevitsa komatiite mantle source $\mathrm{T}_{p o t}=1763^{\circ} \mathrm{C}$, liquidus temperature upon emplacement $\mathrm{T}_{l i q}=1544^{\circ} \mathrm{C}$, depth of melting initiation $294 \mathrm{~km}$, which translates into a pressure of $9.5 \mathrm{GPa}$. Based on these parameters, the temperatures and pressures at which melting terminated for the Jeesiörova-Kevitsa komatiite magma was calculated using the model of Herzberg et al. (2010) to be $1730^{\circ} \mathrm{C}$ and $5.0 \mathrm{GPa}$. Using these parameters, the chemical composition of the original Jeesiörova-Kevitsa komatiite magma from Table 8, and Eq. 4 of Steenstra et al. (2020), the SCSS of the Jeesiörova-Kevitsa komatiite magma upon separation from the melting residue and ensuing emplacement are calculated to be 2270 and 5200 ppm, respectively.

In order to estimate the $S$ content in the Jeesiörova-Kevitsa komatiite magma and, thus, its sulfide saturation status, knowledge of the sulfur content of its mantle source, the $S$ partition coefficient, and the degree of melting is required. The average S content of modern DMM is estimated to be $206 \pm 25$ ppm (Sun et al., 2020). Since the Jeesiörova-Kevitsa komatiite source was as strongly melt-depleted as contemporary DMM, we assume it also had a similar S content.

To estimate the degree of partial melting that produced the original Jeesiörova-Kevitsa komatiite magma, we used a batch melting model and the calculated abundances of 
moderately incompatible lithophile elements (e.g., $\mathrm{Al}, \mathrm{Ti}, \mathrm{Gd}$ ) in this magma and its garnetfree mantle source of spinel lherzolite composition, as indicated by their Al-undepleted nature and the depth of melting initiation of $\sim 290 \mathrm{~km}$. These calculations yield $49 \%$ partial melting. Assuming that sulfur was highly incompatible during komatiite melting, with the degree of incompatibility similar to that of La, the original Jeesiörova-Kevitsa komatiite magma is calculated to have contained $420 \mathrm{ppm}$ S. This $\mathrm{S}$ content is, thus, $\sim 5$ times lower than the SCSS of the Jeesiörova-Kevitsa komatiite magma upon separation from the melting residue and $\sim 12$ times lower than the SCSS of the Jeesiörova-Kevitsa komatiite magma upon emplacement, indicating that it was strongly sulfur-undersaturated upon separating from the source and remained as such all the way to the surface.

The sulfur-undersaturated nature of the Jeesiörova-Kevitsa komatiite magma upon emplacement is also attested to by the incompatible behavior of the highly chalcophile element $\mathrm{Cu}$ during magma differentiation after emplacement. The $\mathrm{Cu}$ abundances in the Kevitsa komatiites strongly correlate with the $\mathrm{MgO}$ content and plot on an olivine control line in the $\mathrm{MgO}$ versus $\mathrm{Cu}$ diagram (Fig. 4a), indicating that sulfide liquid was not a fractionating phase within the compositional range represented by the samples of this study.

To estimate the abundances of incompatible Pt and Pd in the Jeesiörova-Kevitsa komatiite source, we extrapolated the differentiation trends for each of these elements to a mantle $\mathrm{MgO}$ = 38 wt.\% using ISOPLOT. The concentrations of Pt and Pd in the source were, thus, calculated to be $9.54 \pm 0.22$ and $8.13 \pm 0.19 \mathrm{ppb}$, respectively, and the total $\mathrm{Pt}$ and $\mathrm{Pd}$ abundances to be $17.7 \pm 0.8 \mathrm{ppb}$, or $120 \pm 5 \%$ of those in the average estimates for modern BSE of 14.7 $\pm 2.0 \mathrm{ppb}$ (Becker et al., 2006).

The concentration of compatible Os in the source was estimated to be $3.4 \pm 0.1 \mathrm{ppb}$ using the calculated Pt content in the source and the long-term ${ }^{190} \mathrm{Pt} /{ }^{188} \mathrm{Os}$ derived from the initial ${ }^{186} \mathrm{Os} /{ }^{188}$ Os. Further, using the calculated Os concentration and the estimated long-term ${ }^{187} \mathrm{Re} /{ }^{188} \mathrm{Os}$ derived from the initial ${ }^{187} \mathrm{Os} /{ }^{188} \mathrm{Os}$, the Re concentration in the source is calculated to be $0.285 \pm 0.008 \mathrm{ppb}$. Unlike the $\mathrm{Pt}$ and $\mathrm{Pd}$ concentrations, therefore, the calculated Os and Re concentrations in the source of the Jeesiörova-Kevitsa komatiites are, respectively, $13 \%$ and $19 \%$ lower than the average estimates for BSE.

The presence of residual Os/Ir alloys in the melting residue, as evidenced by the compatible behavior of Os and Ir during the Jeesiörova-Kevitsa magma differentiation, makes it possible for the Os/Ir ratio to fractionate between the source and the komatiitic magma. Furthermore, as discussed earlier, chromite fractionation likely had a strong effect on $\mathrm{Ru}$ concentrations in the Jeesiörova-Kevitsa komatiite magma. Based on these observations, we 
were unable to constrain the abundances of $\mathrm{Ir}$ and $\mathrm{Ru}$ in the source with any meaningful degree of accuracy.

The calculated total Pt and Pd abundances in the Jeesiörova-Kevitsa komatiite source are also plotted as a function of age in Fig. 11 and compared with the data for other Archean and Paleoproterozoic komatiite systems studied to date and the BSE estimate. The calculated total Pt and Pd abundances in the source of the Jeesiörova-Kevitsa komatiites are significantly higher than in any other komatiite system examined so far. The significance of this observation will be discussed in the following sections.

\subsection{The siderophile and lithophile element isotope conundrum}

There is an apparent decoupling between the radiogenic lithophile trace element isotope systematics (e.g., Sm-Nd and Lu-Hf) and Re-Os isotope systematics in komatiite mantle sources worldwide. Many komatiite systems, such as those from the Abitibi (Canada) and Belingwe (South Africa) greenstone belts (Puchtel et al., 2009b; Puchtel et al., 2018), the Weltevreden and Komati (South Africa) Formations (Puchtel et al., 2014), and the SumozeroKenozero (Fennoscandia) greenstone belt (Puchtel et al., 2007), are characterized by strong, long-term depletions in incompatible lithophile trace elements, e.g., Nd versus Sm, but chondritic Re/Os. By contrast, certain other komatiite systems, such as the Kostomuksha in Fennoscandia (Puchtel et al., 2005) and the Schapenburg in South Africa (Puchtel et al., 2016a), while being long-term depleted in light REE, evolved with long-term suprachondritic $\mathrm{Re} / \mathrm{Os}$ ratios. In this study, we address this apparent conundrum using the Sm-Nd, Lu-Hf, and Re-Os isotope and lithophile trace element abundance data for the Jeesiörova-Kevitsa komatiite system.

In Section 6.2, we calculated that the mantle source of the Jeesiörova-Kevitsa komatiites had the initial $\varepsilon^{143} \mathrm{Nd}=+4.9$ and $\varepsilon^{176} \mathrm{Hf}=+10.2$. This source was similar to DMM at $2.05 \mathrm{Ga}$ (Goldstein and Jacobsen, 1988) and had long-term coupled Sm/Nd and Lu/Hf isotope systematics (Blichert-Toft and Puchtel, 2010). If the source had originally chondritic $\mathrm{Sm} / \mathrm{Nd}$ and $\mathrm{Lu} / \mathrm{Hf}$, then it experienced a melt-extraction event a minimum of several hundred million years prior to komatiite emplacement. The same melt extraction event might also have been expected to result in depletion of incompatible Re relative to compatible Os, as well as more modest depletion in Pt relative to Os. Over time, these chemical effects would have led to the development of negative $\gamma^{187}$ Os and $\mu^{186}$ Os values. Instead, as shown in Section 6.3, the 
Jeesiörova-Kevitsa komatiite source evolved within the range of chondritic Re/Os and suprachondritic Pt/Os.

\subsection{Tungsten isotopic composition of the Jeesiörova-Kevitsa komatiite source}

The Paleoproterozoic mantle was recently shown to have been characterized by an oxidation state similar to that of the modern mantle (Nicklas et al., 2019). As a result, during melting of the Paleoproterozoic mantle, W likely was characterized by a degree of incompatibility similar to that of Th and U (Newsom et al., 1996; Arevalo and McDonough, 2008; König et al., 2011). Therefore, the BSE-normalized W abundance in the emplaced Jeesiörova-Kevitsa komatiite magma is expected to be similar to those of Th and U. This is the case, with an average calculated $\mathrm{W} / \mathrm{W}^{*}=1.0$. This also implies that $\mathrm{W}$, similarly to $\mathrm{Th}$ and $\mathrm{U}$, was characterized by immobile behavior during the limited postmagmatic alteration of the Jeesiörova-Kevitsa komatiites. Further, similarly to the other lithophile trace elements, such as $\mathrm{Nd}$ and $\mathrm{Hf}$, upper crustal rocks have significantly higher $\mathrm{W}$ abundances than komatiites; they also likely had a different $\mathrm{W}$ isotopic composition compared to komatiites, and, therefore, addition of even a small amount of upper crustal material can significantly change both the $\mathrm{W}$ isotopic composition and $\mathrm{W}$ abundances of a komatiite magma.

In this study, we used the measured $\mathrm{W}$ isotopic composition and $\mathrm{W}$ abundance of the emplaced Jeesiörova-Kevitsa komatiite magma to calculate those of the original, noncontaminated komatiite magma. In order to remove the effect of the $1 \%$ crustal contamination estimated on the basis of the lithophile trace element systematics, we used the $\mathrm{W}$ isotopic composition and W abundances of the average FTA from Puchtel et al. (2016b). The endmember parameters and the results of the mixing calculations are given in Table 8 . The calculations suggest that the original Jeesiörova-Kevitsa komatiite magma contained $\sim 5.8 \mathrm{ppb}$ $\mathrm{W}$, implying that $\sim 50 \%$ of the total $\mathrm{W}$ budget in the emplaced Jeesiörova-Kevitsa komatiite magma was derived from the crustal contaminant.

The average $\mu^{182} \mathrm{~W}$ value of the FTA reported by Puchtel et al. (2016b) was $+12.6 \pm 4.5$, so contamination of the original komatiite magma with W-rich crust would have led to an increase in the $\mu^{182} \mathrm{~W}$ value of the original magma. If the assumptions regarding the original uncontaminated komatiite magma concentration of $\mathrm{W}$, and concentration and ${ }^{182} \mathrm{~W}$ isotopic composition of the crustal contaminant are accurate, the $\mathrm{W}$ isotopic composition of the original Jeesiörova-Kevitsa komatiite magma and, by extension, of its mantle source, after correction for crustal contamination, is calculated to be $\mu^{182} \mathrm{~W}=-10 \pm 5$. Here, the uncertainty 
solely reflects propagated measurement uncertainties for the komatiite and the FTA. Because it is a projected original melt composition, this $\mu^{182} \mathrm{~W}$ must be considered tentative. Nevertheless, negative $\mu^{182} \mathrm{~W}$ values of this magnitude are common in modern ocean island basalt systems (Rizo et al., 2019; Mundl-Petermeier et al., 2019; 2020) and have also been observed in the 3.6 Ga Schapenburg komatiites (Puchtel et al., 2016a), South Africa, and some spatially associated, Archean glacial diamictites (Mundl et al., 2018). By contrast, the majority of evolved Archean crustal rocks similar to those envisioned for the FTA contaminant, are characterized by positive ${ }^{182} \mathrm{~W}$ anomalies (e.g., Touboul et al., 2014; Willbold et al., 2015; Rizo et al., 2016b).

\subsection{Reconciling isotopic characteristics of the Jeesiörova-Kevitsa komatiites}

The combined chemical and isotopic data for the Jeesiörova-Kevitsa komatiites are complex. The $\mathrm{Nd}$ and $\mathrm{Hf}$ isotopic data are consistent with derivation from a mantle domain that experienced at least one melting event prior to the one that produced the komatiitic magma. The Nd-Hf isotope characteristics of this mantle domain are similar to projections of the modern DMM to 2049 Ma. The ${ }^{187}$ Os isotopic data indicate derivation from a broadly chondritic mantle source that was not strongly long-term melt depleted. Because the longterm effects of low degrees of partial melting on Re/Os, compared to Sm/Nd and Lu/Hf, are relatively small (Puchtel et al., 2004b; 2009b), the chondritic ${ }^{187} \mathrm{Os} /{ }^{188}$ Os of the mantle source can be considered at least qualitatively consistent with the $\mathrm{Nd}$ and $\mathrm{Hf}$ isotopic data. By contrast, the fractionated $\mathrm{Pt} / \mathrm{Os}$ of the mantle source, as revealed by the suprachondritic initial ${ }^{186} \mathrm{Os} /{ }^{188} \mathrm{Os}$, and the correspondingly fractionated HSE pattern for the source, requires an event that could have strongly modified HSE relative abundances early in Earth history. Finally, if the negative $\mu^{182} \mathrm{~W}$ value for the Jeesiörova-Kevitsa komatiite system obtained after correction for crustal contamination is accurate, it requires invoking one of a limited number of possible processes to account for the projected anomalous composition for the HfW short-lived radiogenic isotope system.

To address these complexities, we consider two melting models. The parameters used in both models are as follows. (1) The mantle domain that ultimately became the source of the Jeesiörova-Kevitsa komatiites initially had a composition consistent with that of the BSE. The chemical and isotopic parameters of this domain were compiled from Jacobsen and Wasserburg (1980), Hamilton et al. (1983), Bouvier et al. (2008), Hofmann (1988), Shirey and Walker (1998), Brandon et al. (2006), and Becker et al. (2006). (2) This domain had a 
modal mineral composition typical of spinel lherzolite, with $65 \%$ olivine, $24 \%$ orthopyroxene, $10 \%$ clinopyroxene, and $1 \%$ spinel. (3) The melting of the domain was modeled using the batch melting equation of Shaw (1970). The bulk $D^{\mathrm{Sm}}, D^{\mathrm{Nd}}, D^{\mathrm{Lu}}$, and $D^{\mathrm{Hf}}$ during melting were calculated to be $0.040,0.024,0.090$, and 0.037 , respectively, based on the above source modal composition and crystal-liquid $D$ values for the respective mineral phases from Green (1994). The bulk $D^{\mathrm{Re}}$ and $D^{\mathrm{Pt}}$ under the redox conditions of $\triangle \mathrm{FMQ}+0.90 \pm 0.33$ determined by Nicklas et al. (2019) were estimated to be 0.20 and 2.0, respectively (Rehkämper et al., 1999; Mallmann and O'Neill, 2007). The bulk $D^{\mathrm{Os}}$ for the low-degree partial melting, consistent with formation of a MORB-type magma, was adopted to be 50 (e.g., Gannoun et al., 2016 and references therein).

In Model 1, we consider an early, global differentiation event. This model requires a minimum degree of melting and a melt extraction that would lead to fractionation of $\mathrm{Sm} / \mathrm{Nd}$ and $\mathrm{Lu} / \mathrm{Hf}$ in the BSE domain from the chondritic value to that required to bring the $\varepsilon^{143} \mathrm{Nd}$ and $\varepsilon{ }^{176} \mathrm{Hf}$ of the domain to the corrected values of +4.9 and +10.2 , respectively, by the time of komatiite formation at $2049 \mathrm{Ma}$. The effect of this melt extraction event on the Re-Os and Pt-Os isotope systems is then considered. Model 2 considers the youngest-possible, maximum degree of melting event that would fractionate the $\mathrm{Sm} / \mathrm{Nd}$ and $\mathrm{Lu} / \mathrm{Hf}$ ratios in the BSE domain from the chondritic values to those calculated for the Jeesiörova-Kevitsa komatiite source, and again bring the $\varepsilon^{143} \mathrm{Nd}$ and $\varepsilon^{176} \mathrm{Hf}$ values of this domain to +4.9 and +10.2 , respectively, by 2049 Ma. The effect of this melt extraction event on the Re-Os and Pt-Os isotope systems is then also considered.

For Model 1, we assume that the global differentiation event occurred $100 \mathrm{Ma}$ after Solar System formation. This timing is consistent with the recent data on the early formation of the Moon at $4.51 \mathrm{Ga}$ (Barboni et al., 2017). The Jeesiörova-Kevitsa komatiite source would have evolved from chondritic ratios of ${ }^{143} \mathrm{Nd} /{ }^{144} \mathrm{Nd}=0.506807$ and ${ }^{176} \mathrm{Hf} /{ }^{177} \mathrm{Hf}=0.279863$ at 4.467 Ga to the initial ratios of ${ }^{143} \mathrm{Nd} /{ }^{144} \mathrm{Nd}=0.510236 \pm 8$ and ${ }^{176} \mathrm{Hf} /{ }^{177} \mathrm{Hf}=0.281762 \pm 18$ at $2049 \mathrm{Ma}$ with long-term ratios of ${ }^{147} \mathrm{Sm} /{ }^{144} \mathrm{Nd}=0.2123 \pm 5$ and ${ }^{176} \mathrm{Lu} /{ }^{177} \mathrm{Hf}=0.0394 \pm 4$. Such modest change in ${ }^{147} \mathrm{Sm} /{ }^{144} \mathrm{Nd}$ and ${ }^{176} \mathrm{Lu} /{ }^{177} \mathrm{Hf}$ from the chondritic ratios of 0.1967 and 0.0336 , respectively, would require only $\sim 0.6 \%$ melting, followed by removal of the melt. At the same time, this melt extraction event would have decreased the ${ }^{187} \mathrm{Re} /{ }^{188}$ Os in the melting residue from 0.4019 to 0.3912 ; the latter ratio is essentially identical to the calculated longterm ${ }^{187} \mathrm{Re} /{ }^{188} \mathrm{Os}=0.397 \pm 8$ determined for the Jeesiörova-Kevitsa komatiite source. However, 
such low-degree melting event would not have had any measurable effect on the Pt/Os ratio of the source. Therefore, Model 1 cannot explain the observed ${ }^{186} \mathrm{Os} /{ }^{188} \mathrm{Os}$ composition of the Jeesiörova-Kevitsa komatiite system.

For Model 2, using the lithophile trace element data, we first calculate the ${ }^{147} \mathrm{Sm} /{ }^{144} \mathrm{Nd}$ and ${ }^{176} \mathrm{Lu} /{ }^{177} \mathrm{Hf}$ ratios in the Jeesiörova-Kevitsa komatiite source to be 0.2912 and 0.0704 , respectively. Modeling indicates that $9 \%$ melting would have generated a residual mantle domain with these $\mathrm{Sm} / \mathrm{Nd}$ and $\mathrm{Lu} / \mathrm{Hf}$ ratios. The latest time of the melting event required for the mantle domain with such $\mathrm{Sm} / \mathrm{Nd}$ and $\mathrm{Lu} / \mathrm{Hf}$ ratios to have evolved to the initial $\varepsilon^{143} \mathrm{Nd}=$ +4.9 and $\varepsilon^{176} \mathrm{Hf}=+10.2$ by $2049 \mathrm{Ma}$ is $2.45 \mathrm{Ga}$. Any event that occurred later than that would not have afforded sufficient time to develop such radiogenic $\varepsilon^{143} \mathrm{Nd}$ and $\varepsilon^{176} \mathrm{Hf}$ in the mantle domain. It is noteworthy that $2.45 \mathrm{Ga}$ coincides with the ages of abundant mafic layered intrusions (Alapieti et al., 1990; Balashov et al., 1993; Amelin et al., 1995; Yang et al., 2016) and komatiitic lavas (Puchtel et al., 1997; 2016b) throughout the Fennoscandian Shield, indicating that large volumes of mafic magma were indeed produced in this part of the planet at that time.

Using this extent and time of melting, and applying a bulk $D^{\mathrm{Re}}=0.2$, model calculations indicate that the melting event that produced this light REE depletion would have reduced the ${ }^{187} \mathrm{Re} /{ }^{188}$ Os ratio in the chondritic reservoir from 0.4019 to 0.2694 at $2.45 \mathrm{Ga}$. The resultant melt-depleted mantle domain, if allowed to evolve from $2.45 \mathrm{Ga}$ until the time of the komatiite formation at 2049 Ma with this Re/Os ratio, would have developed a negative initial $\gamma^{187}$ Os $=-0.8$, which is close to the observed value and well within the range of chondritic meteorites at $2049 \mathrm{Ma}$ (Fig. 10). At the same time, this melting event would only have reduced the ${ }^{190} \mathrm{Pt} /{ }^{188} \mathrm{Os}$ ratio in the mantle domain by $0.5 \%$. The $400 \mathrm{Ma}$ of growth from 2.45 to $2.05 \mathrm{Ga}$ with this slightly reduced $\mathrm{Pt} / \mathrm{Os}$ ratio will decrease the $\mu^{186}$ Os value of the system by $0.4 \mathrm{ppm}$, not increase it by $29 \mathrm{ppm}$, as observed for the Jeesiörova-Kevitsa komatiite source. Hence, similarly to Model 1, Model 2 can account for the Nd, Hf, and ${ }^{187}$ Os isotopic compositions of the komatiites, but it also fails for ${ }^{186}$ Os.

One significant modification to Models 1 and 2, which would make it possible to account for all the observed isotopic and elemental data for the komatiites, is assuming early perturbation of the Pt/Os ratio in the komatiite source, without affecting Sm-Nd and Lu-Hf evolution, as well as not modifying Re-Os evolution outside of the chondritic range. The most parsimonious process that can achieve this perturbation is crystal-liquid fractionation of metal, given that fractional crystallization of metal can strongly fractionate Pt/Os, but only 
modestly fractionates Re/Os, with solid metal-liquid metal bulk distribution coefficients in this order: $\mathrm{D}_{\mathrm{Os}}>\mathrm{D}_{\mathrm{Re}}>>\mathrm{D}_{\mathrm{Pt}}>1$ (e.g., Cook et al., 2004). Thus, addition to a mantle domain of evolved metal either through late accretion of a fragment of a differentiated planetesimal core, similar to the mechanism proposed by Fischer-Gödde et al. (2011), or addition of metal derived from the Earth's core, but partially crystallized at or near the core-mantle boundary, similar to the mechanism of core-mantle interaction proposed by Humayun (2011), can best achieve the Os isotopic requirements for the komatiites. Either process would have the added benefit of decreasing the $\mu^{182} \mathrm{~W}$ value of the mixed domain to a negative value, as suggested by the contamination-corrected $\mu^{182} \mathrm{~W}=-10$ for the komatiites.

Compilation of time-integrated ${ }^{190} \mathrm{Pt} /{ }^{188} \mathrm{Os}$ and ${ }^{187} \mathrm{Re} /{ }^{188} \mathrm{Os}$ ratios for IIAB, IIIAB, and IVA magmatic iron meteorites from Cook et al. (2004) and McCoy et al. (2011) reveals large, up to three orders of magnitude, variations in the ${ }^{190} \mathrm{Pt} /{ }^{188} \mathrm{Os}$ ratios that resulted from magmatic solid metal-liquid metal fractionation, accompanied by relatively small, about a factor of 2.5 , variations in the ${ }^{187} \mathrm{Re} /{ }^{188} \mathrm{Os}$ ratios in the same magmatic systems. The ${ }^{186,187} \mathrm{Os}$ isotope systematics of the Jeesiörova-Kevitsa komatiite source can be accounted for by mixing with a number of fractionated iron compositions. We performed mixing calculations for Os, Re, and Pt concentrations, as well as for $\mathrm{W}$ isotopic composition and $\mathrm{W}$ abundances, results of which are illustrated in Fig. 12. For the meteoritic endmember, we chose a low-Os group IIIAB iron meteorite, Tieraco Creek; similar results are also obtained for other low-Os irons from this group, e.g., Grant and Chupaderos. The mantle source endmember used in the mixing calculations was the BSE. The HSE and W abundance data and W isotopic composition for the endmembers were adopted from Cook et al. (2004), Becker et al. (2006), Arevalo and McDonough (2008), Wasson (1999), and Kruijer et al. (2017); these are presented in Table 9. Based on the results of calculations, addition of $0.2 \%$ of material with the composition of Tieraco Creek to a mantle domain of BSE composition can explain the HSE and W abundances and Os and W isotopic compositions of the mantle domain that gave rise to the Jeesiörova-Kevitsa komatiite system. One caveat to this model is that the mixing event must have occurred very early, within the first 100 Ma of Solar System history, while late accretion of substantial mass was still possible.

Addition of fractionated metal to the Moon (and presumably Earth, too) in the form of a late accretionary component was advocated by Fischer-Gödde and Becker (2012) in their study of lunar impact melt breccias to explain suprachondritic Pt/Ir, Ru/Ir, and Pd/Ir ratios in some of the impact melts. It has also been argued that the impactors that created the largest impact basins on the Moon and Mars, and presumably Earth as well, were hundreds of $\mathrm{km}$ in 
diameter (Ryder, 2002; Strom et al., 2005; Bottke et al., 2010) and represented by differentiated planetesimals and, thus, would be capable of generating large HSE and negative ${ }^{182} \mathrm{~W}$ heterogeneities in portions of the mantle (Marchi et al., 2018, 2020). Cores of differentiated planetesimals have up to two orders of magnitude higher $\mathrm{W}$ abundances and up to $350 \mathrm{ppm}$ less radiogenic ${ }^{182} \mathrm{~W} /{ }^{184} \mathrm{~W}$ than the modern BSE (Kleine et al., 2002, 2004; Schoenberg et al., 2002; Yin et al., 2002). Thus, any mantle domain to which an excess of this material was added would be ${ }^{182} \mathrm{~W}$-depleted. Such a mantle domain would also be expected to be enriched in HSE, compared to BSE, particularly in Pt and Pd.

In order to further evaluate the effect of addition of such material on ${ }^{182} \mathrm{~W} /{ }^{184} \mathrm{~W}$ and HSE abundances, we plot the $\mu^{182} \mathrm{~W}$ in the Jeesiörova-Kevitsa komatiite system versus the total calculated HSE abundances in its mantle source relative to those in the estimates for modern BSE (Fig. 13). This proportion corresponds to the fraction of the total HSE budget of the BSE added during late accretion assuming an HSE-free mantle following core formation. The ${ }^{182} \mathrm{~W} /{ }^{184} \mathrm{~W}$ of the BSE prior to late accretion is constrained by mass-balance calculations (e.g., Kleine and Walker, 2017) and is supported by the ${ }^{182} \mathrm{~W} /{ }^{184} \mathrm{~W}$ data for the lunar mantle of +25 \pm 5 ppm (Kruijer et al., 2015; Touboul et al., 2015; Kruijer and Kleine, 2017). Calculations indicate that the estimated $10 \mathrm{ppm}$ deficit in $\mu^{182} \mathrm{~W}$ is consistent with the calculated total HSE abundances in the source of the Jeesiörova-Kevitsa komatiite system and the results of the mixing calculations presented above.

A second type of processes to consider is interaction between Earth's core and mantle. This type of process was originally proposed by Walker et al. $(1995,1997)$ and Brandon et al. $(1998,1999)$ as a means of generating coupled ${ }^{186,187}$ Os enrichments observed in some ocean island basalts. Later, Humayun (2011) proposed a mechanism of core-mantle interaction that involved outer core liquid becoming trapped in a cumulate pile of Fe-rich non-metallic precipitates $\left(\mathrm{FeO}, \mathrm{FeS}, \mathrm{Fe}_{3} \mathrm{Si}\right)$ at the top of the core. This metal is presumed to undergo partial fractional crystallization. The resulting, chemically-evolved liquid is then incorporated into the base of the mantle, where mantle plumes subsequently entrain it. If this metal had a composition similar to that of evolved iron meteorites, such as Tieraco Creek, its entrainment into the plume that gave rise to the Jeesiörova-Kevitsa komatiites could explain the ${ }^{186,187}$ Os isotope systematics of these komatiites. As with the grainy late accretion model, this mechanism has the added benefit of explaining the $\mathrm{W}$ isotope systematics of the komatiites. Based on the discovery of negative $\mu^{182} \mathrm{~W}$ values in modern ocean island basalts (Mundl et al., 2017), Rizo et al. (2019) and Mundl-Petermeier et al. (2020) have argued for some form 
of core-mantle exchange/equilibration in order to transfer the inferred negative $\mu^{182} \mathrm{~W}$ value of the core $\left(\mu^{182} \mathrm{~W}=-220\right)$ to plumes rising from the core-mantle boundary. Although ${ }^{186} \mathrm{Os}-$ ${ }^{182} \mathrm{~W}$ data for the same rocks are still limited, all Hawaiian lavas with negative $\mu^{182} \mathrm{~W}$ (ranging between -7.8 and -20.2 ) are also characterized by positive $\mu^{186}$ Os (ranging between +18.6 and +62.8 ) and $\gamma^{187}$ Os (ranging between +2.0 and +7.2 ) values (Fig. 14). The projected negative $\mu^{182} \mathrm{~W}$ value for the Jeesiörova-Kevitsa komatiites is within the range of $\mu^{182} \mathrm{~W}$ values for Hawaii, implying that these komatiites could be a Proterozoic equivalent of Hawaiian picrites. This process would be expected to have decreased ${ }^{182} \mathrm{~W} /{ }^{184} \mathrm{~W}$ in the komatiite source relative to the ambient mantle, and also potentially have increased the HSE abundances over the ambient mantle levels, which is consistent with the observations.

We conclude that at present, both grainy late accretion and core-mantle interaction remain viable mechanisms for explaining the observed combined lithophile trace- and siderophile element isotope and abundance systematics of the Jeesiörova-Kevitsa komatiite system.

\section{Conclusions}

The Jeesiörova-Kevitsa komatiites of the Fennoscandian Shield are unique among the komatiite systems studied so far. They have a relatively young age of $2.05 \mathrm{Ga}$ that has not been reported for the existing terrestrial komatiite record elsewhere, yet are as $\mathrm{MgO}$-rich as some of their late Archean counterparts. These komatiites were derived from a contemporary DMM-like mantle source in terms of $\mathrm{Nd}-\mathrm{Hf}$ isotope systematics; this source was characterized by a negative ${ }^{182} \mathrm{~W}$ anomaly, total absolute HSE abundances $\sim 20 \%$ higher than of the modern BSE, and chondritic initial ${ }^{187} \mathrm{Os} /{ }^{188} \mathrm{Os}$, but suprachondritic initial ${ }^{186} \mathrm{Os} /{ }^{188} \mathrm{Os}$ isotopic compositions. When considered together, these constraints are reconciled within a model that requires derivation of the parental Jeesiörova-Kevitsa komatiite magma from a mantle domain that experienced a melting and melt depletion event within the first $100 \mathrm{Ma}$ of Solar System history. This mantle domain is argued here to have acquired its HSE and Os isotope systematics as a result of either (1) grainy late accretion of differentiated metallic impactors or (2) core-mantle interaction via addition of chemically fractionated outer core metal to the mantle source domain of the komatiites. The survival of the early-formed Jeesiörova-Kevitsa komatiite mantle source for $\geq 2.5$ billion years implies that portions of the mantle remained poorly mixed with respect to HSE and W until at least the Paleoproterozoic. 
1015

${ }_{2}^{1} 1016$ ${ }_{4}^{3} 1017$

${ }^{5} 1018$ 71019 8 9102 10 111021 12 ${ }_{13}^{12} 1022$ 14
15 16 17 18 19 20 21

\section{Acknowledgements}

This study was supported by NSF Petrology and Geochemistry Grants EAR 1447174 and EAR 1754186 to ISP, EAR-1624587 to RJW and AMP, and Academy of Finland Grant 281859 to EJH. AMP would like to acknowledge support from FWF grant V659-N29. We thank V.A. Puchtel and R.W. Nicklas for help with preparation of samples for trace element analysis and ICP-MS measurements. Thorough and constructive reviews by Klaus Mezger, David van Acken, and an anonymous reviewer helped improve the original version of the manuscript. We thank Catherine Chauvel for comments and editorial handling. 


\section{References}

Alapieti, T.T., Filen, B.A., Lahtinen, J.J., Lavrov, M.M., Smolkin, V.F., and Voitsekhovsky, S.N., 1990. Early Proterozoic layered intrusions in the northeastern part of the Fennoscandian Shield. Mineralogy and Petrology 42: 1-22.

Alard, O., Griffin, W. L., Lorand, J.-P., Jackson, S. E., O'Reilly, S. Y., 2000. Non-chondritic distribution of the highly siderophile elements in mantle sulfides. Nature 407 (6806): 891894.

Albarède, F., Blichert-Toft, J., Vervoort, J. D., Gleason, J. D., Rosing, M., 2000. Hf-Nd isotope evidence for a transient dynamic regime in the early terrestrial mantle. Nature $\mathbf{4 0 4}$ (6777): 488-490.

Amelin, Y.V., Heaman, L.M., and Semenov, V.S., 1995. U-Pb geochronology of layered mafic intrusions in the eastern Baltic Shield: implications for the timing and duration of Paleoproterozoic continental rifting. Precambrian Research 75(1-2): 31-46.

Archer, G. J., Mundl, A., Walker, R. J., Worsham, E. A., and Bermingham, K. R., 2017. High-precision analysis of ${ }^{182} \mathrm{~W} /{ }^{184} \mathrm{~W}$ and ${ }^{183} \mathrm{~W} /{ }^{184} \mathrm{~W}$ by negative thermal ionization mass spectrometry: Per-integration oxide corrections using measured ${ }^{18} \mathrm{O} /{ }^{16} \mathrm{O}$. International Journal of mass-spectrometry 414: 80-86.

Archer, G. J., Ash, R. D., Bullock, E. S., and Walker, R. J., 2014. Highly siderophile elements and ${ }^{187} \mathrm{Re}-{ }^{187}$ Os isotopic systematics of the Allende meteorite: Evidence for primary nebular processes and late-stage alteration. Geochimica et Cosmochimica Acta 131: 402414.

Archer, G. J., Brennecka, G. A., Gleißner, P., Stracke, A., Becker, H., and Kleine, T., 2019. Lack of late-accreted material as the origin of ${ }^{182} \mathrm{~W}$ excesses in the Archean mantle: Evidence from the Pilbara Craton, Western Australia. Earth and Planetary Science Letters 528: 115841.

Arevalo, R. and McDonough, W. F., 2008. Tungsten geochemistry and implications for understanding the Earth's interior. Earth and Planetary Science Letters 272 (3-4): 656-665.

Balashov, Y. A., Bayanova, T. B., and Mitrofanov, F. P., 1993. Isotope data on the age and genesis of layered basic-ultrabasic intrusions in the Kola Peninsula and northern Karelia, northeastern Baltic Shield. Precambrian Research 64(1-4): 197-205.

Barboni, M., Boehnke, P., Keller, B., Kohl, I. E., Schoene, B., Young, E. D., and McKeegan, K. D., 2017. Early formation of the Moon 4.51 billion years ago. Science Advances 3 (1): e1602365.

Barnes, S.-J., Naldrett, A. J., Gorton, M. P., 1985. The origin of the fractionation of platinumgroup elements in terrestrial magmas. Chemical Geology 53 (3-4): 303-323.

Barnes, S.-J., Often, M., 1990. Ti-rich komatiites from Northern Norway. Contributions to Mineralogy and Petrology 105 (1): 42-54.

Barnes, S. J., Fiorentini, M. L., 2008. Iridium, ruthenium and rhodium in komatiites: Evidence for iridium alloy saturation. Chemical Geology 257 (1-2): 44-58.

Becker, H., Horan, M. F., Walker, R. J., Gao, S., Lorand, J.-P., Rudnick, R. L., 2006. Highly siderophile element composition of the Earth's primitive upper mantle: Constraints from new data on peridotite massifs and xenoliths. Geochimica et Cosmochimica Acta 70 (17): 4528-4550.

Begemann, F., Ludwig, K.R., Lugmair, G.W., Min., K., Nyquist, L.E., Patchett, P.J., Renne, P.R., Shih, C.-Y., Villa, I.M., and Walker, R.J., 2001. Call for an improved set of decay constants for geochronological use. Geochimica et Cosmochimica Acta 65(1): 111-121.

Blichert-Toft, J., Chauvel, C., and Albaréde, F., 1997. Separation of Hf and Lu for highprecision isotope analysis of rock samples by magnetic sector multiple collector ICP-MS. Contributions to Mineralogy and Petrology 127(3): 248-260. 
1073

11074

21075

${ }_{4}^{3} 1076$

51077

61078

71079

81080

${ }_{10}^{9} 1081$

111082

121083

131084

141085

161086

171087

181088

191089

20 1090

221091

231092

241093

251094

261095

281096

291097

301098

311099

331100

341101

351102

361103

371104

391105

401106

${ }^{41} 1107$

421108

441109

451110

461111

471112

481113

501114

511115

521116

531117
54

551118

561119

571120

58

59

60

61

62

63

64

65

Blichert-Toft, J., 2001. On the Lu-Hf isotope geochemistry of silicate rocks. Geostandards Newsletter 25, 41-56.

Blichert-Toft, J., Puchtel, I. S., 2010. Depleted mantle sources through time: Evidence from Lu-Hf and Sm-Nd isotope systematics of Archean komatiites. Earth and Planetary Science Letters 297 (3-4): 598-606.

Bottke, W. F., Walker, R. J., Day, J. M. D., Nesvorny, D., Elkins-Tanton, L., 2010. Stochastic Late Accretion to Earth, the Moon, and Mars. Science 330 (6010): 1527-1530.

Boyet, M., Carlson, R. W., 2005. ${ }^{142} \mathrm{Nd}$ evidence for early (> $\left.4.53 \mathrm{Ga}\right)$ global differentiation of the silicate Earth. Science 309 (5734): 576-581.

Brandon, A. D., Walker, R. J., Morgan, J. W., Norman, M. D., and Prichard, H. M., 1998. Coupled ${ }^{186}$ Os and ${ }^{187}$ Os evidence for core-mantle interaction. Science 208 (5369): 15701573.

Brandon, A. D., Norman, M. D., Walker, R. J., and Morgan, J. W., 1999. ${ }^{186}$ Oss- $^{187}$ Os systematics of Hawaiian picrites. Earth and Planetary Science Letters 174 (1-2): 25-42.

Brandon, A. D., Humayun, M., Puchtel, I. S., Zolensky, M., 2005. Re-Os isotopic systematics and platinum group element composition of the Tagish Lake carbonaceous chondrite. Geochimica et Cosmochimica Acta 69 (6): 1619-1631.

Brandon, A.D., Walker, R.J., and Puchtel, I.S., 2006. Platinum-osmium isotope evolution of the Earth's mantle: Constraints from chondrites and Os-rich alloys. Geochimica et Cosmochimica Acta 70(8): 2093-2103.

Brenan, J. M., 2008. Re-Os fractionation by sulfide melt-silicate melt partitioning: A new spin. Chemical Geology 248 (3-4): 140-165.

Brügmann G. E., Arndt N. T., Hofmann A. W., and Tobschall H. J., 1987. Noble metal abundances in komatiite suites from Alexo, Ontario, and Gorgona Island, Colombia. Geochimica et Cosmochimica Acta 51 (8): 2159-2169.

Chou, C.-L., Shaw, D. M., Crocket, J. H., 1983. Siderophile trace elements in the Earth's oceanic crust and upper mantle. Journal of Geophysical Research 88 (S2): A507-A518.

Cook D. L., Walker R. J., Horan M. F., Wasson J. T., and Morgan J. W., 2004. Pt-Re-Os systematics of Group IIAB and IIIAB iron meteorites. Geochimica et Cosmochimica Acta 68 (6): 1413-1431.

Creaser, R. A., Papanastassiou, D. A., Wasserburg, G. J., 1991. Negative thermal ion massspectrometry of osmium, rhenium, and iridium. Geochimica et Cosmochimica Acta $\mathbf{5 5}$ (1): 397-401.

Ding, S., Dasgupta, R., and Tsuno, K., 2014. Sulfur concentration of martian basalts at sulfide saturation at high pressures and temperatures - Implications for deep sulfur cycle on Mars. Geochimica et Cosmochimica Acta 131: 227-246.

Ding, S., Hough, T., Dasgupta, R., 2018. New high pressure experiments on sulfide saturation of high-FeO*- basalts with variable $\mathrm{TiO}_{2}$ contents - Implications for the sulfur inventory of the lunar interior. Geochimica et Cosmochimica Acta 222: 319-339.

Fischer-Gödde, M., Becker, H., Wombacher, F., 2010. Rhodium, gold and other highly siderophile element abundances in chondritic meteorites. Geochimica et Cosmochimica Acta 74 (1): 356-379.

Fischer-Gödde M., Becker H., and Wombacher F., 2011. Rhodium, gold and other highly siderophile elements in orogenic peridotites and peridotite xenoliths. Chemical Geology 280 (3-4): 365-383.

Fischer-Gödde M. and Becker H., 2012. Osmium isotope and highly siderophile element constraints on ages and nature of meteoritic components in ancient lunar impact rocks. Geochimica et Cosmochimica Acta 77: 135-156. 
1121

11122

21123

${ }_{4}^{3} 1124$

51125

61126

71127

81128

${ }_{10}^{9} 1129$

111130

121131

131132

141133

161134

171135

181136

191137

201138

221139

231140

241141

${ }_{26}^{25} 1142$

$27^{26} 1143$

281144

291145

301146

311147

331148

341149

351150

361151

371152

391153

401154

411155

421156

441157

451158

461159

471160

48 1161

501162

511163

521164

531165

541166

561167

571168

581169

59

60

61

62

63

64

65

Fonseca, R. O. C., Laurenz, V., Mallmann, G., Luguet, A., Hoehne, N., Jochum, K. P., 2012. New constraints on the genesis and long-term stability of Os-rich alloys in the Earth's mantle. Geochimica et Cosmochimica Acta 87: 227-242.

Fonseca, R. O. C., Mallmann, G., O'Neill, H. S. C., Campbell, I. H., Laurenz, V., 2011. Solubility of Os and Ir in sulfide melt: Implications for Re/Os fractionation during mantle melting. Earth and Planetary Science Letters 311 (3-4): 339-350.

Fortin, M.-A., Riddle, J., Desjardins-Langlais, Y., Baker, D. R., 2015. The effect of water on the sulfur concentration at sulfide saturation (SCSS) in natural melts. Geochimica et Cosmochimica Acta 160: 100-116.

Foster, J. G., Lambert, D. D., Frick, L. R., Maas, R., 1996. Re-Os isotopic evidence for genesis of Archaean nickel ores from uncontaminated komatiites. Nature 382 (6593): 703706.

Galer, S. J. G., Goldstein, S. L., 1991. Early mantle differentiation and its thermal consequences. Geochimica et Cosmochimica Acta 55 (1-2): 227-239.

Gangopadhyay, A. and Walker, R. J., 2003. Re-Os systematics of the ca. 2.7 Ga komatiites from Alexo, Ontario, Canada. Chemical Geology 196 (1-4): 147-162.

Gangopadhyay, A., Walker, R J., Hanski, E., Solheid, P.A., 2006. Origin of Paleoproterozoic Ti-enriched komatiitic rocks from Jeesiörova, Kittilä Greenstone Complex, Finnish Lapland. Journal of Petrology 47, 773-789.

Gannoun A., Burton K. W., Day J. M. D., Harvey J., Schiano P., and Parkinson I. J., 2016. Highly Siderophile Element and Os Isotope Systematics of Volcanic Rocks at Divergent and Convergent Plate Boundaries and in Intraplate Settings. Reviews in Mineralogy and Geochemistry 81: 651-724.

Gast, P.W., Triton, G.R., Hedge, C.E., 1964. Isotopic composition of lead and strontium from Ascension and Gough islands. Science 145, 1181-1185.

Goldstein, S. L., Galer, S. J. G., 1992. On the trail of early mantle differentiation: ${ }^{142} \mathrm{Nd} /{ }^{144} \mathrm{Nd}$ ratios of early Archean rocks. Eos 73 (30): 323.

Goldstein, S. J. and Jacobsen, S. B., 1988. Nd and Sr isotopic systematics of river water suspended material: implications for crustal evolution. Earth and Planetary Science Letters 87 (3): 249-265.

Green T. H., 1994. Experimental studies of trace-element partitioning applicable to igneous petrogenesis - Sedona 16 years later. Chemical Geology 117 (1-4): 1-36.

Hamilton, P. J., O'Nions, R. K., Bridgwater, D., Nutman, A. P., 1983. Sm-Nd studies of Archaean metasediments and metavolcanics from West Greenland and their implications for the Earth's early history. Earth and Planetary Science Letters 62 (2): 263-272.

Hanski, E., Huhma, H. 2005. Central Lapland Greenstone Belt. In: M. Lehtinen, P. Nurmi, O.T. Rämö (Eds.), Precambrian Bedrock of Finland - Key to the Evolution of the Fennoscandian Shield, Elsevier, Amsterdam, p. 139-194.

Hanski, E.J., Kamenetsky, V.S., 2013. Chrome spinel-hosted melt inclusions in primitive Paleoproterozoic volcanic rocks, northern Finland: evidence for coexistence and mixing of komatiitic and picritic magmas. Chemical Geology 343, 25-37. DOI: 10.1016/j.chemgeo.2013.02.009.

Hanski, E., Huhma, H., Rastas, P., Kamenetsky, V. S., 2001. The Paleoproterozoic komatiitepicrite association of Finnish Lapland. Journal of Petrology 42 (5): 855-876.

Hart, S. R., Brooks, S., 1977. The geochemistry and evolution of Early Precambrian mantle. Contributions to Mineralogy and Petrology 61 (2): 109-128.

Herzberg, C., Condie, K., and Korenaga, J., 2010. Thermal history of the Earth and its petrological expression. Earth and Planetary Science Letters 292 (1-2): 79-88.

Hofmann, A. W., 1984. Geochemical mantle models. Terra Cognita 4: 157-165. 
Hofmann, A. W., 1988. Chemical differentiation of the Earth: The relationship between mantle, continental crust and oceanic crust. Earth and Planetary Science Letters 90 (3): 297-314.

Hofmann, A.W., 1997. Mantle geochemistry: the message from oceanic volcanism. Nature 385 (6613): 219-229.

Holzheid, A. and Grove, T. L., 2002. Sulfur saturation limits in silicate melts and their implications for core formation scenarios for terrestrial planets. American Mineralogist 87 (2-3): 227-237.

Horan, M. F., Walker, R. J., Morgan, J. W., Grossman, J. N., Rubin, A. E., 2003. Highly siderophile elements in chondrites. Chemical Geology 196 (1-4): 5-20.

Huhma H., Mänttäri I., Peltonen P., Kontinen A., Halkoaho T., Hanski E., Hokkanen T., Hölttä P., Juopperi H., Konnunaho J., Layahe Y., Luukkonen E., Pietikäinen K., Pulkkinen A., Sorjonen-Ward P., Vaasjoki M., and Whitehouse M., 2012. The age of the Archean greenstone belts in Finland. In: The Archaean of the Karelia Province in Finland. Hölttä P. (Ed). Geological Survey of Finland Special Paper 54: 74-105.

Huhma, H., Hanski, E., Kontinen, A., Vuollo, J., Mänttäri, I., Lahaye, Y. 2018. Sm-Nd and $\mathrm{U}-\mathrm{Pb}$ isotope geochemistry of the Palaeoproterozoic mafic magmatism in eastern and northern Finland. Geological Survey of Finland, Bulletin 405, 150 p.

Humayun M., 2011. A model for osmium isotopic evolution of metallic solids at the coremantle boundary. Geochemistry, Geophysics, Geosystems 12 (3): 1-23.

Ireland T. J., Walker R. J., and Brandon A. D., 2011. ${ }^{186}$ Os- ${ }^{187}$ Os systematics of Hawaiian picrites revisited: New insights into Os isotopic variations in ocean island basalts. Geochimica et Cosmochimica Acta 75 (16): 4456-4475.

Jacobsen, S. B., 1988. Isotopic and chemical constraints on mantle-crust evolution. Geochimica et Cosmochimica Acta 52 (6): 1341-1350.

Jacobsen, S. B., Wasserburg, G. J., 1980. Sm-Nd isotopic evolution of chondrites. Earth and Planetary Science Letters 50 (1): 139-155.

Jacobsen, S. B., Yu, G., 2015. Extinct isotope heterogeneities in the mantles of Earth and Mars: Implications for mantle stirring rates. Meteoritics \& Planetary Science 50 (4): 555567.

Jochum, K. P., Arndt, N. T., and Hofmann, A. W., 1991. Nb-Th-La in komatiites and basalts: constraints on komatiite petrogenesis and mantle evolution. Earth and Planetary Science Letters 107 (2): 272-289.

Jugo, P. J., Luth, R. W., and Richards, J. P., 2005. An Experimental Study of the Sulfur Content in Basaltic Melts Saturated with Immiscible Sulfide or Sulfate Liquids at $1300^{\circ} \mathrm{C}$ and 1.0 GPa. Journal of Petrology 46 (4): 783-798.

Keays, R. R., 1995. The role of komatiitic and picritic magmatism and S-saturation in the formation of ore deposits. Lithos 34 (1-3): 1-18.

Kimura, K., Lewis, R. S., Anders, S., 1974. Distribution of gold and rhenium between nickeliron and silicate melts; implications for abundance of siderophile elements on the Earth and Moon. Geochimica et Cosmochimica Acta 38 (5): 683-701.

Kiseeva, E. S. and Wood, B. J., 2013. A simple model for chalcophile element partitioning between sulphide and silicate liquids with geochemical applications. Earth and Planetary Science Letters 383: 68-81.

Kiseeva, E. S. and Wood, B. J., 2015. The effects of composition and temperature on chalcophile and lithophile element partitioning into magmatic sulphides. Earth and Planetary Science Letters 424: 280-294.

Kiseeva, E. S., Fonseca, R. O. C., and Smythe, D. J., 2017. Chalcophile Elements and Sulfides in the Upper Mantle. Elements 113: 111-116. 
Kleine, T., Münker, C., Mezger, K., Palme, H., 2002. Rapid accretion and early core formation on asteroids and the terrestrial planets from Hf-W chronometry. Nature 418 (6901): 952-955.

Kleine, T., Mezger, K., Münker, C., Palme, H., Bischoff, A., 2004. ${ }^{182} \mathrm{Hf}_{-}{ }^{182} \mathrm{~W}$ isotope systematics of chondrites, eucrites, and martian meteorites: Chronology of core formation and early mantle differentiation in Vesta and Mars. Geochimica et Cosmochimica Acta 68 (13): 2935-2946.

Kleine, T., Walker, R. J., 2017. Tungsten isotopes in planets. Annual Review of Earth and Planetary Sciences 45 (1): 389-417.

König, S., Münker, C., Hohl, S., Paulick, H., Barth, A. R., Lagos, M., Pfander, J., Büchl, A., 2011. The Earth's tungsten budget during mantle melting and crust formation. Geochimica et Cosmochimica Acta 75 (8): 2119-2136.

Kruijer, T. S., Kleine, T., 2017. Tungsten isotopes and the origin of the Moon. Earth and Planetary Science Letters 475 (Supplement C): 15-24.

Kruijer, T. S., Kleine, T., Fischer-Gödde, M., Sprung, P., 2015. Lunar tungsten isotopic evidence for the late veneer. Nature 520 (7548): 534-537.

Kruijer, T. S., Kleine, T., Borg, L. E., Brennecka, G. A., Irving, A. J., Bischoff, A., Agee, C. B., 2017. The early differentiation of Mars inferred from Hf-W chronometry. Earth and Planetary Science Letters 474 (Supplement C): 345-354.

Li, J. and Agee, C. B., 2001. The effect of pressure, temperature, oxygen fugacity and composition on partitioning of nickel and cobalt between liquid Fe-Ni-S alloy and liquid silicate: implications for the earth's core formation. Geochimica et Cosmochimica Acta $\mathbf{6 5}$ (11): 1821-1832.

Liu, Y., Samaha, N.-T., and Baker, D. R., 2007. Sulfur concentration at sulfide saturation (SCSS) in magmatic silicate melts. Geochimica et Cosmochimica Acta 71 (7): 1783-1799.

Lorand, J.-P., Alard, O., 2001. Platinum-group element abundances in the upper mantle: new constraints from in situ and whole-rock analyses of Massif Central xenoliths (France). Geochimica et Cosmochimica Acta 65 (16): 2789-2806.

Luguet, A., Shirey, S. B., Lorand, J.-P., Horan, M. F., Carlson, R. W., 2007. Residual platinum-group minerals from highly depleted harzburgites of the Lherz massif (France) and their role in HSE fractionation of the mantle. Geochimica et Cosmochimica Acta 71 (12): 3082-3097.

Maier, W. D., Barnes, S. J., Campbell, I. H., Fiorentini, M. L., Peltonen, P., Barnes, S. J., Smithies, R. H., 2009. Progressive mixing of meteoritic veneer into the early Earth's deep mantle. Nature 460 (7255): 620-623.

Mallmann, G. and O'Neill, H. St C., 2007. The effect of oxygen fugacity on the partitioning of Re between crystals and silicate melt during mantle melting. Geochimica et Cosmochimica Acta 71 (11): 2837-2857.

Marchi, S., Canup, R. M., and Walker, R. J., 2018. Heterogeneous delivery of silicate and metal to the Earth by large planetesimals. Nature Geoscience 11: 77-81.

Marchi S., Walker, R. J., and Canup, R. M., 2020. A compositionally heterogeneous martian mantle due to late accretion. Science Advances 6 (7): eaay2338.

Mavrogenes, J. A. and O'Neill, H. S. C., 1999. The relative effects of pressure, temperature and oxygen fugacity on the solubility of sulfide in mafic magmas. Geochimica et Cosmochimica Acta 63 (7-8): 1173-1180.

McCoy, T. J., Walker, R. J., Goldstein, J. I., Yang, J., McDonough, W. F., Rumble, D., Chabot, N. L., Ash, R. D., Corrigan, C. M., Michael, J. R., and Kotula, P. G., 2011. Group IVA irons: New constraints on the crystallization and cooling history of an asteroidal core with a complex history. Geochimica et Cosmochimica Acta 75 (22): 6821-6843. 
McDonough, W. F. and Sun, S. S., 1995. The composition of the Earth. Chemical Geology 120 (3-4): 223-253.

McKenzie, D. and Bickle, M. J., 1988. The volume and composition of melt generated by extension of the lithosphere. Journal of Petrology 29 (3): 625-679.

Morgan, J. W., 1985. Osmium isotope constraints on Earth's late accretionary history. Nature 317 (6039): 703-705.

Morgan, J. W., 1986. Ultramafic xenoliths: Clues to Earth's late accretionary history. Journal of Geophysical Research 91 (B12): 12375-12387.

Mundl, A., Touboul, M., Jackson, M. G., Day, J. M. D., Kurz, M. D., Lekic, V., Helz, R. T., Walker, R. J., 2017. Tungsten-182 heterogeneity in modern ocean island basalts. Science 356 (6333): 66-69.

Mundl, A., Walker, R. J., Reimink, J. R., Rudnick, R. L., Gaschnig, R. M., 2018. Tungsten182 in the upper continental crust: Evidence from glacial diamictites. Chemical Geology 494: $144-152$.

Mundl-Petermeier, A., Walker, R.J., Jackson, M.G., Blichert-Toft, J., Kurz, M.D., and Haldórsson, S.A. (2019) Temporal evolution of primordial tungsten-182 and ${ }^{3} \mathrm{He} /{ }^{4} \mathrm{He}$ signatures in the Iceland mantle plume. Chemical Geology 525, 245-259.

Mundl-Petermeier, A., Walker, R.J., Fischer, R.A., Lekic, V., Jackson, M.G., and Kurz, M.D., 2020. Anomalous $\mu^{182} \mathrm{~W}$ signatures in high ${ }^{3} \mathrm{He} /{ }^{4} \mathrm{He}$ ocean island basalts - fingerprints of Earth's core? Geochimica et Cosmochimica Acta 271: 194-211.

Mungall, J. E. and Naldrett, A. J., 2008. Ore deposits of the platinum-group elements. Elements 4 (4): 253-258.

Mutanen, T. 1997. Geology and ore petrology of the Akanvaara and Koitelainen mafic layered intrusions and the Keivitsa-Satovaara layered complex, northern Finland. Geological Survey of Finland, Bulletin 395, 233 p.

Mutanen, T. 2005. The Akanvaara intrusion and the Keivitsa-Satovaara Complex, with stops at Kaikkivaltiaanlehto and Särkivaara intrusions. Geological Survey of Finland, Guide $51 \mathrm{~b}, 124 \mathrm{p}$.

Mutanen, T., Huhma, H. 2001. U-Pb geochronology of the Koitelainen, Akanvaara and Keivitsa layered intrusions and related rocks. Geological Survey of Finland, Special Paper 33: 229-246.

Naldrett, A. J., 2010. Secular Variation of Magmatic Sulfide Deposits and Their Source Magmas. Economic Geology 105 (3): 669-688.

Nesbitt, R. W., Sun, S. S., Purvis, A. C., 1979. Komatiites: geochemistry and genesis. Canadian Mineralogist 17 (2): 165-186.

Newsom, H. E., Sims, K. W. W., Noll, P. D., Jaeger, W. L., Maehr, S. A., Beserra, T. B., 1996. The depletion of tungsten in the bulk silicate Earth: Constraints on core formation. Earth and Planetary Science Letters 60 (5): 1155-1169.

Nicklas, R. W., Puchtel, I. S., and Ash, R. D., 2016. High-precision determination of the oxidation state of komatiite lavas using vanadium liquid-mineral partitioning. Chemical Geology 433: 36-45.

Nicklas R.W., Puchtel I.S., Ash R.D., Piccoli P., Hanski E., Nisbet E.G., Waterton P., Pearson D.G., and Anbar A.D., 2019. Secular Mantle Oxidation across the Archean-Proterozoic Boundary: Evidence from V partitioning in Komatiites and Picrites. Geochimica et Cosmochimica Acta 250: 49-75.

O'Neill, H. St C. and Mavrogenes, J. A., 2002. The Sulfide Capacity and the Sulfur Content at Sulfide Saturation of Silicate Melts at $1400^{\circ} \mathrm{C}$ and 1 bar. Journal of Petrology 43 (6): 1049-1087.

Peters B. J., Mundl-Petermeier A., Horan M. F., Carlson R. W. and Walker R. J., 2019. Chemical Separation of Tungsten and Other Trace Elements for TIMS Isotope Ratio 
Measurements Using Organic Acids. Geostandards and Geoanalytical Research 43 (2): 245-259.

Puchtel, I.S., Haase, K.M., Hofmann, A.W., Chauvel, C., Kulikov, V.S., Garbe-Schönberg, C.D., and Nemchin, A.A., 1997. Petrology and geochemistry of crustally contaminated komatiitic basalts from the Vetreny Belt, southeastern Baltic Shield: Evidence for an early Proterozoic mantle plume beneath rifted Archean continental lithosphere. Geochimica et Cosmochimica Acta 61 (6): 1205-1222.

Puchtel I. S., Hofmann A. W., Mezger K., Jochum K. P., Shchipansky A. A., and Samsonov A. V., 1998. Oceanic plateau model for continental crustal growth in the Archaean: A case study from the Kostomuksha greenstone belt, NW Baltic Shield. Earth and Planetary Science Letters 155 (1-2): 57-74.

Puchtel, I. S. and Humayun, M., 2000. Platinum group elements in Kostomuksha komatiites and basalts: Implications for oceanic crust recycling and core-mantle interaction. Geochimica et Cosmochimica Acta 64 (24): 4227-4242.

Puchtel, I. S., Humayun, M., 2005. Highly siderophile element geochemistry of ${ }^{187}$ Osenriched 2.8-Ga Kostomuksha komatiites, Baltic Shield. Geochimica et Cosmochimica Acta 69 (6): 1607-1618.

Puchtel, I. S., Brandon, A. D., Humayun, M., 2004a. Precise Pt-Re-Os isotope systematics of the mantle from 2.7-Ga komatiites. Earth and Planetary Science Letters 224 (1-2): 157174.

Puchtel, I. S., Humayun, M., Campbell, A., Sproule, R., Lesher, C. M., 2004b. Platinum group element geochemistry of komatiites from the Alexo and Pyke Hill areas, Ontario, Canada. Geochimica et Cosmochimica Acta 68 (6): 1361-1383.

Puchtel, I. S., Brandon, A. D., Humayun, M., Walker, R. J., 2005. Evidence for the early differentiation of the core from Pt-Re-Os isotope systematics of 2.8-Ga komatiites. Earth and Planetary Science Letters 237 (1-2): 118-134.

Puchtel, I. S., Humayun, M., Walker, R. J., 2007. Os-Pb-Nd isotope and highly siderophile and lithophile trace element systematics of komatiitic rocks from the Volotsk suite, SE Baltic Shield. Precambrian Research 158 (1-2): 119-137.

Puchtel, I. S., Walker, R. J., Anhaeusser, C. R., Gruau, G., 2009a. Re-Os isotope systematics and HSE abundances of the $3.5 \mathrm{Ga}$ Schapenburg komatiites, South Africa: Hydrous melting or prolonged survival of primordial heterogeneities in the mantle? Chemical Geology 262 (3-4): 355-369.

Puchtel, I. S., Walker, R. J., Brandon, A. D., Nisbet, E. G., 2009b. Pt-Re-Os and Sm-Nd isotope and HSE and REE systematics of the 2.7 Ga Belingwe and Abitibi komatiites. Geochimica et Cosmochimica Acta 73 (20): 6367-6389.

Puchtel, I. S., Blichert-Toft, J., Touboul, M., Walker, R. J., Byerly, G., Nisbet, E. G., Anhaeusser, C. R., 2013. Insights into early Earth from Barberton komatiites: Evidence from lithophile isotope and trace element systematics. Geochimica et Cosmochimica Acta 108: 63-90.

Puchtel, I. S., Walker, R. J., Touboul, M., Nisbet, E. G., Byerly, G. R., 2014. Insights into Early Earth from the Pt-Re-Os isotope and Highly Siderophile Element abundance systematics of Barberton komatiites. Geochimica et Cosmochimica Acta 125: 394-413.

Puchtel, I. S., Blichert-Toft, J., Touboul, M., Horan, M. F., Walker, R. J., 2016a. The coupled ${ }^{182} \mathrm{~W}-{ }^{142} \mathrm{Nd}$ record of early terrestrial mantle differentiation. Geochemistry, Geophysics, Geosystems 17 (6): 2168-2193.

Puchtel, I. S., Touboul, M., Blichert-Toft, J., Walker, R. J., Brandon, A. D., Nicklas, R. W., Kulikov, V. S., Samsonov, A. V., 2016b. Lithophile and siderophile element systematics of the mantle at the Archean-Proterozoic boundary: Evidence from $2.4 \mathrm{Ga}$ komatiites. Geochimica et Cosmochimica Acta 180: 227-255. 
1368

11369

21370

${ }_{4}^{3} 1371$

51372

61373

71374

${ }^{8} 1375$

${ }_{10}^{9} 1376$

111377

121378

131379

141380

$16^{1381}$

171382

181383

191384

${ }_{21} 1385$

221386

231387

241388

251389

261390

281391

291392

$30_{1393}$

${ }_{32} 1394$

331395

341396

351397

361398

371399

391400

401401

411402

${ }_{43} 1403$

441404

451405

461406

471407

${ }_{49}^{48} 1408$

501409

511410

521411

531412

54
55

561414

571415

581416

591417

61

62

63

64

65

Puchtel, I. S., Blichert-Toft, J., Touboul, M., and Walker, R. J., 2018. ${ }^{182} \mathrm{~W}$ and HSE constraints from $2.7 \mathrm{Ga}$ komatiites on the heterogeneous nature of the Archean mantle. Geochimica et Cosmochimica Acta 228: 1-26.

Rehkämper M., Halliday A. N., Fitton J. G., Lee D.-C., Wieneke M., and Arndt N. T., 1999. Ir, $\mathrm{Ru}, \mathrm{Pt}$ and $\mathrm{Pd}$ in basalts and komatiites: New constraints for the geochemical behavior of the platinum group elements in the mantle. Geochimica et Cosmochimica Acta 63 (22): 3915-3934.

Rizo H., Andrault D., Bennett N. R., Humayun M., Brandon A. D., Vlastelic I., Moine B., Poirier A., Bouhifd M. A., and Murphy D. T., 2019. ${ }^{182} \mathrm{~W}$ evidence for core-mantle interaction in the source of mantle plumes. Geochemical Perspectives Letters 11: 6-11.

Rizo, H., Walker, R. J., Carlson, R. W., Horan, M. F., Mukhopadhyay, S., Manthos, V., Francis, D., Jackson, M. G., 2016a. Preservation of Earth-forming events in the tungsten isotopic composition of modern flood basalts. Science 352 (6287): 809-812.

Rizo, H., Walker, R. J., Carlson, R. W., Touboul, M., Horan, M. F., Puchtel, I. S., Boyet, M., Rosing, M. T., 2016b. Early Earth differentiation investigated through ${ }^{142} \mathrm{Nd},{ }^{182} \mathrm{~W}$, and highly siderophile element abundances in samples from Isua, Greenland. Geochimica et Cosmochimica Acta 175: 319-336.

Rudnick, R.L., and Fountain, D.M., 1995. Nature and composition of the continental crust: a lower crustal perspective. Reviews of Geophysics 33 (3): 267-309.

Rudnick, R.L., and Gao, S., 2014. Composition of the Continental Crust. Treatise on Geochemistry, Macmillan Publishers Limited: 1-51.

Ryder, G., 2002. Mass flux in the ancient Earth-Moon system and benign implications for the origin of life on Earth. Journal of Geophysical Research 107 (E4): 6.1-6.13.

Saverikko, M. 1985. The pyroclastic komatiite complex at Sattasvaara in northern Finland. Bulletin of the Geological Society of Finland 57, 55-87.

Schoenberg, R., Kamber, B. S., Collerson, K. D., Eugster, O., 2002. New W-isotope evidence for rapid terrestrial accretion and very early core formation. Geochimica et Cosmochimica Acta 66 (17): 3151-3160.

Shirey, S. B., Walker, R. J., 1998. The Re-Os isotope system in cosmochemistry and hightemperature geochemistry. Annual Reviews of Earth and Planetary Sciences 26: 423-500.

Smoliar, M. I., Walker, R. J., Morgan, J. W., 1996. Re-Os ages of Group IIA, IIIA, IVA, and IVB iron meteorites. Science 271 (5762): 1099-1102.

Smythe, D. J., Wood, B. J., and Kiseeva, E. S., 2017. The S content of silicate melts at sulfide saturation: New experiments and a model incorporating the effects of sulfide composition. American Mineralogist 102 (4): 795-803.

Sossi, P.A., O’Neill, H.St.C., 2016. Liquidus temperatures of komatiites and the effect of cooling rate on element partitioning between olivine and komatiitic melt. Contributions to Mineralogy and Petrology 171: 49.

Steenstra, E.S., Berndt, J., Klemme, S., Rohrbach, A., Bullock, E.S., van Westrenen, W., 2020. An experimental assessment of the potential of sulfide saturation of the source regions of eucrites and angrites: Implications for asteroidal models of core formation, late accretion and volatile element depletions. Geochimica et Cosmochimica Acta 269: 39-62.

Steenstra, E. S., Seegers, A. X., Eising, J., Tomassen, B. G. J., Webers, F. P. F., Berndt, J., Klemme, S., Matveev, S., van Westrenen, W., 2018. Evidence for a sulfur-undersaturated lunar interior from the solubility of sulfur in lunar melts and sulfide-silicate partitioning of siderophile elements. Geochimica et Cosmochimica Acta 231: 130-156.

Strom, R. G., Malhotra, R., Ito, T., Yoshida, F., and Kring, D. A., 2005. The origin of planetary impactors in the inner Solar system. Science 309 (5742): 1847-1850.

Sun, Z., Xiong, X., Wang, J., Liu, X., Li, L., Ruan, M., Zhang, L., and Takahashi, E., 2020. Sulfur abundance and heterogeneity in the MORB mantle estimated by copper 
partitioning and sulfur solubility modelling. Earth and Planetary Science Letters 538: 116169.

Thompson, P. M. E., Kempton, P. D., White, R. V., Kerr, A. C., Tarney, J., Saunders, A. D., Fitton, J. G., and McBirney, A., 2003. Hf-Nd isotope constraints on the origin of the Cretaceous Caribbean plateau and its relationship to the Galapagos plume. Earth and Planetary Science Letters 217 (1-2): 59-75.

Törmänen, T., Konnunaho, J., Hanski, E., Moilanen, M., Heikura, P., 2016. The Paleoproterozoic komatiite-hosted PGE mineralization at Lomalampi, Central Lapland Greenstone Belt, northern Finland. Mineralium Deposita 51: 411-430.

Touboul, M., Puchtel, I. S., Walker, R. J., 2012. ${ }^{182}$ W Evidence for Long-Term Preservation of Early Mantle Differentiation Products. Science 335: 1065-1069.

Touboul, M., Liu, J., O'Neil, J., Puchtel, I. S., Walker, R. J., 2014. New Insights into the Hadean Mantle Revealed by ${ }^{182} \mathrm{~W}$ and Highly Siderophile Element Abundances of Supracrustal Rocks from the Nuvvuagittuq Greenstone Belt, Quebec, Canada. Chemical Geology 383: 63-75.

Touboul, M., Puchtel, I. S., Walker, R. J., 2015. Tungsten isotopic evidence for disproportional late accretion to the Earth and Moon. Nature 520 (7548): 530-533.

Tusch, J., Sprung, P., van de Löcht, J., Hoffmann, J. E., Boyd, A. J., Rosing, M. T., and Münker, C., 2019. Uniform ${ }^{182} \mathrm{~W}$ isotope compositions in Eoarchean rocks from the Isua region, SW Greenland: The role of early silicate differentiation and missing late veneer. Geochimica et Cosmochimica Acta 257: 284-310.

van Acken, D., Brandon, A. D., and Humayun, M., 2011. High-precision osmium isotopes in enstatite and Rumuruti chondrites. Geochimica et Cosmochimica Acta 75 (14): 40204036.

Walker, R. J., 2016. Siderophile Elements in Tracing Planetary Formation and Evolution. Geochemical Perspectives 5 (1): 1-145.

Walker, R. J., Morgan, J. W., and Horan, M. F., 1995. ${ }^{187}$ Os enrichment in some plumes: evidence for core-mantle interaction? Science 269 (5225): 819-822.

Walker, R. J., Morgan, J. W., Beary, E. S., Smoliar, M. I., Czamanske, G. K., and Horan, M. F., 1997. Applications of the ${ }^{190} \mathrm{Pt}^{186} \mathrm{Os}$ isotope system to geochemistry and cosmochemistry. Geochimica et Cosmochimica Acta 61 (22): 4799-4807.

Walker, R. J., Shirey, S. B., and Stecher, O., 1988. Comparative Re-Os, Sm-Nd and Rb-Sr isotope and trace element systematics for Archean komatiite flows from Munro Township, Abitibi belt, Ontario. Earth and Planetary Science Letters 87 (1-2): 1-12.

Walker, R. J., Horan, M. F., Morgan, J. W., Becker, H., Grossman, J. N., Rubin, A. E., 2002. Comparative ${ }^{187} \mathrm{Re}_{-}{ }^{187}$ Os systematics of chondrites: Implications regarding early solar system processes. Geochimica et Cosmochimica Acta 66 (23): 4187-4201.

Walker, R. J., Bermingham, K., Liu, J., Puchtel, I. S., Touboul, M., and Worsham, E. A., 2015. In search of late-stage planetary building blocks. Chemical Geology 411: 125-142.

Wasson, J. T., 1999. Trapped melt in IIIAB irons; solid/liquid elemental partitioning during the fractionation of the IIIAB magma. Geochimica et Cosmochimica Acta 63 (18): 28752889.

White, W. M. and Hofmann, A. W., 1982. Sr and Nd isotope geochemistry of oceanic basalts and mantle evolution. Nature 296 (5860): 821-825.

White, W. M. and Patchett, J., 1984. Hf-Nd-Sr isotopes and incompatible element abundances in island arcs: implications for magma origins and crust-mantle evolution. Earth and Planetary Science Letters 67 (2): 167-185.

Willbold, M., Elliott, T., Moorbath, S., 2011. The tungsten isotopic composition of the Earth's mantle before the terminal bombardment. Nature 477 (7363): 195-198. 
1467 Willbold, M., Mojzsis, S. J., Chen, H. W., Elliott, T., 2015. Tungsten isotope composition of the Acasta Gneiss Complex. Earth and Planetary Science Letters 419: 168-177.

Wood, B. J. and Kiseeva, E. S., 2015. Trace element partitioning into sulfide: How lithophile elements become chalcophile and vice versa. American Mineralogist 100 (11-12): 23712379.

Yang, S.-H., Hanski, E., Li, C., Maier, W. D., Huhma, H., Mokrushin, A. V., Latypov, R., Lahaye, Y., O'Brien, H., and Qu, W.-J., 2016. Mantle source of the 2.44-2.50-Ga mantle plume-related magmatism in the Fennoscandian Shield: evidence from $\mathrm{Os}, \mathrm{Nd}$, and $\mathrm{Sr}$ isotope compositions of the Monchepluton and Kemi intrusions. Mineralium Deposita 51: 1055-1073.

Yin, Q., Jacobsen, S. B., Yamashita, K., Blichert-Toft, J., Telouk, P., Albarede, F., 2002. A short timescale for terrestrial planet formation from Hf-W chronometry of meteorites. Nature 418 (6901): 949-952.

Zindler, A., Jagoutz, E., Goldstein, S. L., 1982. Nd, Sr and Pb isotopic systematics in a threecomponent mantle: a new perspective. Nature 298 (5874): 519-523. 


\section{Figure captions}

Fig. 1. (a) Geological map showing the distribution of the $2.05 \mathrm{Ga}$ komatiites and related picrites in the Central Lapland Greenstone Belt, Finland (modified after Hanski et al., 2001), and the locations of the Jeesiörova komatiites and the Kevitsa mafic-ultramafic intrusion. (b) Geological map of the Kevitsa intrusion (modified after Mutanen and Huhma, 2001). (c) Location of drill hole DDH 814 and other drill holes penetrating Kevitsa komatiite dikes (red dots).

Fig. 2. Photomicrographs of olivine-phyric Kevitsa komatiite dikes. (a) Sample showing various olivine morphologies. (b) Olivine phenocrysts in a groundmass composed of clinopyroxene, plagioclase, olivine, brown amphibole, and oxide. (c) Close-up view of the groundmass. (d) Large olivine phenocryst with ragged grain boundaries. (e) Thin olivinephyric vein injected into olivine-pyroxene cumulate of the Kevitsa intrusion. (f) Chilled margin with small olivine and clinopyroxene phenocrysts set in a fine-grained groundmass. $\mathrm{Am}=$ brown amphibole, $\mathrm{Pl}=$ plagioclase, $\mathrm{Ol}=$ olivine, $\mathrm{Cp}=$ clinopyroxene. Plane-polarized light in all panels except for (c).

Fig. 3. Thin section scanner micrographs in transmitted light showing olivine megacrysts and phenocrysts in the Kevitsa komatiite. Note the large chromite grains attached to the megacryst in (a).

Fig. 4. Abundances of selected major (wt.\%) and lithophile trace (ppm) elements and W (ppb) plotted against $\mathrm{MgO}$ (wt.\%) in the Jeesiörova and Kevitsa komatiites.

Fig. 5. BSE-normalized abundances of lithophile trace elements in the Jeesiörova (a) and Kevitsa (b) komatiites arranged in order of decreasing incompatibility during mantle melting. The normalizing value for $\mathrm{W}$ is from Arevalo and McDonough (2008) and, for the other elements, from Hofmann (1988).

Fig. 6. (a) Re-Os isochron diagram for whole-rock samples and olivine and chromite separates from the Jeesiörova and Kevitsa komatiites analyzed in this study. (b) Pt-Os isotopic data for chromite separates from the Jeesiörova komatiites.

Fig. 7. CI chondrite-normalized HSE abundances in whole-rock samples of the (a) Jeesiörova komatiites, (b) Kevitsa komatiites, and (c) olivine separates from the Kevitsa komatiites.

Fig. 8. Abundances of HSE in the Jeesiörova and Kevitsa komatiites and olivine separates (in $\mathrm{ppb}$ ) plotted against $\mathrm{MgO}$ contents (wt.\%).

Fig. 9. (a) ${ }^{147} \mathrm{Sm}_{-}{ }^{143} \mathrm{Nd}$ and (b) ${ }^{176} \mathrm{Lu}^{-}{ }^{176} \mathrm{Hf}$ isochron diagrams for the Jeesiörova-Kevitsa komatiites and clinopyroxene separates. See text for additional details. (c) Diagram illustrating average initial $\varepsilon^{143} \mathrm{Nd}$ and $\varepsilon^{176} \mathrm{Hf}$ values for the emplaced Jeesiörova-Kevitsa komatiites (light-green symbol) and their mantle source (dark-green symbol), as well as for the Chondritic Uniform Reservoir (CHUR) and Depleted MORB Mantle (DMM) calculated at the time of the emplacement (2049 Ma). The CHUR and DMM parameters 
are from Jacobsen and Wasserburg (1980), Bouvier et al. (2008), and Blichert-Toft and Puchtel (2010). Note the coupled, or congruent, behavior between the two isotope systems in the source of the Jeesiörova-Kevitsa komatiites, after correction of the komatiite data for $1.0 \%$ crustal contamination.

Fig. 10. (a) Initial ${ }^{187} \mathrm{Os} /{ }^{188} \mathrm{Os}$ isotopic compositions, expressed in terms of $\gamma^{187} \mathrm{Os}$, of Archean and Paleoproterozoic komatiite systems plotted as a function of age. The data are from Foster et al. (1996); Puchtel et al. (2004a; 2005; 2007; 2009a; 2009b; 2014; 2016a; 2016b; 2018), and this study. The data for chondritic meteorites are compiled from Walker et al. (2002), Brandon et al. (2005), and Fischer-Gödde et al. (2010). (b). Initial ${ }^{186} \mathrm{Os} /{ }^{188} \mathrm{Os}$ isotopic compositions, expressed in terms of $\mu^{186} \mathrm{Os}$, of Archean and Paleoproterozoic komatiite systems studied to date, plotted as a function of age. The data are from Puchtel et al. (2004a, 2005, 2009b, 2014, 2016b; 2018), and this study. The data for chondritic meteorites are compiled from Horan et al. (2003), Brandon et al. (2005, 2006), and Fischer-Gödde et al. (2010). See text for more details.

Fig. 11. Calculated total Pt and Pd abundances in the sources of Archean and Paleoproterozoic komatiite systems plotted as per cent of the total Pt and Pd abundances in the estimates for the modern BSE of Becker et al. (2006). Data sources are as follows: 2.05 Ga Jeesiörova-Kevitsa - this study; 2.41 Ga Vetreny Belt - Puchtel et al. (2016b); 2.69 Ga Belingwe - Puchtel et al. (2009b); 2.72 Ga Pyke Hill and Alexo - Puchtel et al. (2004b); 2.72 Ga Boston Creek - Puchtel et al. (2018); 2.82 Ga Kostomuksha - Puchtel and Humayun (2005); 2.88 Ga Volotsk-Kamennoozero - Puchtel et al. (2007); $3.26 \mathrm{Ga}$ Weltevreden and 3.48 Ga Komati - Puchtel et al. (2014); 3.55 Ga Schapenburg - Puchtel et al. (2016a). Uncertainties are 2SD. See text for additional details.

Fig. 12. Diagram illustrating potential genetic relationships between long-term ${ }^{187} \mathrm{Re}^{188} \mathrm{Os}$ and ${ }^{190} \mathrm{Pt} /{ }^{188} \mathrm{Os}$ in IIIAB fractionated iron meteorites and in the Jeesiörova-Kevitsa (J-K) komatiite source. J-K source 1 and 2 denote the calculated Re/Os and Pt/Os in the source after and before the global melt depletion event, respectively, that is assumed to have occurred within the first $100 \mathrm{Ma}$ of Solar System history and is necessary to account for the Nd-Hf isotope systematics of the Jeesiörova-Kevitsa komatiites. The data for the IIIAB iron meteorite Tieraco Creek used in the modeling are from Cook et al. (2004). Addition of $0.2 \%$ of Tieraco Creek metal to the mantle domain with BSE Re/Os and Pt/Os prior to the global melt depletion event can explain the ${ }^{186,187} \mathrm{Os} /{ }^{188} \mathrm{Os}$ isotope systematics of the Jeesiörova-Kevitsa komatiite source. See text for more details.

Fig. 13. $\mu^{182} \mathrm{~W}(\mathrm{ppm})$ versus total calculated HSE abundances in the sources of Archean and Paleoproterozoic komatiite systems studied to date relative to those in the estimates for the present-day BSE of Becker et al. (2006). This proportion corresponds to the fraction of the total HSE budget of the BSE added during late accretion assuming an HSE-free terrestrial mantle prior to late accretion. The $\mu^{182} \mathrm{~W}$ value of the BSE prior to late accretion is constrained via mass-balance calculations and is supported by the $\mathrm{W}$ isotopic data for the lunar mantle $\left(\mu^{182} \mathrm{~W}=+25 \pm 5\right.$ ppm: Kruijer et al., 2015; Touboul et al., 2015). 
1562 The W isotopic data and estimates of the HSE contents for the komatiite systems are from Puchtel and Humayun (2005), Touboul et al. (2012), Puchtel et al. (2014; 2016a; 2016b; 2018), and this study.

Fig. 14. $\mu^{182} \mathrm{~W}$ versus $\mu^{186}$ Os data (ppm) for the Jeesiörova-Kevitsa komatiites and Hawaiian picrites. The Os data for Hawaii are compiled from Brandon et al. (1998) and Ireland et al. 9 
Table 1. Major and minor element data for Jeesiörova and Kevitsa komatiites.

\begin{tabular}{|c|c|c|c|c|c|c|c|c|c|c|c|c|c|c|c|}
\hline Sample & 12D-PPR & 13-EJH & 17.1-PPR & LP10 & KD03 & KD05 & KD06 & KD07 & KD08 & KD09 & KD10 & KD11 & KD12 & KD13 & KD14 \\
\hline $\mathrm{SiO}_{2}$ & 44.8 & 43.8 & 43.0 & 43.6 & 46.6 & 45.0 & 44.9 & 44.6 & 44.1 & 43.4 & 43.5 & 44.1 & 45.1 & 45.0 & 46.9 \\
\hline $\mathrm{TiO}_{2}$ & 0.691 & 0.632 & 0.681 & 0.583 & 0.730 & 0.612 & 0.628 & 0.533 & 0.554 & 0.488 & 0.487 & 0.582 & 0.662 & 0.679 & 0.778 \\
\hline $\mathrm{Al}_{2} \mathbf{O}_{3}$ & 7.70 & 7.47 & 8.01 & 6.94 & 10.1 & 8.55 & 8.74 & 7.34 & 7.94 & 6.50 & 6.35 & 8.20 & 9.09 & 9.57 & 10.6 \\
\hline $\mathrm{Fe}_{2} \mathrm{O}_{3 t o t}$ & 12.0 & 12.4 & 13.7 & 12.1 & 12.4 & 12.6 & 12.6 & 12.0 & 12.3 & 12.2 & 12.3 & 12.4 & 12.7 & 12.9 & 13.0 \\
\hline MnO & 0.169 & 0.221 & 0.227 & 0.301 & 0.190 & 0.179 & 0.177 & 0.180 & 0.176 & 0.178 & 0.183 & 0.178 & 0.181 & 0.184 & 0.190 \\
\hline MgO & 25.3 & 27.1 & 25.7 & 28.6 & 18.1 & 22.6 & 22.3 & 26.4 & 25.2 & 28.3 & 28.3 & 24.2 & 21.2 & 20.3 & 16.2 \\
\hline $\mathrm{CaO}$ & 8.21 & 7.33 & 7.51 & 6.86 & 10.2 & 8.74 & 8.88 & 7.42 & 7.88 & 7.18 & 7.16 & 8.41 & 9.14 & 9.41 & 10.6 \\
\hline $\mathrm{Na}_{2} \mathrm{O}$ & 0.077 & 0.074 & 0.092 & 0.090 & 1.21 & 1.13 & 1.15 & 0.92 & 1.11 & 0.94 & 0.88 & 1.15 & 1.25 & 1.28 & 1.29 \\
\hline $\mathrm{K}_{2} \mathrm{O}$ & 0.004 & 0.018 & 0.056 & 0.019 & 0.068 & 0.040 & 0.047 & 0.135 & 0.086 & 0.043 & 0.119 & 0.062 & 0.054 & 0.069 & 0.089 \\
\hline $\mathbf{P}_{2} \mathbf{O}_{5}$ & 0.053 & 0.033 & 0.034 & 0.027 & 0.063 & 0.039 & 0.040 & 0.039 & 0.036 & 0.031 & 0.028 & 0.039 & 0.045 & 0.047 & 0.056 \\
\hline LOI & 11.3 & 7.20 & 6.39 & 7.49 & 0.13 & 0.63 & 0.55 & 1.72 & 1.40 & 1.47 & 2.15 & 1.25 & 1.01 & 1.22 & 0.09 \\
\hline Total & 99.85 & 99.81 & 100.00 & 99.55 & 100.00 & 99.90 & 100.22 & 100.05 & 99.68 & 100.21 & 99.88 & 99.88 & 99.92 & 99.84 & 99.85 \\
\hline $\mathrm{Cr}$ & 3834 & 3674 & 3267 & 3806 & 1847 & 2309 & 2241 & 2895 & 2843 & 3333 & 3280 & 2719 & 2317 & 2127 & 1557 \\
\hline $\mathrm{Al}_{2} \mathrm{O}_{3} / \mathrm{TiO}_{2}$ & 11.1 & 11.8 & 11.8 & 11.9 & 13.9 & 14.0 & 13.9 & 13.8 & 14.3 & 13.3 & 13.0 & 14.1 & 13.7 & 14.1 & 13.7 \\
\hline
\end{tabular}

Data (in wt.\% except for $\mathrm{Cr}$ in ppm) were recalculated on an anhydrous basis, but not re-normalized to $100 \%$ in order to preserve information on the quality of the analyses. Here and in Tables 2 and 3, samples from 12D-PPR to LP10 are Jeesiörova komatiites and those from KD03 to KD14 - Kevitsa komatiite dikes. 
61574 Table 2. Trace element data for Jeesiörova and Kevitsa komatiites.

\begin{tabular}{|c|c|c|c|c|c|c|c|c|c|c|c|c|c|c|c|c|}
\hline Sample & 12D-PPR & 13-EJH & 17.1-PPR & LP-10 & KD-03 & KD-05 & KD-06 & KD-07 & KD-08 & KD-09 & KD-10 & KD-11 & KD-12 & KD-13 & KD-14 & BSE \\
\hline Sc & 28.8 & 26.4 & 28.4 & 24.8 & 33.6 & 30.4 & 29.3 & 26.8 & 26.6 & 25.0 & 25.3 & 28.4 & 31.2 & 31.7 & 35.0 & 14.9 \\
\hline V & 217 & 196 & 207 & 184 & 277 & 238 & 238 & 204 & 210 & 182 & 190 & 223 & 245 & 251 & 294 & 77.0 \\
\hline $\mathbf{N i}$ & 1547 & 1616 & 1535 & 1734 & 856 & 1173 & 1138 & 1479 & 1389 & 1611 & 1624 & 1322 & 1062 & 1014 & 748 & 2080 \\
\hline $\mathrm{Cu}$ & 141 & 5.22 & 9.45 & 6.01 & 129 & 114 & 114 & 96 & 104 & 89.0 & 89.9 & 108 & 119 & 123 & 139 & 28.0 \\
\hline Ga & 10.6 & 9.51 & 10.6 & 8.90 & 13.9 & 11.9 & 11.5 & 10.0 & 10.5 & 9.21 & 9.23 & 11.1 & 12.4 & 12.6 & 14.7 & 4.00 \\
\hline Th & 0.0768 & 0.0722 & 0.0769 & 0.0677 & 0.0843 & 0.0752 & 0.0746 & 0.0643 & 0.0674 & 0.0584 & 0.0583 & 0.0696 & 0.0763 & 0.0794 & 0.0888 & 0.0813 \\
\hline W & n.d. & n.d. & n.d. & 26.7 & n.d. & 9.93 & 8.76 & n.d. & 12.7 & 12.1 & 11.6 & 11.4 & 11.9 & 11.8 & n.d. & 13.0 \\
\hline $\mathbf{U}$ & 0.0281 & 0.0269 & 0.0275 & 0.0240 & 0.0247 & 0.0208 & 0.0210 & 0.0190 & 0.0199 & 0.0173 & 0.0168 & 0.0212 & 0.0221 & 0.0225 & 0.0260 & 0.0203 \\
\hline $\mathbf{N b}$ & 0.359 & 0.331 & 0.345 & 0.294 & 0.379 & 0.335 & 0.320 & 0.267 & 0.296 & 0.263 & 0.266 & 0.310 & 0.355 & 0.347 & 0.393 & 0.618 \\
\hline La & 0.687 & 0.658 & 0.589 & 0.561 & 0.652 & 0.569 & 0.557 & 0.489 & 0.501 & 0.442 & 0.439 & 0.522 & 0.596 & 0.610 & 0.687 & 0.614 \\
\hline $\mathrm{Ce}$ & 2.23 & 2.13 & 1.98 & 1.79 & 2.26 & 1.93 & 1.90 & 1.70 & 1.75 & 1.51 & 1.49 & 1.83 & 2.03 & 2.11 & 2.40 & 1.60 \\
\hline $\mathbf{P r}$ & 0.414 & 0.410 & 0.391 & 0.345 & 0.502 & 0.429 & 0.416 & 0.361 & 0.387 & 0.328 & 0.333 & 0.399 & 0.448 & 0.460 & 0.526 & 0.242 \\
\hline Nd & 2.71 & 2.65 & 2.61 & 2.25 & 3.43 & 2.91 & 2.87 & 2.50 & 2.62 & 2.25 & 2.30 & 2.77 & 3.06 & 3.13 & 3.62 & 1.19 \\
\hline Sm & 1.19 & 1.15 & 1.18 & 1.01 & 1.57 & 1.34 & 1.35 & 1.15 & 1.19 & 1.04 & 1.05 & 1.25 & 1.41 & 1.45 & 1.66 & 0.387 \\
\hline Hf & 0.803 & 0.775 & 0.782 & 0.706 & 1.036 & 0.924 & 0.913 & 0.797 & 0.822 & 0.720 & 0.723 & 0.873 & 0.944 & 0.967 & 1.093 & 0.268 \\
\hline $\mathbf{Z r}$ & 28.4 & 25.2 & 28.2 & 24.3 & 36.9 & 31.9 & 32.0 & 26.5 & 28.3 & 25.3 & 25.0 & 29.3 & 33.2 & 34.5 & 39.1 & 9.71 \\
\hline Eu & 0.566 & 0.268 & 0.311 & 0.343 & 0.646 & 0.553 & 0.525 & 0.462 & 0.468 & 0.381 & 0.372 & 0.501 & 0.593 & 0.593 & 0.677 & 0.146 \\
\hline Gd & 1.81 & 1.69 & 1.63 & 1.54 & 2.20 & 1.91 & 1.90 & 1.60 & 1.70 & 1.49 & 1.48 & 1.79 & 1.99 & 2.04 & 2.32 & 0.513 \\
\hline Tb & 0.311 & 0.289 & 0.307 & 0.264 & 0.381 & 0.326 & 0.325 & 0.282 & 0.293 & 0.257 & 0.259 & 0.312 & 0.348 & 0.355 & 0.404 & 0.0940 \\
\hline Dy & 1.98 & 1.86 & 1.96 & 1.74 & 2.48 & 2.14 & 2.14 & 1.81 & 1.93 & 1.71 & 1.70 & 2.01 & 2.27 & 2.34 & 2.63 & 0.638 \\
\hline Y & 9.79 & 9.20 & 9.51 & 8.34 & 12.3 & 10.5 & 10.7 & 9.07 & 9.76 & 8.50 & 8.45 & 10.0 & 11.0 & 11.4 & 12.9 & 3.94 \\
\hline Ho & 0.398 & 0.373 & 0.387 & 0.353 & 0.504 & 0.433 & 0.432 & 0.362 & 0.386 & 0.340 & 0.339 & 0.399 & 0.445 & 0.463 & 0.533 & 0.142 \\
\hline Er & 1.09 & 1.01 & 1.07 & 0.955 & 1.37 & 1.17 & 1.18 & 1.00 & 1.05 & 0.919 & 0.915 & 1.09 & 1.23 & 1.27 & 1.44 & 0.417 \\
\hline $\mathbf{T m}$ & 0.148 & 0.140 & 0.142 & 0.132 & 0.186 & 0.157 & 0.161 & 0.138 & 0.143 & 0.126 & 0.126 & 0.152 & 0.167 & 0.172 & 0.196 & 0.0643 \\
\hline Yb & 0.911 & 0.880 & 0.929 & 0.817 & 1.21 & 1.02 & 1.02 & 0.87 & 0.923 & 0.815 & 0.816 & 0.964 & 1.08 & 1.11 & 1.26 & 0.414 \\
\hline Lu & 0.129 & 0.127 & 0.129 & 0.117 & 0.170 & 0.145 & 0.147 & 0.125 & 0.132 & 0.115 & 0.116 & 0.137 & 0.154 & 0.158 & 0.179 & 0.0637 \\
\hline $\mathrm{Ti} / \mathrm{Zr}$ & 146 & 151 & 145 & 144 & 119 & 115 & 118 & 120 & 118 & 115 & 116 & 119 & 120 & 118 & 119 & 112 \\
\hline $\mathrm{Nb} / \mathrm{Nb}^{*}$ & 0.566 & 0.550 & 0.586 & 0.546 & 0.585 & 0.587 & 0.568 & 0.545 & 0.582 & 0.593 & 0.601 & 0.588 & 0.602 & 0.570 & 0.576 & 1.00 \\
\hline $\mathbf{W} / \mathbf{W} *$ & n.d. & n.d. & n.d. & 2.07 & n.d. & 0.785 & 0.691 & n.d. & 1.09 & 1.19 & 1.16 & 0.931 & 0.902 & 0.874 & n.d. & 1.00 \\
\hline$(\mathbf{L a} / \mathbf{S m})_{N}$ & 0.362 & 0.359 & 0.315 & 0.350 & 0.261 & 0.267 & 0.261 & 0.268 & 0.264 & 0.268 & 0.264 & 0.263 & 0.267 & 0.265 & 0.260 & 1.00 \\
\hline$(\mathrm{Gd} / \mathrm{Yb})_{\mathrm{N}}$ & 1.60 & 1.56 & 1.41 & 1.53 & 1.47 & 1.51 & 1.49 & 1.48 & 1.49 & 1.48 & 1.47 & 1.50 & 1.49 & 1.48 & 1.48 & 1.00 \\
\hline
\end{tabular}

Abundances recalculated on an anhydrous basis in ppm, except for W (ppb). $N$ - normalized to the BSE values of Hofmann (1988) for all elements except Ga (McDonough and Sun, 1995) and W (Arevalo and McDonough, 2008), as reported in the table. 
61578 Table 3. Highly siderophile element abundances (in ppb) and Re-Os isotopic data for Jeesiörova and Kevitsa komatiites and olivine and

71579 chromite separates.

\begin{tabular}{|c|c|c|}
\hline Sample No. & $\mathbf{R e}$ & Os \\
\hline 12D-PPR WR & 0.9867 & 5.434 \\
\hline 13-EJH WR & 0.6650 & 4.269 \\
\hline
\end{tabular}

\begin{tabular}{|l|c|c|}
\hline $17.1-P P R ~ W R$ & 0.6650 & 4.269 \\
\hline LP-10 WR & 0.8497 & 3.213 \\
\hline KD-03 WR & 0.3756 & 4.435 \\
\hline KD-05 WR & 1.188 & 1.528 \\
\hline KD-06 WR & 1.007 & 2.149 \\
\hline
\end{tabular}

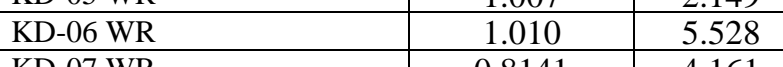

\begin{tabular}{|l|l|l}
\hline KD-07 WR & 0.8141 & 4.161 \\
\hline
\end{tabular}

\begin{tabular}{|l|l|l}
\hline KD-08 WR & 0.8693 & 3.684 \\
\hline
\end{tabular}

\begin{tabular}{|l|l|l}
\hline KD-09 WR & 0.7062 & 3.956
\end{tabular}

\begin{tabular}{|c|c|}
\hline KD-10 WR & 0.6813 \\
\hline
\end{tabular}

\begin{tabular}{l|l} 
KD-11 WR & 0.9146
\end{tabular}

\begin{tabular}{l|l}
\hline KD-12 WR & 1.051 \\
\hline
\end{tabular}

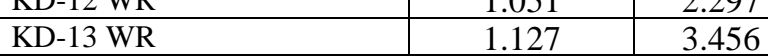

Replicate

KD-14 WR

12D-PPR Chr

17.1-PPR Chr

12D-PPR_1 Chr

12D-PPR $3 \mathrm{Ch}$

12D-PPR_4 Chr

12D-PPR $5 \mathrm{Chr}$

13-EJH $1 \mathrm{Chr}$

13-EJH_2 Chr

$\mathrm{KD}-05 \mathrm{Ol}$

\begin{tabular}{l|l}
0.34468 \\
\hline
\end{tabular}

KD-05 Chr

KD-08 Chr

KD-10 Chr

KD-12 Chr

LP-10 Chr

1.109

\begin{tabular}{l|l}
\hline 109 & 2.456 \\
\hline .284 & 2.063
\end{tabular}

2.063

1.284

1.195

2.035

122.7

156.7

56.7

0.8898

141.0
149.8

\begin{tabular}{c|c|c}
$\mathbf{I r}$ & $\mathbf{R u}$ & \\
\hline 4.226 & 7.436 & \\
\hline 3.279 & 6.235 & \\
\hline 2.637 & 5.869 & 19 \\
\hline
\end{tabular}

\section{Pt}

17.89

\begin{tabular}{l|l|l}
\hline 2.637 & 5.869 & 19.17 \\
\hline 3.631 & 6.657 & 16.75 \\
\hline
\end{tabular}

\begin{tabular}{l|l|l}
\hline .631 & 6.657 & 16.75 \\
\hline 1.472 & 2.573 & 22.3 \\
\hline
\end{tabular}

\begin{tabular}{l|l|l}
1.472 & 2.573 & 22.31 \\
\hline 1.845 & 3.549 & 19.77
\end{tabular}

\begin{tabular}{l|l}
3.006 & 3.824 \\
\hline
\end{tabular}

\begin{tabular}{l|l|l}
2.571 & 4.082 & 16.82 \\
\hline
\end{tabular}

\begin{tabular}{l|l}
\hline 2.824 & 4.300 \\
\hline
\end{tabular}

\begin{tabular}{l|l|l}
2.824 & 4.300 & 17.77 \\
\hline 2.870 & 5.001 & 16.02
\end{tabular}

\begin{tabular}{l|l|l}
2.870 & 5.001 & 16.02 \\
\hline 2.434 & 5.027 & 16.22 \\
\hline
\end{tabular}

\begin{tabular}{l|l}
2.434 & 5.027 \\
\hline & 4.262 \\
\hline
\end{tabular}

\begin{tabular}{l|l|l}
1.166 & 3.436 & 21.10 \\
\hline 1.933 & 3.384 & 21.04 \\
\hline
\end{tabular}

\begin{tabular}{l|l}
3.384 & 21.04 \\
\hline 2.168 & 23.68 \\
\hline
\end{tabular}

\begin{tabular}{l|l}
1.593 & 2.168 \\
\hline
\end{tabular}

\begin{tabular}{l|r} 
& 1.014 \\
\hline und & 0.7288
\end{tabular}

153.3

150.2

157.5

\begin{tabular}{l|r}
0.5624 & 157.5 \\
\hline 0.2597 & 53.32 \\
\hline 0.3449 & 53.59
\end{tabular}

\begin{tabular}{|l|l|l} 
& & \\
\hline & & \\
\hline 1022 & & 23.67 .85 \\
\hline
\end{tabular}

17.76

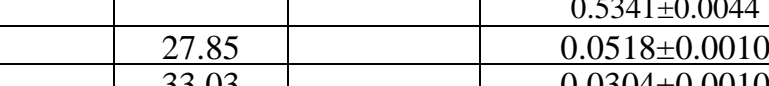

103.6

101.7

108.0

38.45

2.262

undances recalculated on an anhydrous basis.

55.28

\begin{tabular}{|l|l|l|l|l}
\hline 108.0 & & 52.97 & & \\
\hline 38.33 & & 6.164 & & \\
\hline 38.45 & & 7.314 & & \\
\hline 2.262 & 2.296 & 1.525 & 1.426 & \\
\hline 2.285 & 4.158 & 1.936 & 1.698 & \\
\hline & & & & \\
\hline & & & & \\
\hline & & & & \\
\hline & & & & \\
\hline & & & & \\
\hline
\end{tabular}

\begin{tabular}{|l|l|}
\hline 0.6178 & 3.126 \\
\hline 0.4528 & 35.29
\end{tabular}

\begin{tabular}{l|l}
\hline 0.617828 & 35.29 \\
\hline
\end{tabular}

15.54

specified in the text. The HSE normalizing values are Initial $\gamma^{18}$

\begin{tabular}{lr} 
& $0.4568 \pm 0.0062$ \\
\hline
\end{tabular} $0.0203 \pm 0.0009$ $0.0171 \pm 0.0009$ $0.0202 \pm 0.0009$ $0.0172 \pm 0.0009$ $0.0234 \pm 0.0027$ $0.0310 \pm 0.0026$ $0.9547 \pm 0.0050$ $0.0617 \pm 0.0016$ $0.0617 \pm 0.0016$ $0.1660 \pm 0.0023$ $0.0737 \pm 0.0011$

19

\begin{tabular}{|c|c|}
\hline & 0 \\
\hline & 0 \\
\hline
\end{tabular}

\begin{tabular}{|c|c|}
\hline${ }^{187} \mathbf{O} \mathbf{s}^{188} \mathbf{O s}$ & $\boldsymbol{\gamma}^{\mathbf{1 8 7}} \mathbf{O s}(\mathbf{2 0 4 9})$ \\
\hline $0.14236 \pm 7$ & -1.0 \\
\hline $0.13836 \pm 6$ & -0.7 \\
\hline $0.15817 \pm 7$ & +0.6 \\
\hline $0.12871 \pm 6$ & +1.3 \\
\hline $0.24505 \pm 2$ & -0.1 \\
\hline $0.19117 \pm 8$ & -0.9 \\
\hline $0.14353 \pm 7$ & -0.1 \\
\hline $0.14662 \pm 1$ & +0.7 \\
\hline $0.15200 \pm 8$ & -0.6 \\
\hline $0.14307 \pm 6$ & +0.1 \\
\hline $0.14820 \pm 7$ & -0.6 \\
\hline $0.15471 \pm 7$ & +0.1 \\
\hline $0.19087 \pm 10$ & +0.5 \\
\hline $0.16626 \pm 10$ & -1.4 \\
\hline $0.20361 \pm 9$ & -0.3 \\
\hline $0.21969 \pm 2$ & -0.2 \\
\hline $0.11378 \pm 5$ & -0.8 \\
\hline $0.13226 \pm 8$ & +0.6 \\
\hline $0.11462 \pm 7$ & -0.2 \\
\hline $0.11357 \pm 6$ & -0.5 \\
\hline $0.11336 \pm 6$ & -0.4 \\
\hline $0.11339 \pm 6$ & -0.2 \\
\hline $0.11329 \pm 7$ & -0.4 \\
\hline $0.11337 \pm 5$ & -0.3 \\
\hline $0.11394 \pm 6$ & +0.1 \\
\hline $0.11393 \pm 7$ & -0.2 \\
\hline $0.11455 \pm 4$ & -0.4 \\
\hline $0.14627 \pm 4$ & 0.0 \\
\hline $0.11497 \pm 6$ & -0.2 \\
\hline $0.11837 \pm 8$ & -0.4 \\
\hline $0.11531 \pm 7$ & -0.3 \\
\hline $0.12945 \pm 13$ & 0.0 \\
\hline $0.11655 \pm 7$ & -0.2 \\
\hline
\end{tabular}

through 12D-PPR_6 and 13-EJH_1 and 13-EJH_2 denote spiked subsamples of unspiked digestions for the Pt-Os study. 
Table 4. High-precision Os isotopic data and Re/Os and Pt/Os ratios for chromite separates from the Jeesiörova komatiites.

\begin{tabular}{|l|c|c|c|c|c|c|c|}
\hline Sample No. & ${ }^{187} \mathbf{R e} /{ }^{188} \mathbf{O s}$ & ${ }^{187} \mathbf{O s} /{ }^{188} \mathbf{O s}$ & $\gamma^{\mathbf{1 8 7}} \mathbf{O s}(T)$ & ${ }^{190} \mathbf{P t} /{ }^{188} \mathbf{O s}$ & ${ }^{184} \mathbf{O s} /{ }^{\mathbf{1 8 8}} \mathbf{O s}$ & ${ }^{186} \mathbf{O s} /{ }^{188} \mathbf{O s}$ & $\boldsymbol{\mu}^{\mathbf{1 8 6}} \mathbf{O s}(\boldsymbol{T})$ \\
\hline 12D-PPR_1 Chr & $0.0518 \pm 0.0010$ & $0.1146036 \pm 06$ & -0.23 & $0.0001697 \pm 34$ & $0.0013031 \pm 2$ & $0.1198369 \pm 6$ & $+25 \pm 5$ \\
\hline 12D-PPR_2 Chr & $0.0304 \pm 0.0010$ & $0.1135064 \pm 05$ & -0.54 & $0.0002238 \pm 45$ & $0.0013028 \pm 2$ & $0.1198381 \pm 5$ & $+34 \pm 4$ \\
\hline 12D-PPR_3 Chr & $0.0203 \pm 0.0009$ & $0.1134565 \pm 07$ & -0.27 & $0.0002299 \pm 46$ & $0.0013023 \pm 3$ & $0.1198377 \pm 7$ & $+30 \pm 6$ \\
\hline 12D-PPR_4 Chr & $0.0171 \pm 0.0009$ & $0.1134060 \pm 05$ & -0.22 & $0.0002425 \pm 48$ & $0.0013033 \pm 2$ & $0.1198381 \pm 5$ & $+33 \pm 4$ \\
\hline 12D-PPR_5 Chr & $0.0202 \pm 0.0009$ & $0.1134294 \pm 06$ & -0.29 & $0.0003009 \pm 60$ & $0.0013033 \pm 2$ & $0.1198378 \pm 6$ & $+29 \pm 5$ \\
\hline 12D-PPR_6 Chr & $0.0172 \pm 0.0009$ & $0.1134048 \pm 06$ & -0.22 & $0.0003213 \pm 64$ & $0.0013033 \pm 2$ & $0.1198376 \pm 6$ & $+27 \pm 5$ \\
\hline 13-EJH Chr & $0.0272 \pm 0.0019$ & $0.1138779 \pm 11$ & -0.11 & $0.0001204 \pm 24$ & $0.0013024 \pm 4$ & $0.1198370 \pm 10$ & $+27 \pm 8$ \\
\hline
\end{tabular}

Initial $\gamma^{187}$ Os and $\mu^{186}$ Os values were calculated at $T=2049$ Ma using the parameters specified in the text. 
1584 Table 5. Tungsten isotopic compositions of Kevitsa komatiites.

\begin{tabular}{|c|c|c|}
\hline Sample & $\boldsymbol{\mu}^{\mathbf{1 8 2}} \mathbf{W}( \pm \mathbf{2 S E})$ & $\boldsymbol{\mu}^{\mathbf{1 8 3}} \mathbf{W}(\mathbf{\pm 2 S E})$ \\
\hline KD-08 & $-1.7 \pm 3.6$ & $-0.8 \pm 4.3$ \\
\hline Replicate & $+2.2 \pm 4.3$ & $-2.1 \pm 4.8$ \\
\hline KD-12 & $+5.9 \pm 3.0$ & $+2.1 \pm 3.6$ \\
\hline Replicate & $-0.2 \pm 3.3$ & $-2.6 \pm 4.1$ \\
\hline Average ( \pm 2 SE) & $\mathbf{+ 1 . 5} \pm \mathbf{3 . 3}$ & $\mathbf{- 0 . 8} \pm \mathbf{2 . 1}$ \\
\hline
\end{tabular}

Uncertainties on $\mathrm{W}$ isotopic compositions for individual samples are the 2SE in-run uncertainties of the individual analyses. 
1588 Table 6. Sm-Nd isotope and concentration data for Jeesiörova and Kevitsa komatiites.

1

2

3

\begin{tabular}{|l|c|c|c|c|c|c|c|}
\hline Sample & Sm, ppm & $\mathbf{N d}, \mathbf{p p m}$ & ${ }^{147} \mathbf{S m} /{ }^{144} \mathbf{N d}$ & $\mathbf{\pm 2 S D}$ & ${ }^{143} \mathbf{N d} /{ }^{144} \mathbf{N d}$ & $\mathbf{\pm 2 S E}$ & $\boldsymbol{\varepsilon}^{\mathbf{1 4 3} \mathbf{N d}(\mathbf{T})}$ \\
\hline 13-EJH WR & 1.081 & 2.446 & 0.2673 & 0.0005 & 0.513768 & 0.000004 & +3.5 \\
\hline 17.1-PPR WR & 1.123 & 2.445 & 0.2779 & 0.0006 & 0.513917 & 0.000003 & +3.6 \\
\hline KD-05 WR & 1.379 & 2.966 & 0.2811 & 0.0006 & 0.513959 & 0.000004 & +3.6 \\
\hline KD-08 WR & 1.176 & 2.546 & 0.2794 & 0.0006 & 0.513950 & 0.000003 & +3.8 \\
\hline KD-10 WR & 0.9099 & 1.950 & 0.2821 & 0.0006 & 0.513981 & 0.000003 & +3.7 \\
\hline KD-12 WR & 1.501 & 3.245 & 0.2798 & 0.0006 & 0.513946 & 0.000003 & +3.7 \\
\hline 13-EJH Cpx & 0.9271 & 1.542 & 0.3636 & 0.0007 & 0.515069 & 0.000003 & +3.5 \\
\hline 17.1-PPR Cpx & 0.9256 & 1.496 & 0.3743 & 0.0008 & 0.515217 & 0.000003 & +3.6 \\
\hline KD-05 Cpx & 0.6775 & 1.309 & 0.3131 & 0.0006 & 0.514395 & 0.000003 & +3.7 \\
\hline KD-08 Cpx & 0.6564 & 1.335 & 0.2975 & 0.0006 & 0.514177 & 0.000004 & +3.5 \\
\hline KD-10 Cpx_1 & 0.6936 & 1.368 & 0.3066 & 0.0006 & 0.514317 & 0.000004 & +3.9 \\
\hline KD-10 Cpx_2 & 0.7036 & 1.388 & 0.3066 & 0.0006 & 0.514316 & 0.000003 & +3.8 \\
\hline KD-12 Cpx & 0.8599 & 1.676 & 0.3104 & 0.0006 & 0.514366 & 0.000003 & +3.8 \\
\hline
\end{tabular}

Initial $\varepsilon^{143} \mathrm{Nd}$ values were calculated at $T=2049 \mathrm{Ma}$ using the parameters specified in the text. WR - whole-rock samples; Cpx - clinopyroxene separates. 
1592 Table 7. Lu-Hf isotope and concentration data for the Jeesiörova komatiites and USGS SRM ${ }_{2}^{1} 1593$ BCR-1.

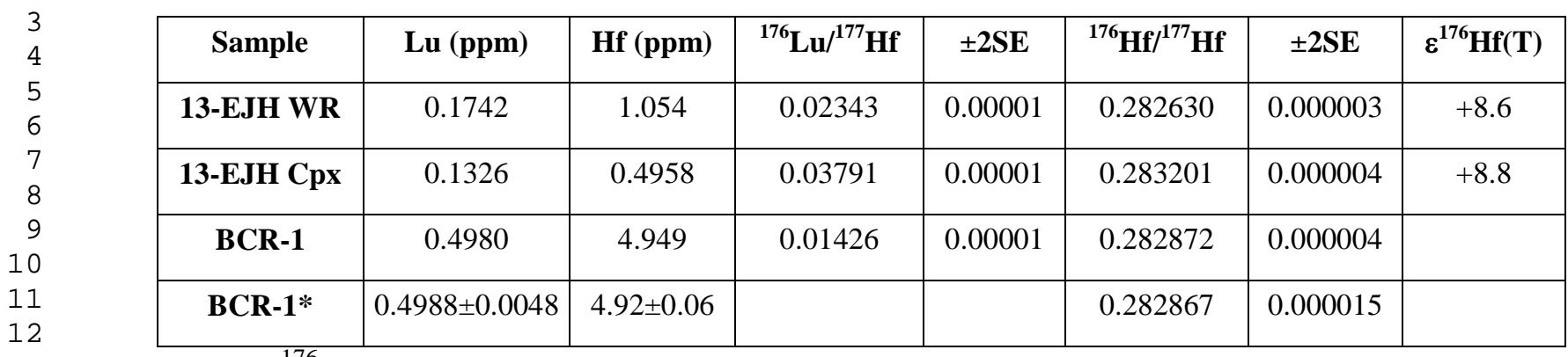

Initial $\varepsilon^{176} \mathrm{Hf}$ values were calculated at $T=2049 \mathrm{Ma}$, using the parameters specified in the ${ }_{16}^{15} 1596$ text. *Denotes the GeoRem recommended values. 
Table 8. Compositions of the emplaced Jeesiörova-Kevitsa komatiite magma, crustal contaminant endmember, and the calculated original komatiite magma.

\section{Original komatiite magma}

\begin{tabular}{|c|c|c|c|}
\hline $\mathbf{S i O}$ & 44.1 & 68.2 & 43.9 \\
\hline $\mathbf{T i O}_{\mathbf{2}}$ & 0.554 & 0.335 & 0.556 \\
\hline $\mathbf{A l}_{\mathbf{2}} \mathbf{O}_{\mathbf{3}}$ & 7.94 & 17.1 & 7.85 \\
\hline $\mathbf{F e}_{\mathbf{2}} \mathbf{O}_{\mathbf{3} \text { tot }}$ & 12.3 & 3.28 & 12.4 \\
\hline
\end{tabular}

\begin{tabular}{|c|c|c|c|}
\hline $\mathbf{F e}_{2} \mathbf{O}_{3 \text { tot }}$ & 12.3 & 3.28 & 12.4 \\
\hline $\mathbf{M n O}$ & 0.176 & 0.048 & 0.177 \\
\hline $\mathbf{M g O}$ & 25.2 & 1.35 & 25.4 \\
\hline $\mathbf{C a O}$ & 7.88 & 4.01 & 7.92 \\
\hline
\end{tabular}

\begin{tabular}{|c|c|c|c|}
\hline $\mathbf{C a O}$ & 7.88 & 4.01 & 7.92 \\
\hline $\mathbf{T h}$ & 0.0674 & & 0.0327 \\
\hline $\mathbf{W}$ & 11.7 & 3.51 & 5.81 \\
\hline
\end{tabular}

\begin{tabular}{|c|c|c|c|}
\hline $\mathbf{W}$ & 11.7 & 595 & 5.81 \\
\hline $\mathbf{U}$ & 0.0199 & 0.980 & 0.0102 \\
\hline $\mathbf{L b}$ & 0.296 & 3.06 & 0.268 \\
\hline $\mathbf{C a}$ & 0.501 & 25.0 & 0.253 \\
\hline
\end{tabular}

\begin{tabular}{|c|c|c|c|}
\hline La & 0.501 & 25.0 & 0.253 \\
\hline Ce & 1.75 & 46.2 & 1.30 \\
\hline Pr & 0.387 & 4.99 & 0.340 \\
\hline Nd & 2.62 & 17.2 & 2.48 \\
\hline Sm & 1.19 & 2.57 & 1.18 \\
\hline Hf & 0.822 & 3.81 & 0.792 \\
\hline
\end{tabular}

\begin{tabular}{|c|c|c|c|}
\hline Hf & 0.822 & 3.81 & 0.792 \\
\hline Gd & 1.70 & 2.01 & 1.70 \\
\hline Tb & 0.293 & 0.243 & 0.293 \\
\hline Dy & 1.93 & 1.33 & 1.94 \\
\hline Ho & 0.386 & 0.252 & 0.387 \\
\hline Er & 1.05 & 0.704 & 1.06 \\
\hline Tm & 0.143 & 0.0987 & 0.144 \\
\hline $\mathbf{Y b}$ & 0.923 & 0.652 & 0.926 \\
\hline Lu & 0.132 & 0.0970 & 0.133 \\
\hline $\mathbf{N b} / \mathbf{N b}^{*}$ & 0.582 & 0.118 & 1.07 \\
\hline $\mathbf{W} / \mathbf{W}^{*}$ & 1.00 & 1.00 & 1.00 \\
\hline$(\mathrm{Nb} / \mathrm{Th})_{\mathrm{N}}$ & 0.577 & 0.115 & 1.08 \\
\hline$(\mathbf{L a} / \mathbf{S m})_{N}$ & 0.264 & 6.14 & 0.135 \\
\hline$(\mathbf{G d} / \mathbf{Y b})_{N}$ & 1.49 & 2.50 & 1.48 \\
\hline$\varepsilon^{143} \mathrm{Nd}(T)$ & $+3.7 \pm 0.3$ & $-14.5 \pm 1.0$ & $+4.9 \pm 0.5$ \\
\hline$\varepsilon^{176} \mathbf{H f}(T)$ & $+8.7 \pm 0.3$ & $-21.8 \pm 1.9$ & $+10.2 \pm 0.6$ \\
\hline$u^{182} W$ & $+1.5 \pm 3.3$ & $+12.6 \pm 4.5$ & $-10 \pm 5$ \\
\hline
\end{tabular}

1- emplaced magma composition for the Jeesiörova-Kevitsa komatiites; 2 - FTA composition compiled from the average Vodla Block tonalite composition of Puchtel et al. (2016b). 3 original parental komatiite magma for the Jeesiörova-Kevitsa komatiites. The initial $\varepsilon N d$ and $\varepsilon$ Hf values were calculated at $T=2049$ Ma. 
1605 Table 9. Results of mixing calculations between an IIIAB iron meteorite endmember and the BSE mantle domain.

2

\begin{tabular}{|c|c|c|c|c|}
\hline & Tieraco Creek & BSE & BSE+0.2\% TC & Mantle source \\
\hline Os, ppb & 31.7 & $3.40 \pm 0.50$ & $3.50 \pm 0.50$ & $3.39 \pm 0.10$ \\
\hline $\mathbf{R e}, \mathbf{p p b}$ & 3.10 & $0.289 \pm 0.007$ & $0.295 \pm 0.010$ & $0.285 \pm 0.010$ \\
\hline $\mathbf{P t}, \mathbf{p p b}$ & 2089 & $6.1 \pm 1.6$ & $10.3 \pm 1.6$ & $9.54 \pm 0.22$ \\
\hline $\mathbf{W}, \mathbf{p p b}$ & 200 & $13.0 \pm 10$ & $13.4 \pm 10$ & $5.8 \pm 5$ \\
\hline${ }^{\mathbf{1 8 7}} \mathbf{R e} /{ }^{\mathbf{1 8}} \mathbf{O s}$ & 0.464 & 0.402 & 0.403 & $0.397 \pm 0.008$ \\
\hline${ }^{190} \mathbf{P t} /{ }^{\mathbf{1 8 8}} \mathbf{O s}$ & 0.0630 & 0.00171 & 0.00284 & $0.00269 \pm 0.008$ \\
\hline $\mathbf{u}^{\mathbf{1 8 2}} \mathbf{W}$ & -335 & 0 & -10 & $-10 \pm 5$ \\
\hline
\end{tabular}

The composition of the Jeesiörova-Kevitsa komatiite mantle source is calculated to have resulted from mixing of $0.2 \%$ of material of the IIIAB iron meteorite Tieraco Creek into a mantle domain with the BSE composition. Uncertainties on the HSE abundances in the average estimate for the BSE are 1SE (Becker et al., 2006). 


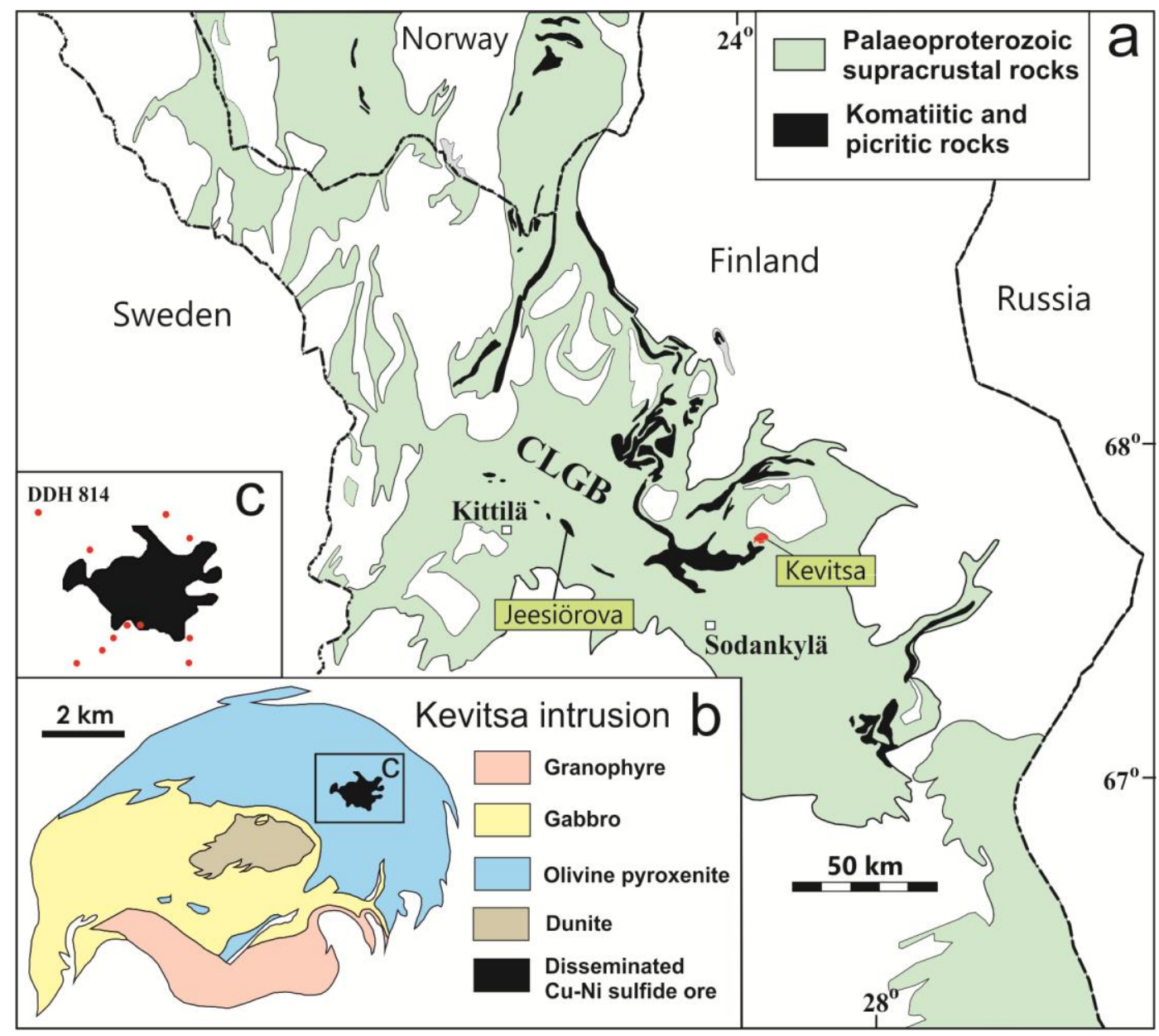

Fig. 1. 

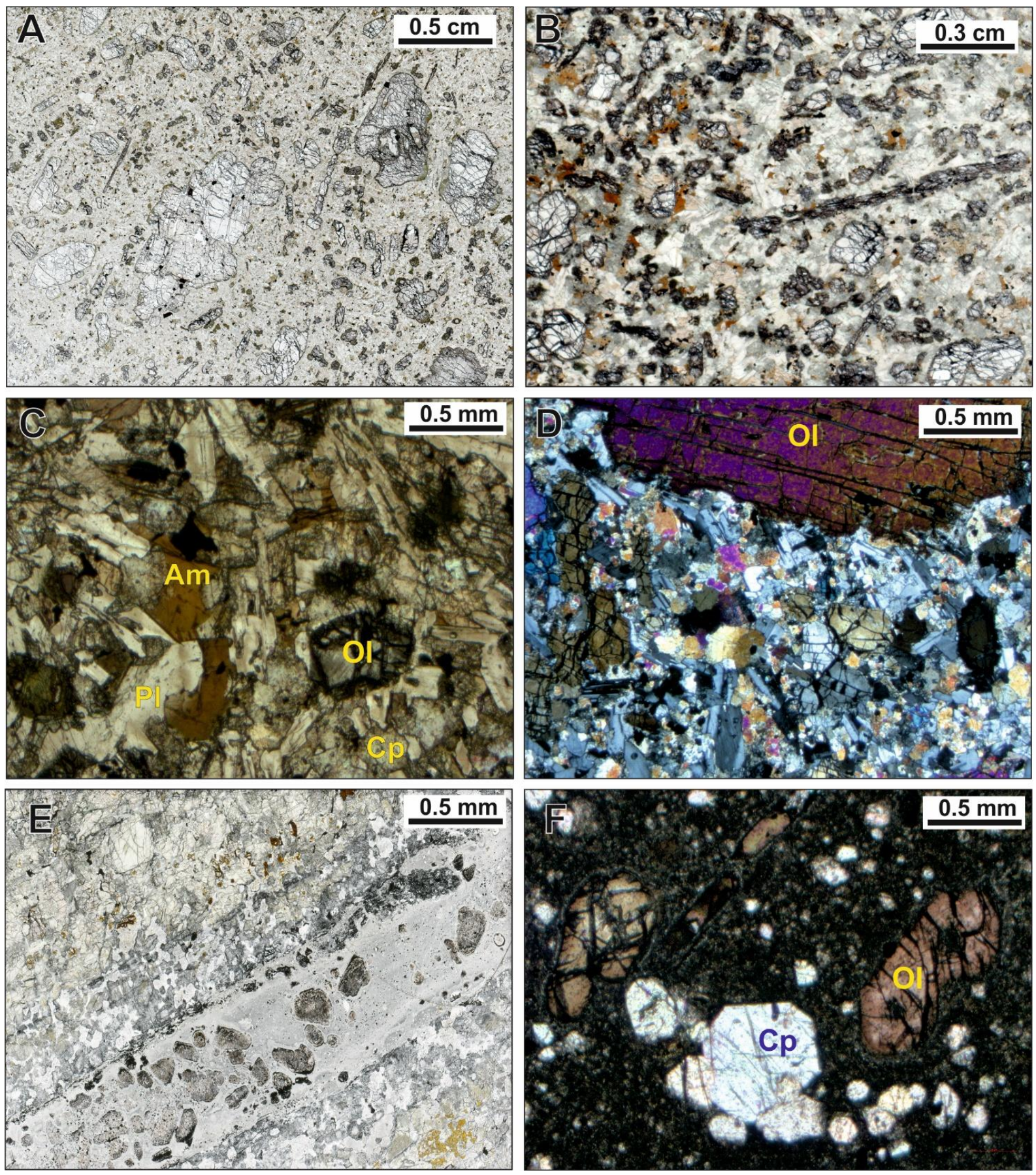

45

461617

47

481618 Fig. 2.

${ }_{50}^{49} 1619$

51

52

53

54

55

56 

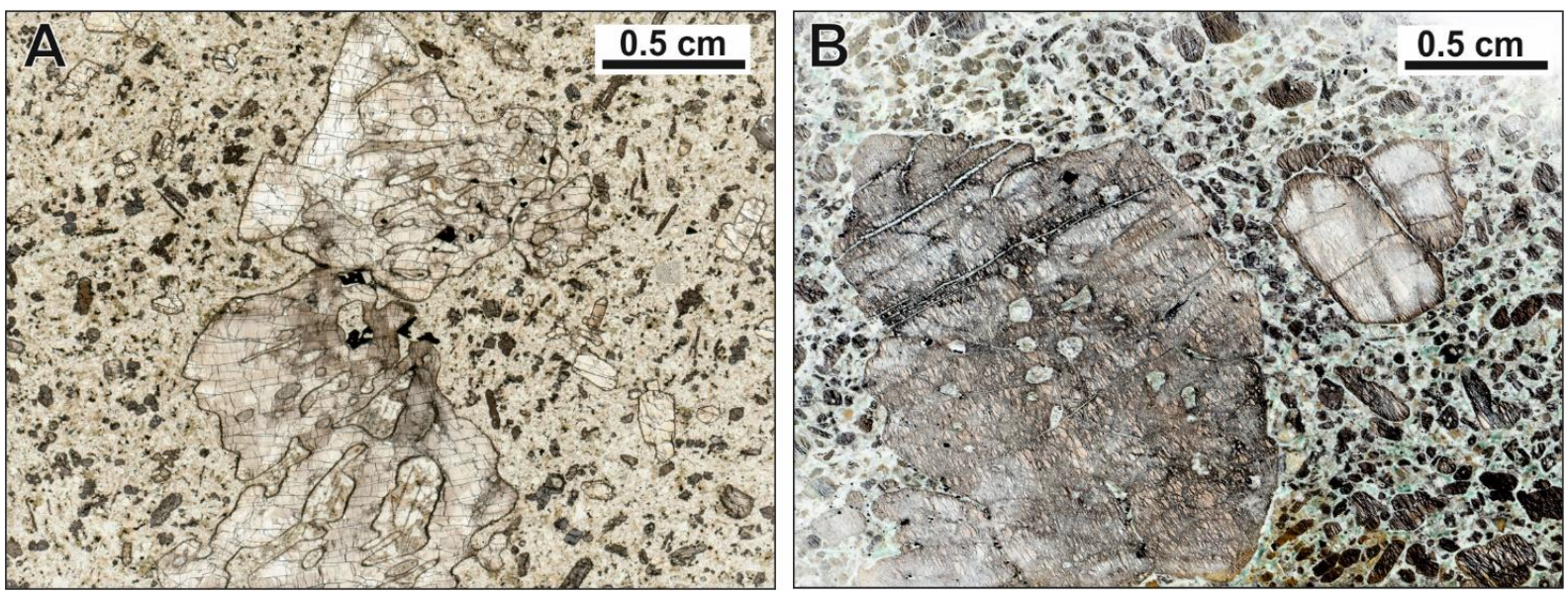

Fig. 3. 
1

2

3

4

5

6

7

8

9
10

11

12

13

14

15

16

17

18

19

20

21

22

23
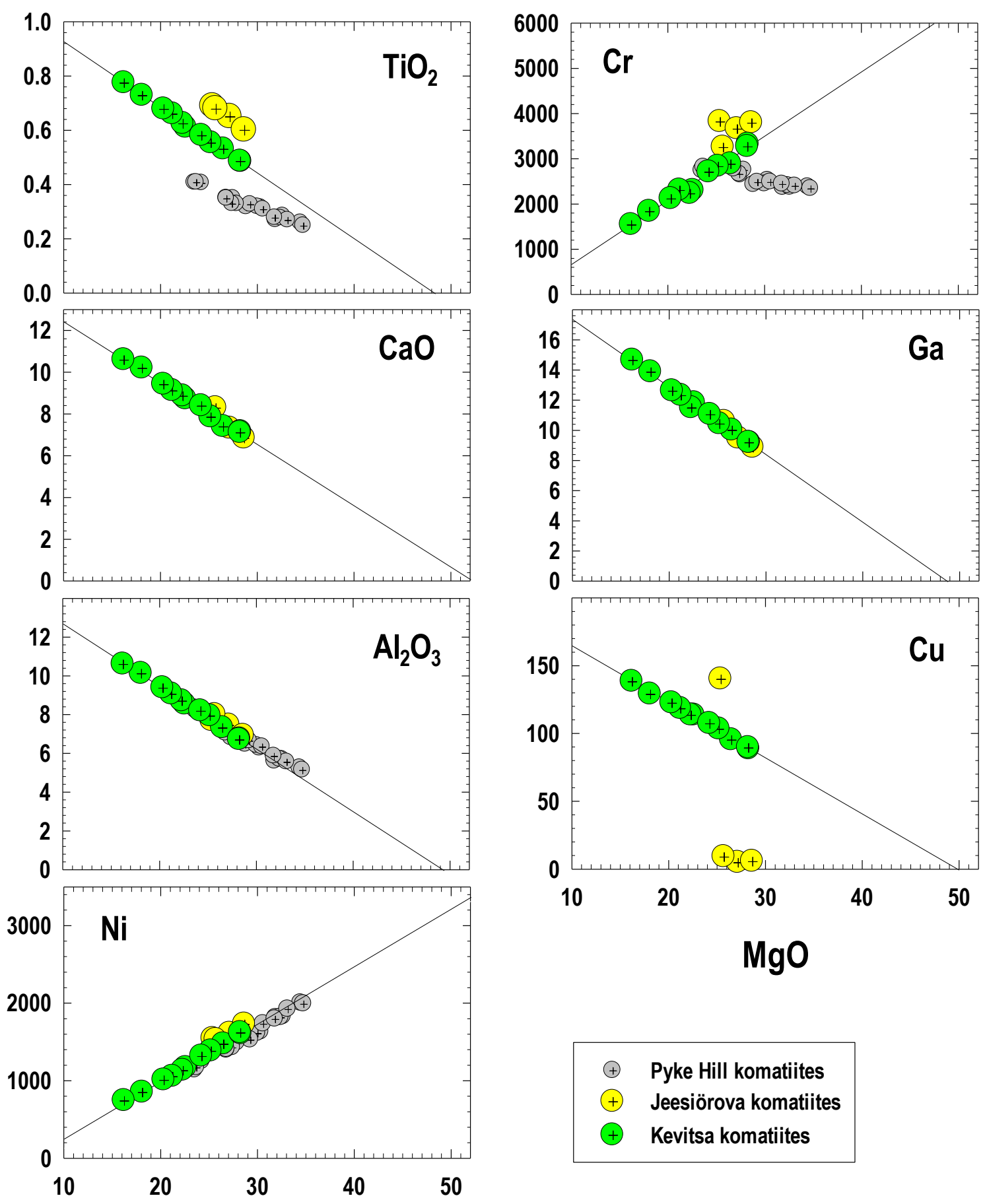

MgO

Fig. 4A. 
1

2

3

4

5

6
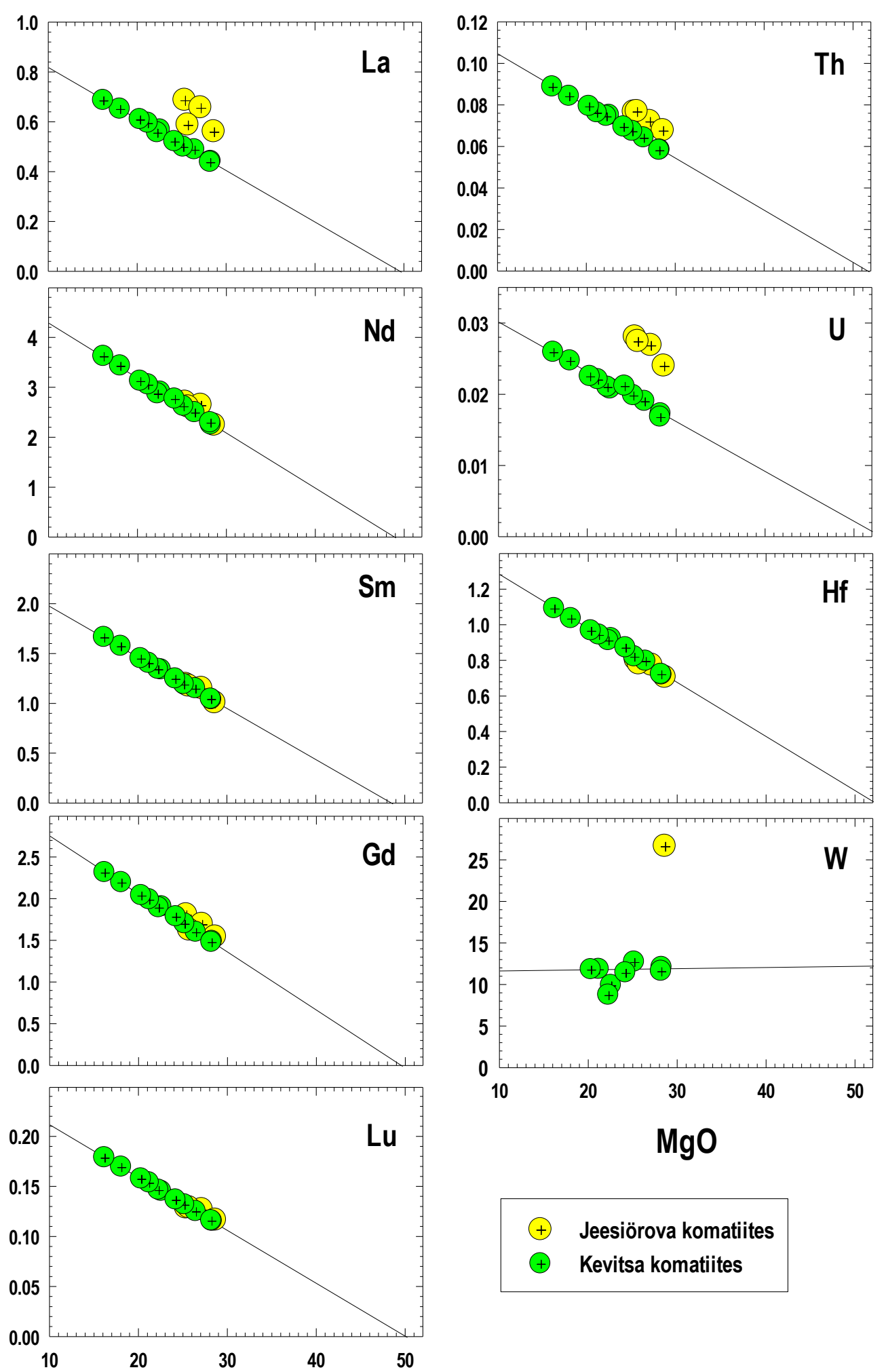

( Jeesiörova komatiites

( Kevitsa komatiites

Fig. 4B. 

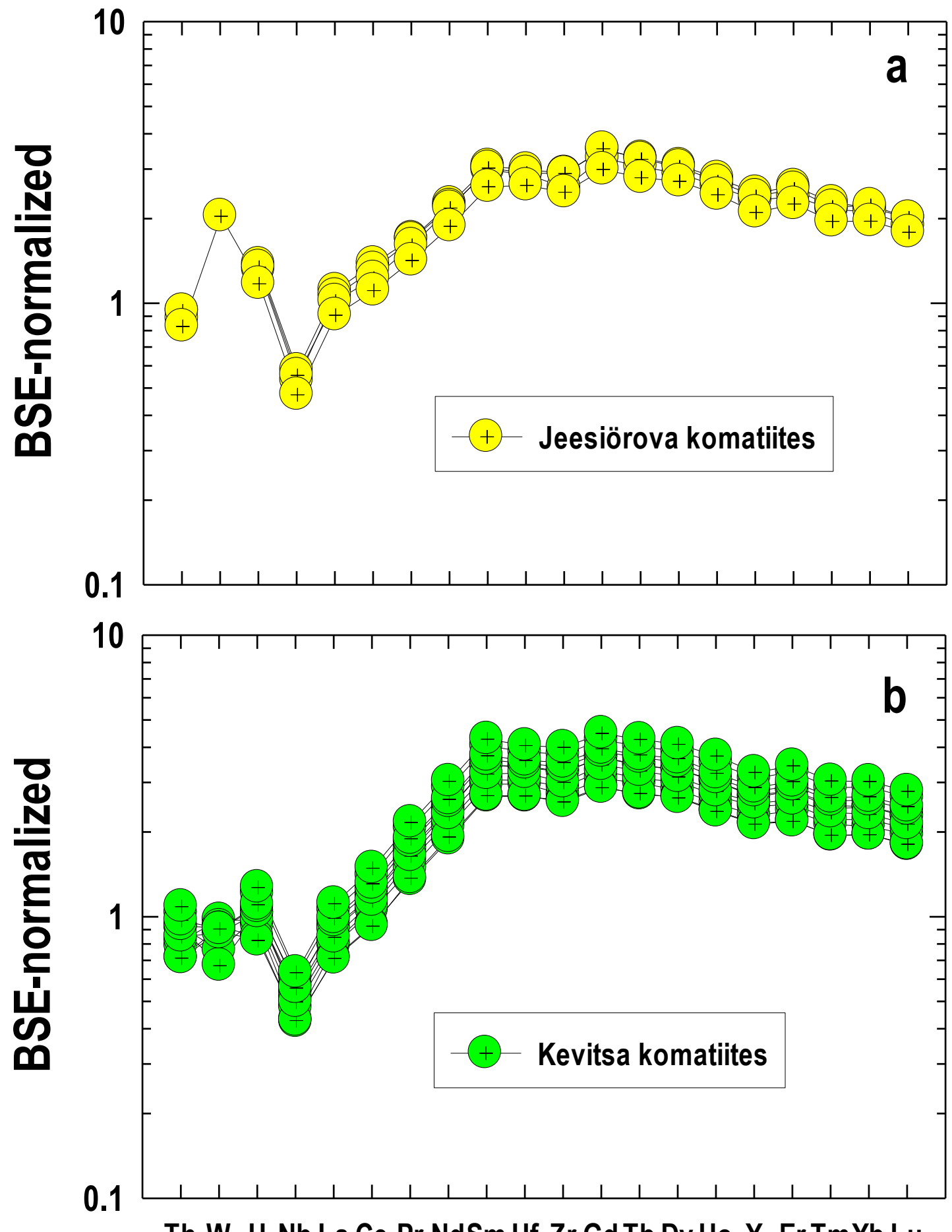

Th W U Nb La Ce PrNdSm Hf Zr GdTb Dy Ho Y ErTm Yb Lu

Fig. 5. 

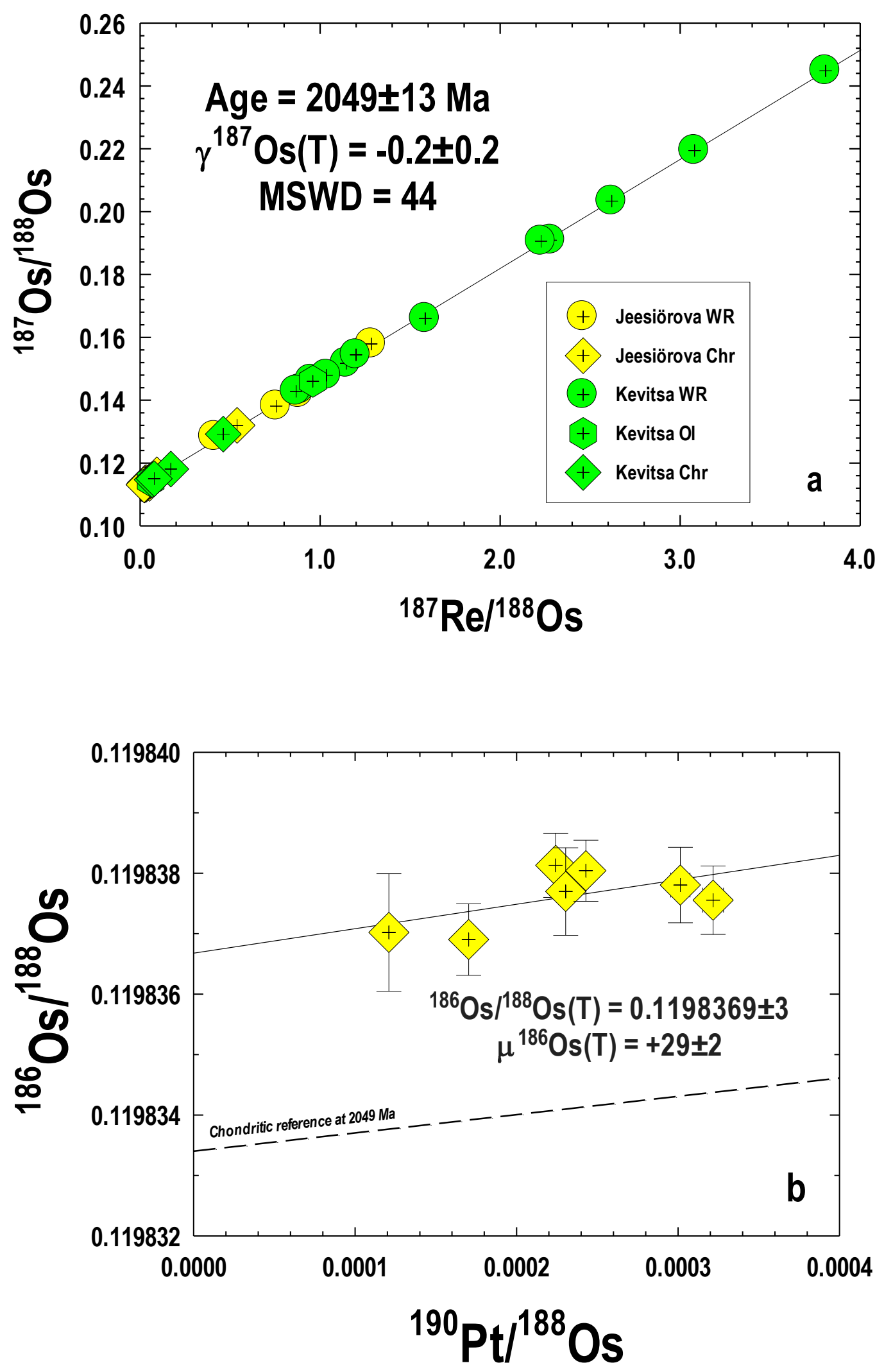

Fig. 6. 
1

2

3

4

5

6

7

8

9

10

11

12

13

14

15

16

17

18

19

20

21

22

23

24

25

26

27

28

29

30

31

32

33

34

35

36

37

38

39

40

41

42

43

44

45

${ }_{47}^{46} 1638$

481639

49

501640

51

52

53

54

55

56

57

58

59

60

61

62

63

64

65
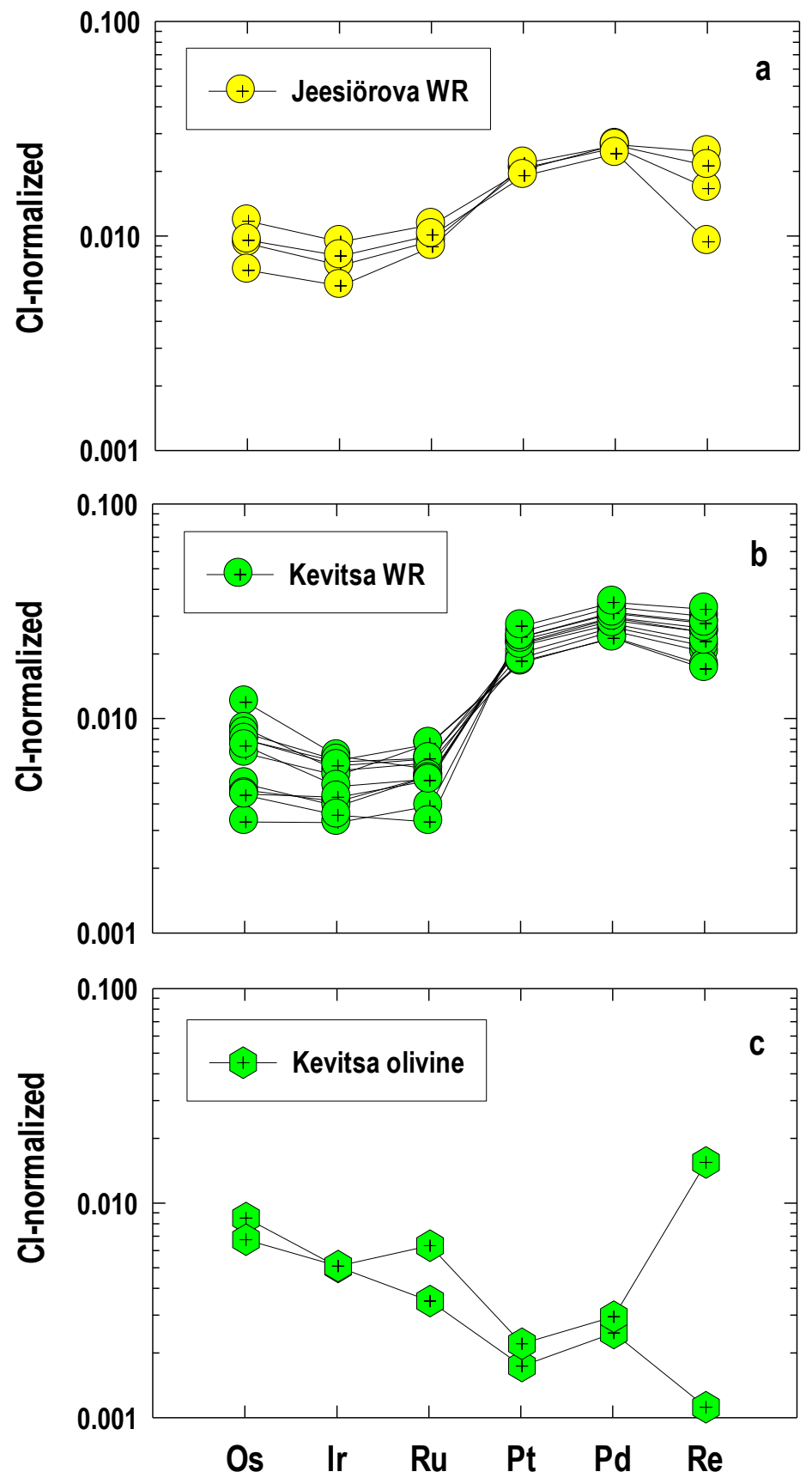

Fig. 7. 

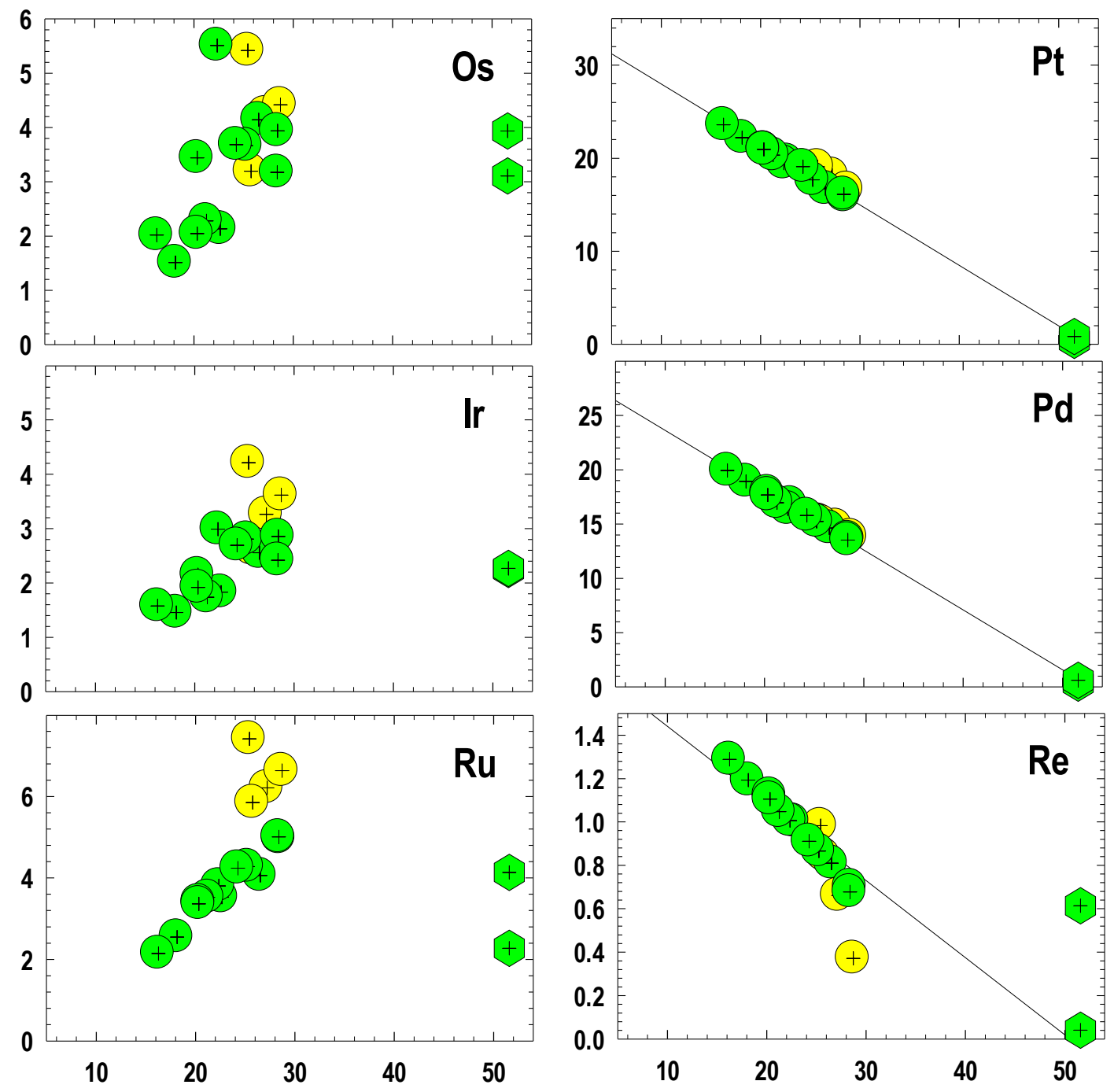

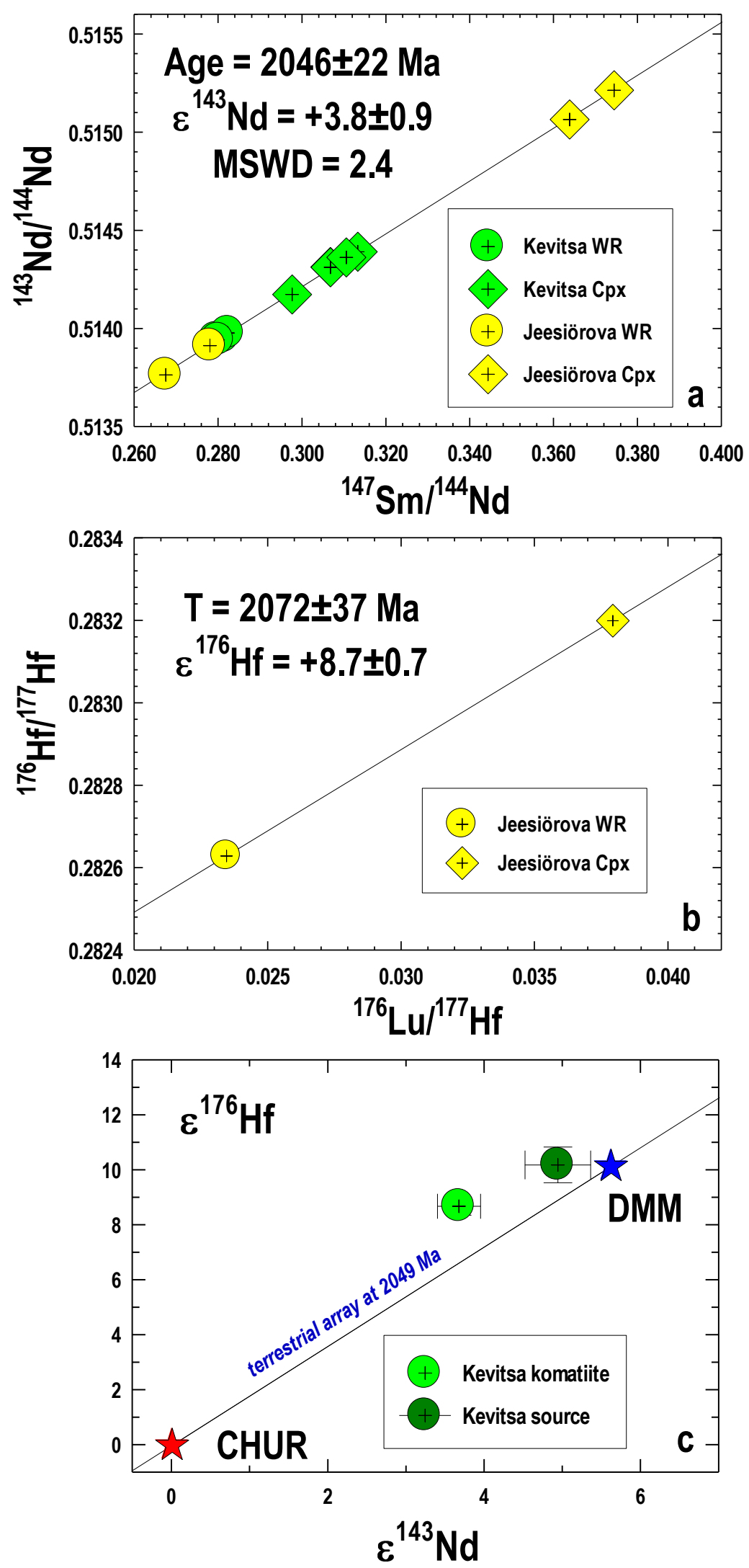

Fig. 9. 
1

2

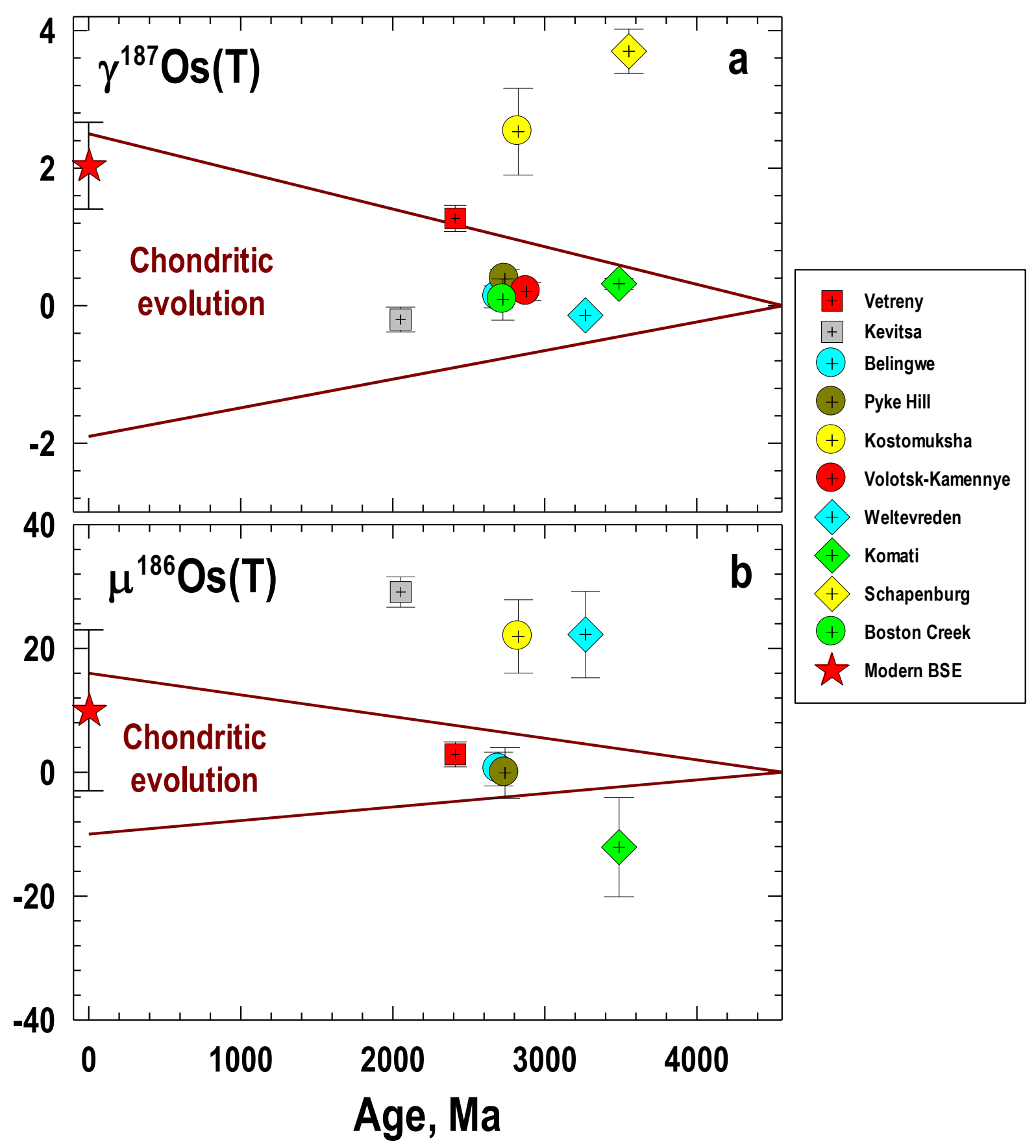

Fig. 10. 
1

2

3

4

5

6

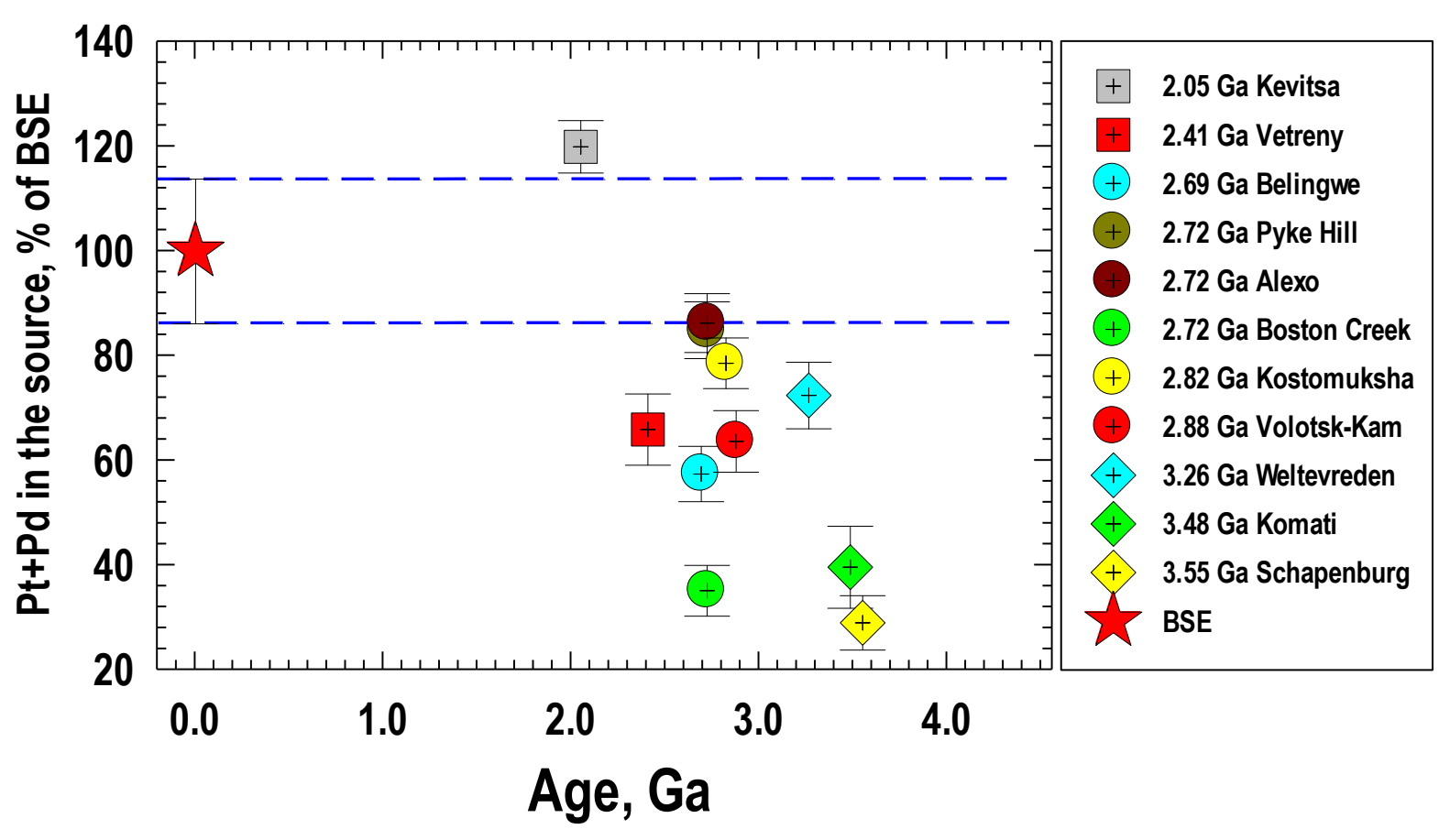

Fig. 11. 
1

2

3

4

5

6

7

8

10

11

12

13

14

15

16

17

18

19

20

21

22

23

24

25

26

271654

281655

301656

${ }^{31} 1657$

331658

34

35

36

37

38

39

40

41

42

43

44

45

46

47

48

49

50

51

52

53

54

55

56

57

58

59

60

61

62

63

64

65

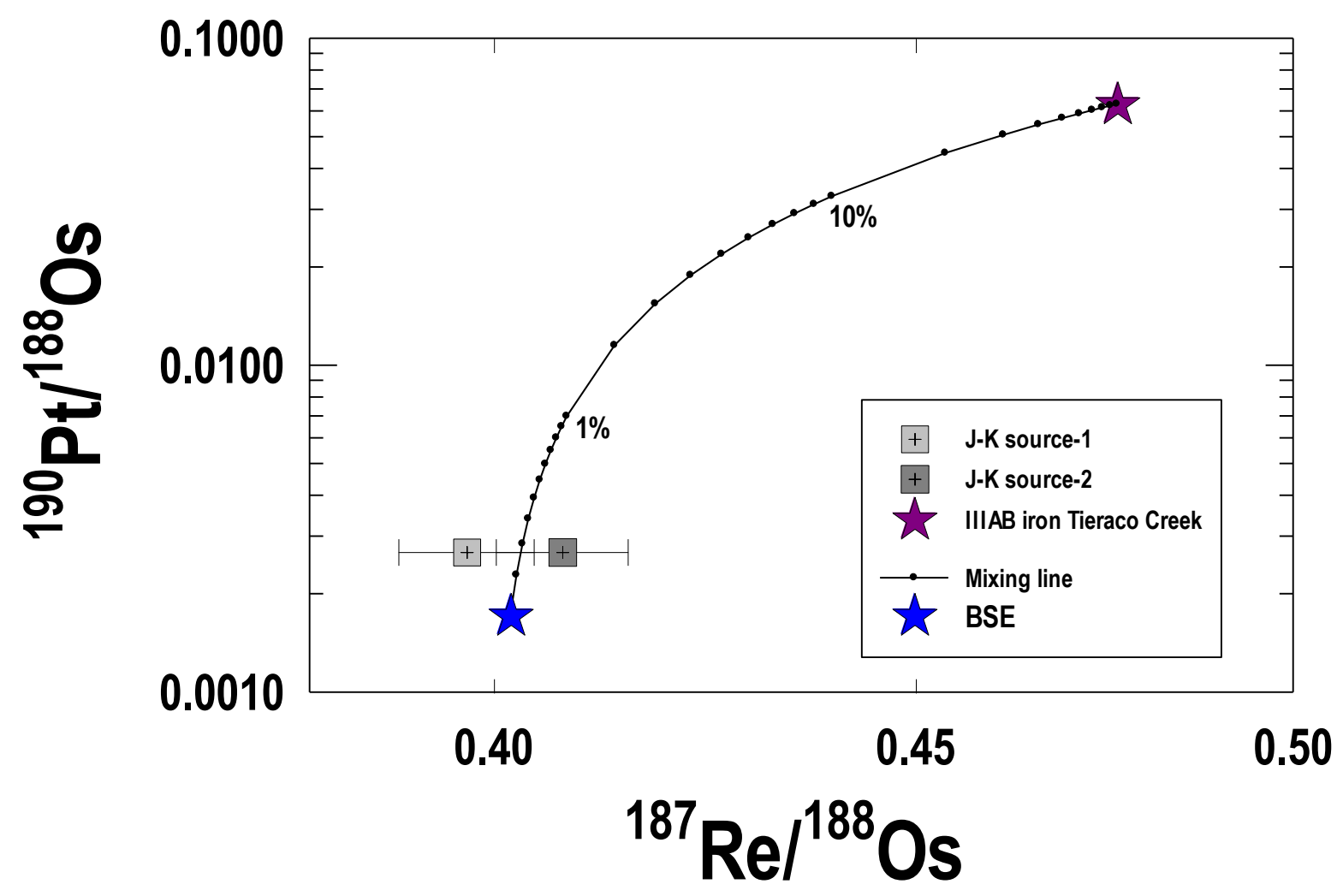

Fig. 12. 
Fig. 13.

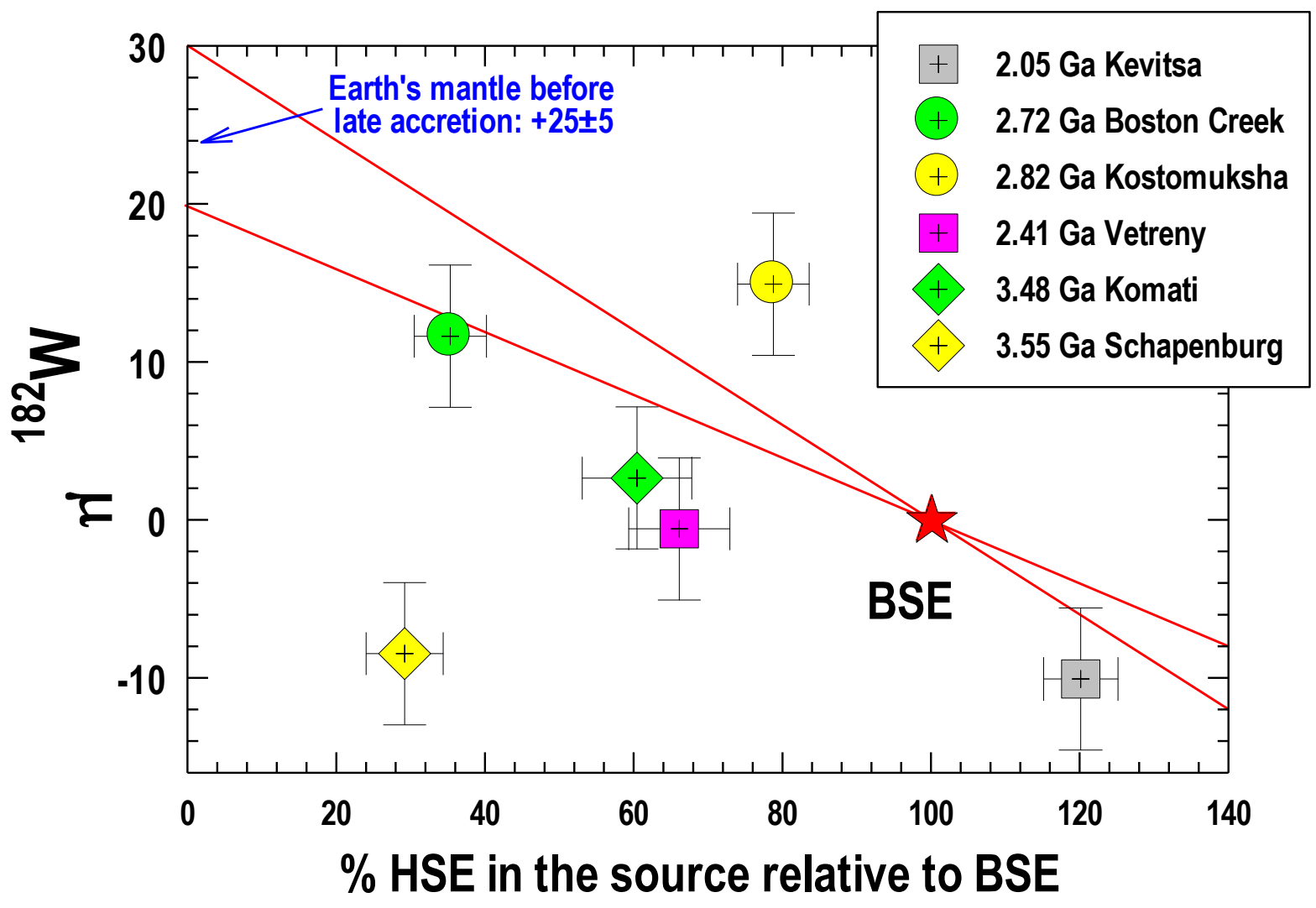


1

2

3

4

5

6

7

8

9
10

11

12

13

14

15

16

17

18

19

20

21

22

23

24

25

26

27

28

${ }^{29} 1663$

301664

${ }_{32} 1665$

331666

34

35

36

37

38

39

40

41

42

43

44

45

46

47

48

49

50

51

52

53

54

55

56

57

58

59

60

61

62

63

64

65

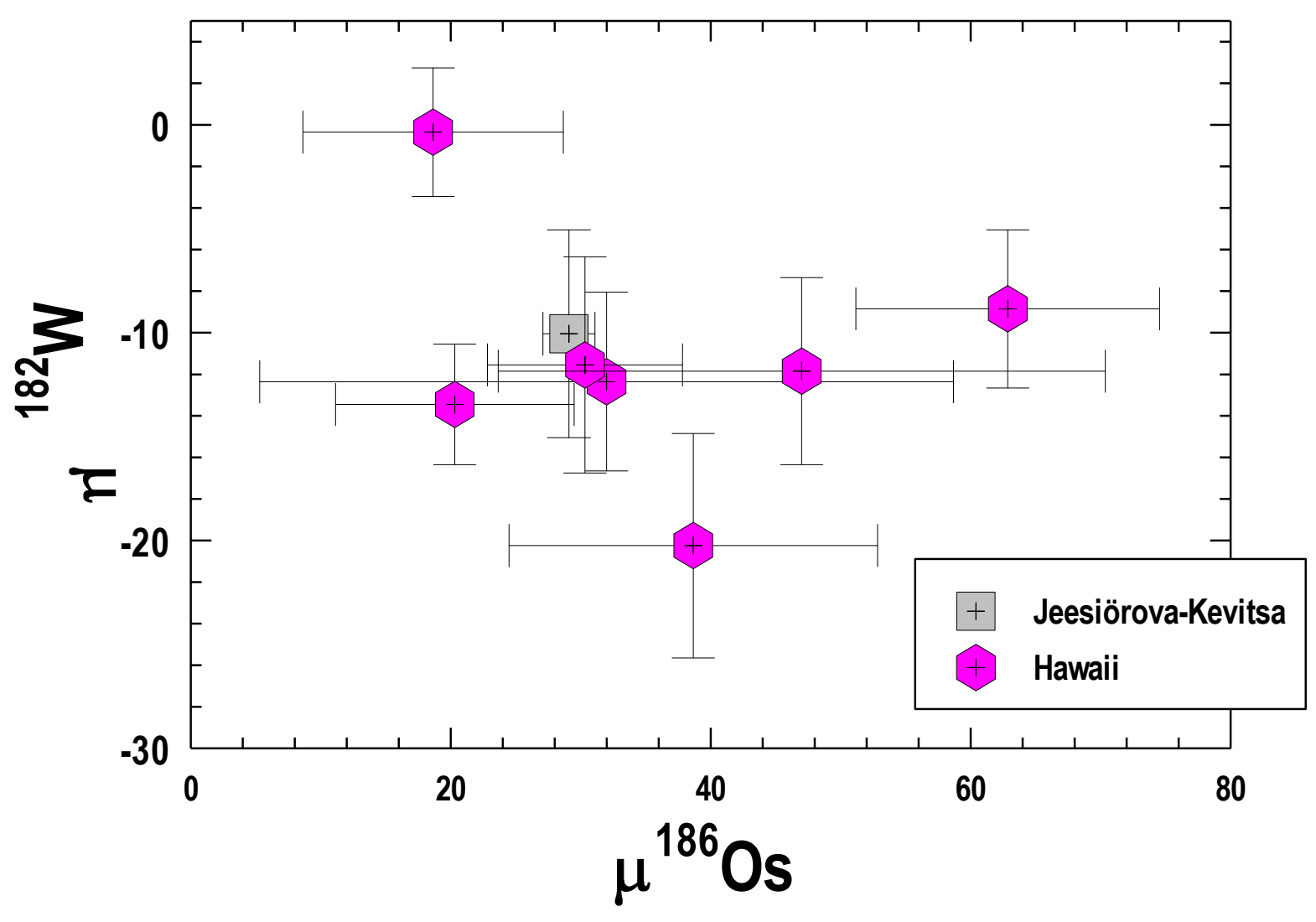

Fig. 14. 

Click here to download Background dataset for online publication only: Supplementary Tables A1 and A2.docx 
Supplementary Table A3
Click here to download Background dataset for online publication only: Supplementary Table A3.xIsx

Supplementary Table A3
Click here to download Background dataset for online publication only: Supplementary Table A3.xIsx

(1)

$+2$

$+2$ . (1) (1) (1) (1) (1) (1) (1) (1) (1) (1) (1) (1) (1) (1) 


\section{${ }^{*}$ Declaration of Interest Statement}

\section{Declaration of interests}

The authors declare that they have no known competing financial interests or personal relationships that could have appeared to influence the work reported in this paper. 